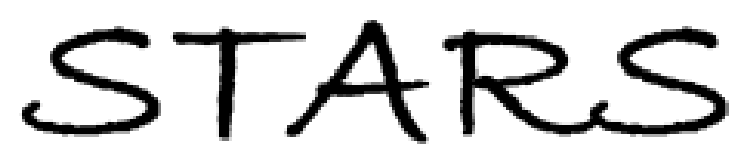

University of Central Florida

STARS

4-1-2015

\title{
Investigating Solutions To Wind Washing Issues In Two-Story Florida Homes, Phase 2
}

Florida Solar Energy Center

Charles Withers, Jr.

Florida Solar Energy Center, chuck@fsec.ucf.edu

Part of the Energy Systems Commons

Find similar works at: https://stars.library.ucf.edu/fsec

University of Central Florida Libraries http://library.ucf.edu

This Contract Report is brought to you for free and open access by STARS. It has been accepted for inclusion in FSEC Energy Research Center ${ }^{\circledR}$ by an authorized administrator of STARS. For more information, please contact

STARS@ucf.edu.

\section{STARS Citation}

Florida Solar Energy Center and Withers, Jr., Charles, "Investigating Solutions To Wind Washing Issues In Two-Story Florida Homes, Phase 2" (2015). FSEC Energy Research Center®. 154.

https://stars.library.ucf.edu/fsec/154

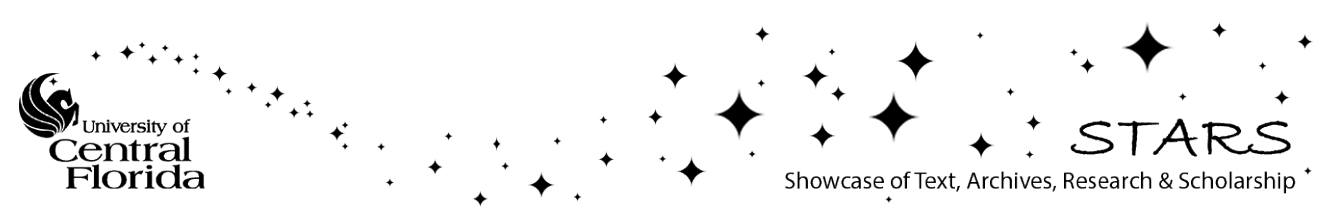




\title{
FLORIDA SOLAR ENERGY CENTER \\ Creating Energy Independence
}

\section{Investigating Solutions to Wind Washing Issues in Two-Story Florida Homes, Phase 2}

FSEC-CR-2041-15

\author{
Final Report \\ April 2015 \\ Authors \\ Charles Withers Jr. \\ Jamie Kono \\ (321) 638-1000 \\ www.floridaenergycenter.org
}




\section{Disclaimer}

The Florida Solar Energy Center/University of Central Florida nor any agency thereof, nor any of their employees, makes any warranty, express or implied, or assumes any legal liability or responsibility for the accuracy, completeness, or usefulness of any information, apparatus, product, or process disclosed, or represents that its use would not infringe privately owned rights. Reference herein to any specific commercial product, process, or service by trade name, trademark, manufacturer, or otherwise does not necessarily constitute or imply its endorsement, recommendation, or favoring by the Florida Solar Energy Center/University of Central Florida or any agency thereof. The views and opinions of authors expressed herein do not necessarily state or reflect those of the Florida Solar Energy Center/University of Central Florida or any agency thereof. 


\section{Investigating Solutions to Wind Washing Issues in Two-Story Florida Homes, Phase 2}

C. Withers and J. Kono Building America Partnership for Improved Residential Construction

April 2015 


\section{NOTICE}

This report was prepared as an account of work sponsored by an agency of the United States government. Neither the United States government nor any agency thereof, nor any of their employees, subcontractors, or affiliated partners makes any warranty, express or implied, or assumes any legal liability or responsibility for the accuracy, completeness, or usefulness of any information, apparatus, product, or process disclosed, or represents that its use would not infringe privately owned rights. Reference herein to any specific commercial product, process, or service by trade name, trademark, manufacturer, or otherwise does not necessarily constitute or imply its endorsement, recommendation, or favoring by the United States government or any agency thereof. The views and opinions of authors expressed herein do not necessarily state or reflect those of the United States government or any agency thereof.

Available electronically at http://www.osti.gov/scitech

Available for a processing fee to U.S. Department of Energy and its contractors, in paper, from:

U.S. Department of Energy

Office of Scientific and Technical Information

P.O. Box 62

Oak Ridge, TN 37831-0062

phone: 865.576 .8401

fax: 865.576 .5728

email: mailto:reports@adonis.osti.gov

Available for sale to the public, in paper, from:

U.S. Department of Commerce

National Technical Information Service

5285 Port Royal Road

Springfield, VA 22161

phone: 800.553 .6847

fax: 703.605.6900

email: orders@ntis.fedworld.gov

online ordering: http://www.ntis.gov/ordering.htm 


\title{
Investigating Solutions to Wind Washing Issues in Two-Story Florida Homes, Phase 2
}

\author{
Prepared for: \\ The National Renewable Energy Laboratory \\ On behalf of the U.S. Department of Energy's Building America Program \\ Office of Energy Efficiency and Renewable Energy \\ 15013 Denver West Parkway \\ Golden, CO 80401 \\ NREL Contract No. DE-AC36-08GO28308 \\ Prepared by: \\ Charles R. Withers, Jr. and Jamie Kono \\ BA-PIRC/Florida Solar Energy Center \\ Florida Solar Energy Center \\ 1679 Clearlake Road \\ Cocoa, Florida 32922 \\ NREL Technical Monitor: Stacey Rothgeb \\ Prepared under Subcontract No. KNDJ-0-40339-04
}

April 2015 
The work presented in this report does not represent performance of any product relative to regulated minimum efficiency requirements.

The laboratory and/or field sites used for this work are not certified rating test facilities. The conditions and methods under which products were characterized for this work differ from standard rating conditions, as described.

Because the methods and conditions differ, the reported results are not comparable to rated product performance and should only be used to estimate performance under the measured conditions. 


\section{Contents}

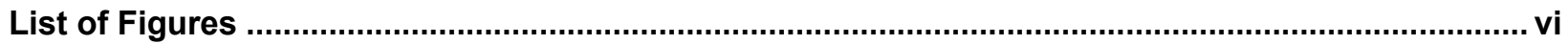

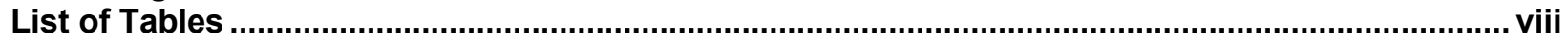

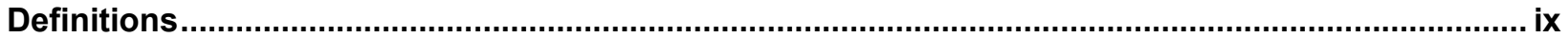

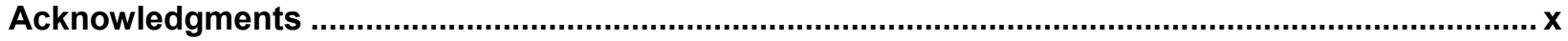

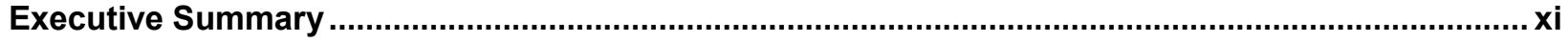

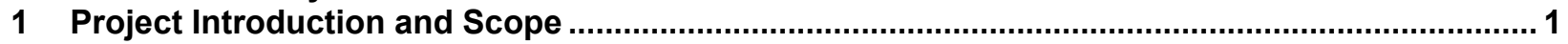

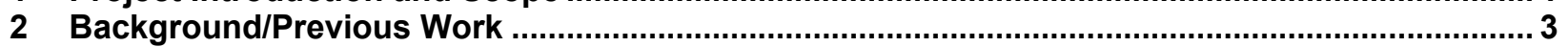

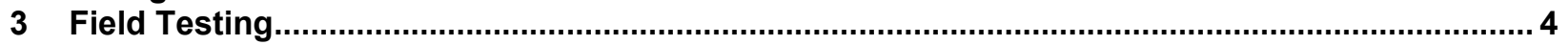

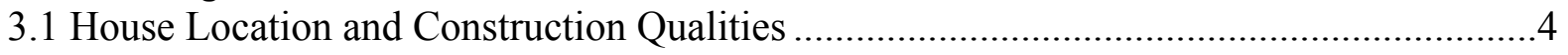

3.2 Test and Inspection Description.............................................................................

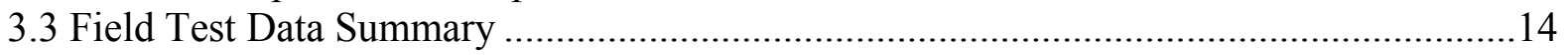

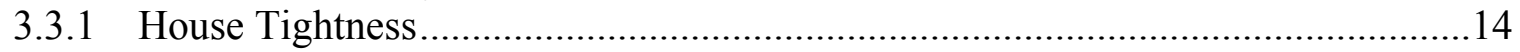

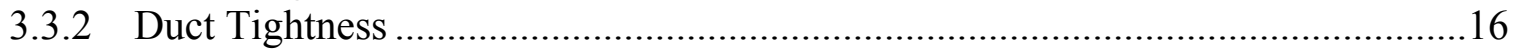

3.3.3 Floor Cavity Pathway Diagnostic Pressure Test.............................................17

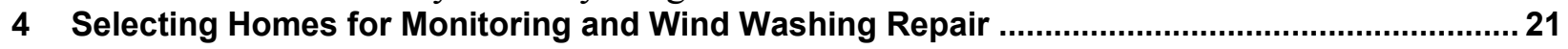

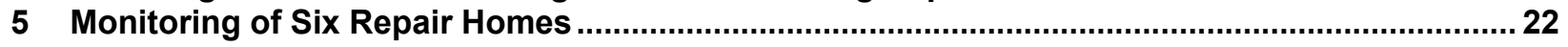

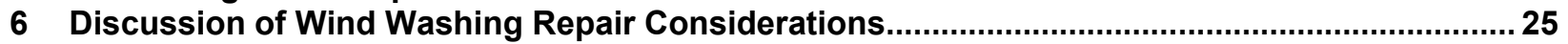

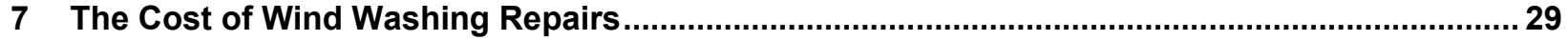

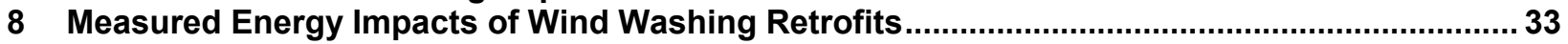

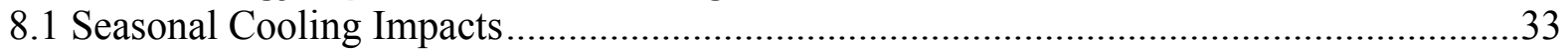

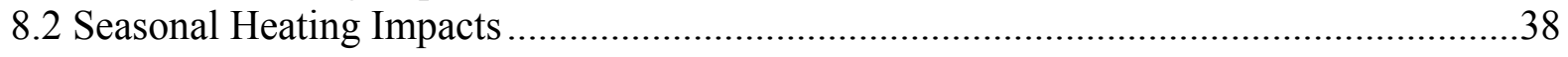

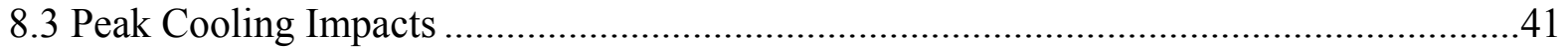

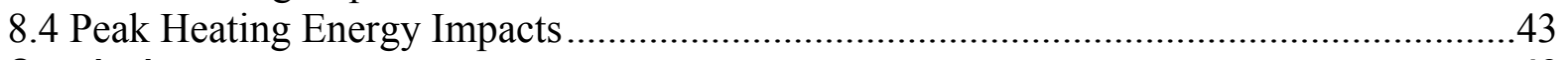

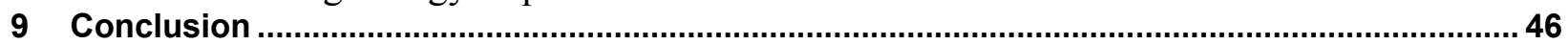

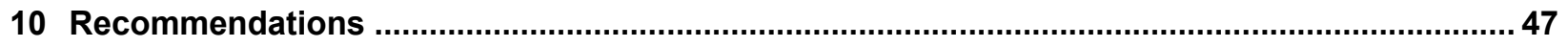

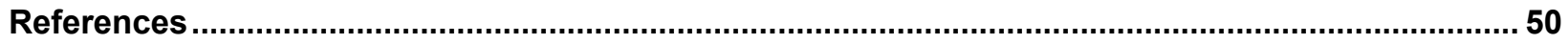

Appendix: Description of Wind Washing Repairs in Six Homes ............................................... 51 


\section{List of Figures}

Figure 1. Wind-driven attic air is pushed into the space between floors........................................ 1 Figure 2. Elevated floor temperature results from hot attic air flowing through the floor cavity....... 1 Figure 3. Florida counties where wind washing field tests were performed .................................... 4

Figure 4. House H36M. Research team member performs a visual inspection in the attic space. Each accessible attic space is inspected to identify the presence and magnitude of wind washing characteristics.

Figure 5. Photo from inside the east attic section at House H36M. The arrow points to the floor cavity opening. Attic vents are out of view on the right.

Figure 6. House H36M. View inside an east attic floor cavity section, with uninsulated knee wall area above. Complementary wind washing pathways are located at the other end of the floor cavity in the west attic.

Figure 7. View inside one section of floor cavity from the east attic of House H36M. This floor cavity is wide open to the attic space.

Figure 8. Most of the floor cavity openings from the west attic of House H36M are substantially blocked by frame members positioned between solid floor joists (see close-up in Figure 9).... 7

Figure 9. Most of the openings between the attic and floor cavities are blocked by frame members, leaving a $1-5 / 8-i n$. gap that occurs continuously. Pieces of original dirty insulation $(R-11)$ have fallen from the roof deck above.

Figure 10. A baseline house pressure measurement is taken at the start of a blower door test at House H50.

Figure 11. A house air infiltration test (with AHUs operating continuously) is performed at House H52 using a Bacharach specific gas analyzer.

Figure 12. In House H36M, a Ppan test indicates both the magnitude and the general location of duct leaks with the air handling unit (AHU) off and the house depressurized to $-50 \mathrm{~Pa}$. The blower door fan in the background is used for both the house tightness and Ppan tests......... 9

Figure 13. Air temperature and RH measurements were taken at House H36M using a Vaisala HM34 probe.

\section{9}

igure 14. Preparing to measure the second-story AHU airflow rate at House H53 using a True Flow plate

igure 15. Floor cavity air pressure is measured by placing a tube into the floor cavity through a small drilled hole, with homeowner approval, at House $\mathrm{H} 52$.

igure 16. Floor cavity pressure is often measured by inserting a tube into the floor cavity using an extension pole at House $\mathrm{H} 50$.

ure 17. Summer IR image shows where hot attic air has penetrated into the floor cavity that lies behind the stairwell wall. The wall surface temperature at the floor cavity interface was $83^{\circ} \mathrm{F}$ compared to $77^{\circ}-78^{\circ} \mathrm{F}$ room air temperature.

Figure 18. Winter IR image shows where cold outdoor air has penetrated into the floor cavity that lies behind the stairwell wall. The wall surface temperature at the floor cavity interface was $73.9^{\circ} \mathrm{F}$, about $1.5^{\circ} \mathrm{F}$ colder than the room air temperature. Overnight low outdoor temperature was about $44^{\circ} \mathrm{F}$ several hours prior to the image with calm wind conditions....... 11

Figure 19. Stairwell where the thermal anomalies occurred ......................................................... 12

Figure 20. A bathroom floor had relatively cold surface temperatures compared to the heated area around it because of wind washing in the floor cavities below the floor. ........................... 12

Figure 21. Photo of bathroom floor ........................................................................................ 12

Figure 22. IR image of exterior west-facing wall. The soffit vent area is about $57.8^{\circ} \mathrm{F} \ldots \ldots \ldots \ldots \ldots \ldots . . . . . . . .13$

Figure 23. Photo of exterior west-facing wall................................................................................. 13

Figure 24. IR image of openings between the east attic and floor cavities near the second-floor

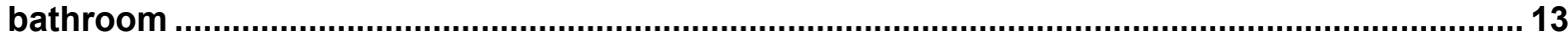

Figure 25. Photo of openings between the east attic and floor cavities near the second-floor bathroom

Figure 26. The measured floor cavity area plotted at the measured house pressure wrt floor cavity.

Figure 27. Installed data logger shown connected to sensor wires and to laptop at House H39L... 23 
Figure 28. Temperature and RH measurement of first-floor return air at House H36M

Figure 29. Vaisala temperature and RH probe in attic space near open floor cavity of House H23K.

Figure 30. A telescoping pole was used with a portable mounting block to place a Vaisala temperature/RH probe inside the floor cavity at House H23K. Sensors were located away from ducts and duct leaks.

Figure 31. A copper-constantan (type T) thermocouple was used to sample return air temperature on the second floor of House H39L.

Figure 32. A thermocouple was inserted into the supply plenum (through the side wall of the plenum behind the foil tape) of the second-floor heat pump system to sample supply air temperature at House $\mathrm{H} 39 \mathrm{~L}$

Figure 33. Foam insulation was used to seal the attic-to-floor cavity opening and insulate the knee wall above the floor cavity opening in Phase 1 House H16B.

Figure 34. Floor cavity opening and knee wall can be seen in House H16B prior to foam insulation application.

Figure 35. About $30 \mathrm{ft}$ of plastic drop sheet was placed down to protect floor in House H45H from spray foam line prior to being run through the home and up through the attic access port in the closet.

Figure 36. Exterior wall and window area was protected from potential overspray of foam applied within the soffit area above

Figure 37. Daily cooling energy and daily average dT between outside and inside for House H23K.

Figure 38. Daily cooling energy and daily average dT between outside and inside for House H36S

Figure 39. Daily cooling energy and daily average dT between outside and inside for House H37M

Figure 40. Daily cooling energy and daily average dT between outside and inside for House H39L

Figure 41. Daily cooling energy and daily average dT between outside and inside for House H45H.

Figure 42. Daily cooling energy and daily average dT between outside and inside for House H47W.

Figure 43. Pre-repair composite of attic and outdoor temperatures for House H36S

Figure 44. Daily heating energy and daily average dT between outside and inside for House H23K.

gure 45. Daily heating energy and daily average dT between outside and inside for House H36S

igure 46. Daily heating energy and daily average dT between outside and inside for House H37M; the post-repair period was period higher because of equipment problem .......... 39

Figure 47. Daily heating energy and daily average dT between outside and inside for House H39L

Figure 48. Daily heating energy and daily average dT between outside and inside for House H45H.

Figure 49. Cooling energy before and after repair of House H23K with hour of day shown on the $x$-axis

Figure 50. Cooling energy before and after repair of house H37M with hour of day shown on the $x$-axis

Figure 51. Cooling energy before and after repair of house $\mathrm{H} 45 \mathrm{H}$ with hour of day shown on the $\mathrm{x}$-axis

Figure 53. Heating energy before and after repair for house H39L with hour of day shown on the $\mathrm{x}$-axis

Unless otherwise noted, all figures were created by BA-PIRC. 


\section{List of Tables}

Table ES1. Average Annual and Peak Energy Cooling and Heating Impacts From Wind Wash Repairs From Phase 1 and Phase 2 Study Combined

Table 1. Summary Showing Average House Envelope and Duct Tightness Measurements With the Range of Lowest to Highest Value From 24 Tested Houses of Phase 2 .............................. 14

Table 2. Typical Data Monitoring Channel Map for Repair Homes ..................................................... 22

Table 3. Wind Washing Repair Areas, Labor Time, and Research Project Costs ............................ 30

Table 4. Estimated Cost of Wind Washing Repairs Using Project and National Cost Data ............... 30

Table 5. Average Annual Cooling Energy Before and After Repairs With Savings From Six

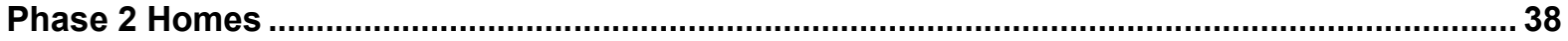

Table 6. Average Annual Heating Energy Before and After Repairs With Savings From Four

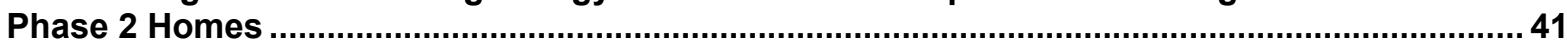

Table 7. Peak Cooling Energy Savings for Six Homes of Phase 2 ...............................................43

Table 8. Peak Heating Energy Savings for Four Homes of Phase 2 ................................................ 45

Unless otherwise noted, all tables were created by BA-PIRC. 


\section{Definitions}

$\mathrm{ACH}$; ach

AHU

ASTM

DOE

$\mathrm{dP}$

dT

HVAC

IECC

IR

LDF

Ppan

$\mathrm{RH}$

RLF

TMY

wrt
Air changes per hour

Air handler unit

American Society for Testing and Materials

U.S. Department of Energy

Differential pressure

Temperature difference

Heating, ventilation, and air conditioning

International Energy Conservation Code

Infrared

Low-density foam; Insulating open cell foam with density around $0.50 \mathrm{lb} / \mathrm{ft}^{3}$

Pressure pan

Relative humidity

Return leak fraction

Typical Meteorological Year

With respect to 


\section{Acknowledgments}

The authors would like to recognize Jim Cummings for his role as a principal investigator throughout much of this research endeavor. We appreciate project support from Philip Wemhoff and Jeremy Nelson in assisting in the effort of finding homes and coordinating scheduling, and Philip Wemhoff, Robin Peterson, David Hoak, and David Beal for assisting with house testing. Thanks to Danielle Daniel for report editing. A special recognition and thanks are given to JEA for facilitating the search for homes in the Jacksonville area and providing utility billing data for four monitored homes. And finally, thanks to Craig Muccio of Florida Power \& Light Company, Eric Martin, and the National Renewable Energy Laboratory team for continued support of this research by the U.S. Department of Energy's Building America team, Building America Partnership for Improved Residential Construction. 


\section{Executive Summary}

With U.S. Department of Energy goals of reducing existing home energy use by $30 \%$ and new home energy use by $50 \%$, it is imperative to focus on several energy efficiency measures, including the quality of air and thermal barriers. This report provides results from a second-phase research study of a phenomenon generally referred to as wind washing. Wind washing is the movement of unconditioned air around or through building thermal barriers in such a way as to diminish or nullify the intended thermal performance. In some cases, thermal and air barriers are installed very poorly or not at all, and air can readily move from unconditioned attic spaces into quasi-conditioned interstitial spaces. This study focused on the impact of poorly sealed and insulated floor cavities adjacent to attic spaces in Florida homes. In these cases, unconditioned attic air can be transferred into floor cavities through pathways driven by natural factors such as wind, or by thermal differences between the floor cavity and the attic. Air can also be driven into a floor cavity through mechanical forces imposed by return duct leakage in the floor cavity.

The U.S. Department of Energy Building America team, Building America Partnership for Improved Residential Construction, conducted an earlier Phase 1 study in 32 two-story Florida homes (Cummings et al. 2009). Repairs were completed in six of those homes to characterize cooling season energy and cooling peak demand savings. This Phase 2 study expands the sample size from 32 to 56 field-tested homes, increases the number of repaired homes from 6 to 12 , and expands the energy analysis to also examine heating energy impacts. Table ES1 shows the annual and peak energy savings for all 12 monitored houses studied in Phases 1 and 2. Cooling results are based on 12 homes and heating results are based on five homes. Regression leastsquares best-fit analysis was used from monitored heating and cooling data to create equations that could be used with Typical Meteorological Year data of four Florida cities to predict the annual cooling and heating savings for typical weather conditions. The average predicted annual cooling and heating energy savings is $1,034 \mathrm{kWh}$ per home from wind washing repairs. This is a potential savings of $\$ 119$ each year for each homeowner based on an average rate of $\$ 0.115 / \mathrm{kWh}$. The savings can be expected to last as long as the home, because the repair lifetime has no limit under normal circumstances.

Table ES1. Average Annual and Peak Energy Cooling and Heating Impacts From Wind Wash Repairs From Phase 1 and Phase 2 Study Combined

\begin{tabular}{|c|c|c|c|c|}
\hline & $\begin{array}{c}\text { Annual } \\
\text { Cooling kWh }\end{array}$ & $\begin{array}{c}\text { Summer Peak } \\
\text { Hour Cooling kW }\end{array}$ & $\begin{array}{c}\text { Annual } \\
\text { Heating kWh }\end{array}$ & $\begin{array}{c}\text { Winter Peak Hour } \\
\text { Heating kW }\end{array}$ \\
\hline Pre-Repair & 9,392 & 3.66 & 502 & 1.86 \\
\hline Post-Repair & 8,483 & 3.27 & 378 & 1.53 \\
\hline Savings & 909 & 0.39 & 125 & 0.33 \\
\hline Savings \% & $9.7 \%$ & $10.7 \%$ & $24.9 \%$ & $18.7 \%$ \\
\hline
\end{tabular}

Repairs were made by either spray application of low-density, insulating foam or by careful placement of kraft paper-faced insulation batts. Generally, repairs made from materials readily available at home improvement stores are less expensive. However, the ability to effectively seal and insulate open floor cavities from attic spaces with such materials can be limited by ease of mobility within attics and the presence of numerous obstacles or complex geometries where repairs are to be made. Professionally applied, low-density foam may be the only practical option 
when making repairs from within small attic spaces or when the area to be sealed is not a relatively simple planar-type geometry.

House performance-related tests were completed in 56 Florida homes studied in Phases 1 and 2 combined. The purpose of the house tests was to gather data relevant to wind washing and to find reasonable candidates for monitoring and retrofit. The field assessments characterized wind washing failures of the house air and thermal boundary, including a blower door test, air boundary location, pressure mapping, air leakage assessment, duct leakage assessment, infrared scans of house surfaces, and visual inspections. A comprehensive visual attic inspection was the most important and effective method of identifying homes needing floor cavity repair.

Wind washing repairs resulted in 12 houses becoming $18.6 \%$ tighter based on normalized blower door test results (from 11ACH50 to 8.9ACH50). In homes with vented recessed can lights within the floor cavity, the house tightness increased by about $23 \%$. The repairs also resulted in less duct leakage to outside by enclosing existing duct leakage in the floor cavity between the first and second floors. The measured return leakage fraction decreased $37 \%$ and supply duct leakage indicated by pressure pan method decreased $38 \%$. Air infiltration rates measured by tracer gas decay, while all central cooling systems were on, decreased $30 \%$ (from 0.49 ach to 0.34 ach).

As contractors become more familiar with wind washing repair techniques, and lower cost repair options become more utilized, an average repair cost of $\$ 350$ is achievable. One repair in this study was completed using only $\$ 25$ in materials and 2.5 person-hours. Based on a cost of $\$ 350$ and estimated annual heating and cooling energy savings of $\$ 191(1034 \mathrm{kWh}$ at $\$ 0.115 / \mathrm{kWh})$, wind washing repair can achieve a simple payback within 3 years. It should be noted that the wind washing repair has a life expectancy equal to the life of the house and that it will require no maintenance.

Peak demand reduction from wind washing repair should also look attractive to electric utilities, which, in turn, may offer homeowners rebates and other incentives. Such incentives may further enhance the cost effectiveness of wind washing repair.

While some of the project findings will apply most directly to homes in hot-humid climates, the repair techniques and general principles of air-transported and convective heat exchange will also be applicable to colder climates.

The following points describe various factors that may affect the impact of energy savings, and improved comfort, and moisture management after wind washing repairs.

- Sizes and locations of floor cavity pathways:

- Larger pathways with complementary pathways to other vented attic spaces are more conducive to higher flow rates and will have a greater impact than one small hole located on one side of the floor cavity perimeter. Complementary pathways occur where pathways occur on more than one side of the floor cavity. An example is where the floor cavity is either surrounded by continuous vented attic space or may have two separate vented attic spaces on opposing sides or perhaps adjacent sides. 
- Homes with a small second-floor area as a percentage of the total house area may have lower energy savings potential. This is due to a smaller overall area for heat flux to occur from floor cavity to indoors.

- Attic conditions:

- Qualities such as an unshaded roof with dark composite shingles and low attic height will have a hotter attic in summer and a higher cooling energy penalty compared to a heavily shaded roof, high mass tile, or reflective metal roof.

- Limited soffit venting is more restrictive to wind forces that can push air into attic and floor cavities.

- Energy savings of floor cavity and knee wall repair is not expected if the repair location is within an unvented attic with insulation at the roof deck. An example of this would be where spray foam insulation was applied to the entire underside of the roof deck all the way down, sealing the roof eave from the attic space.

- Driving forces across floor cavity pathways:

- Natural forces from wind are variable in magnitude and direction. Stronger winds oriented in line with leakage pathways will have greater impact.

- Mechanical driving forces such as duct leakage can increase the flow rate across pathways and thus increase energy impacts.

Occupant behavior:

- Occupants who have lower cooling or higher heating thermostat set points after repair may see minimal or no wind wash repair energy savings.

o Preference for a very low cooling or a high heating set point may diminish measurable peak demand even if the central system is correctly sized by the Manual J method. 


\section{Project Introduction and Scope}

In some two-story homes, attic spaces over first floors that abut parts of the second-story conditioned space may have two potential breaches of the air and thermal boundaries:

- Attic air above the first-floor space can be driven into the cavity between the first and second floors by wind, thermal buoyancy forces, and mechanical driving forces (duct leaks, unbalanced return air, unbalanced exhaust air, etc.; Figures 1 and 2).

- Insulation batts installed on knee walls may have gaps (between the batt and the gypsum wallboard) that allow circulation of hot air against the wall board. These breaches of the air and thermal boundaries can lead to significant sensible heat penetrating into the house and, in some cases, substantial latent heat (water vapor) penetrating into the structure.

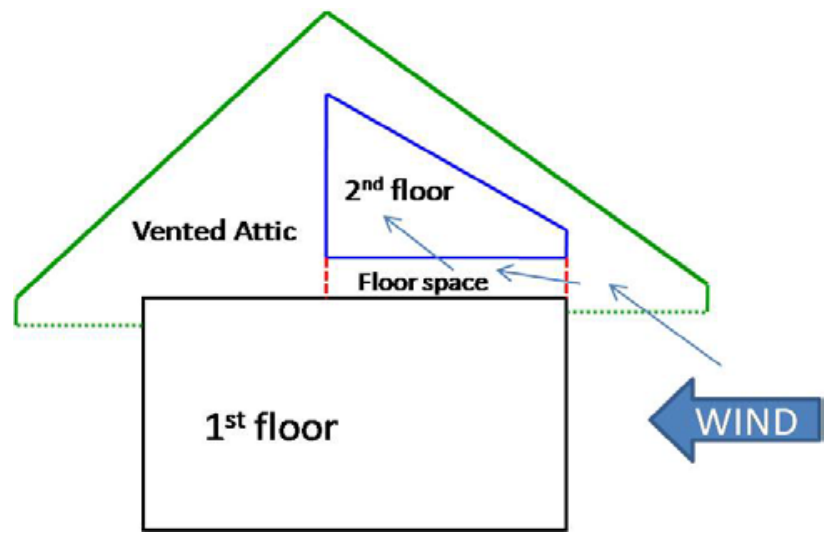

Figure 1. Wind-driven attic air is pushed into the space between floors.

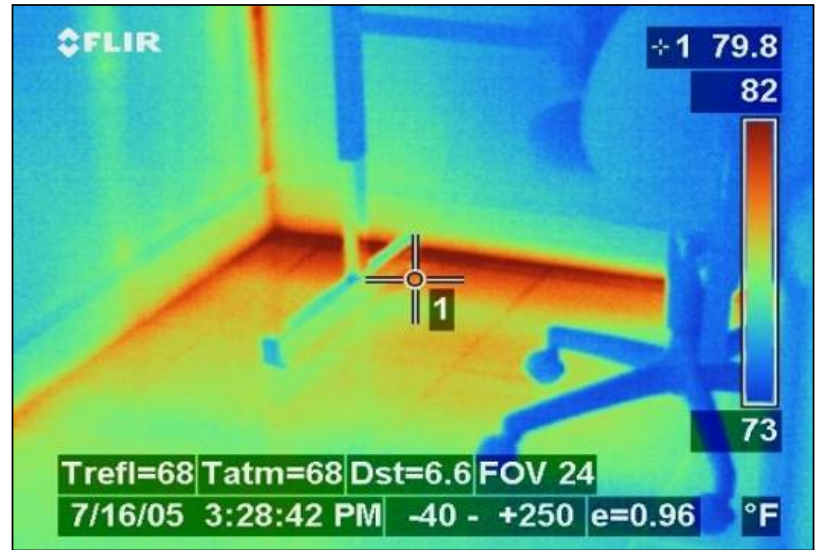

Figure 2. Elevated floor temperature results from hot attic air flowing through the floor cavity.

This project is the second phase continuation of a wind washing impact study. The second phase has been carried out to increase the sample size of Phase 1. Details on this project evaluation method, results, and recommendations follow in the next several sections. 
This project has six primary tasks:

1. Perform field assessment of a sample of 24 homes.

2. Make repairs of wind washing features in six homes.

3. Monitor energy savings that result from repairing wind washing in these six homes.

4. Analyze heating and cooling energy use to assess seasonal energy savings and peak demand reduction.

5. Develop recommendations for wind washing retrofits.

6. Develop recommendations for avoidance of wind washing in new construction. 


\section{Background/Previous Work}

With U.S. Department of Energy (DOE) goals of reducing energy use in existing residential stock by $30 \%$ and in new construction by $50 \%$ compared to 2009 code, it becomes increasingly important to eliminate floor cavity air and thermal pathways as an important part to reaching this goal. Residential construction is increasing from simple one-story to two-story homes in efforts to limit lot size and maintain floor area. Consequently, more attic spaces are horizontally adjacent to conditioned spaces, and air and thermal boundary failures are now more widespread. As a result, second-story cooling loads have, in many cases, increased substantially. First-floor cooling loads have also increased because of warmer ceilings and air penetration from the floor cavity through recessed lights and other ceiling pathways. In some cases, cooling loads can exceed the cooling system capacity.

An earlier Phase 1 study was carried out in 32 homes in Florida in 2008-2009 (Cummings et al. 2009). Repairs were implemented in 6 of those 32 homes to characterize cooling season energy and peak demand savings. Cooling season savings averaged $15.3 \%$, and peak cooling energy reduction averaged $12.6 \%$ in these 6 homes. The current Phase 2 study expands the sample size from 32 to 56 field-tested homes, increases the number of repaired homes from 6 to 12, and expands the energy analysis to examine heating season impacts.

Knee wall and wind washing problems have also been otherwise recognized in the literature, especially in response to freezing pipes in cold climates. For example, a DOE Technology Factsheet titled "Ceilings and Attics: Install Insulation and Provide Ventilation" (DOE 2000) and the DOE-sponsored Builder's Guide (Hot-Humid Climates) (Lstiburek 2005) provide information related to floor truss closure and insulation. However, energy penalties and retrofit savings opportunities in hot-humid climates have not been documented. Before wide-scale retrofit programs can begin, utilities and other parties need more knowledge about the energy and demand savings opportunities from repair as well as the associated costs.

This project report focuses on the Phase 2 objectives; however, Phase 1 is referenced throughout, and some results such as monitored energy savings and repair costs are used with the Phase 2 data to increase sample size. 


\section{Field Testing}

The primary purpose of the site testing was to learn more about the nature and extent of wind washing potential, particularly from floor cavities to adjacent attic or other unconditioned spaces. It was also important to identify homes suitable for the retrofit part of the study. Homeowners with two-story homes were contacted and given a website with information describing the nature of wind washing and the purpose of the study. Those interested could contact project staff to further determine the suitability of their homes for the study. After homes with potential wind washing were identified, a site visit was scheduled, and detailed field testing was completed. These tests and inspections collected a battery of data during a period of several hours while at each site.

\subsection{House Location and Construction Qualities}

Field testing and inspection were completed in 24 homes of Phase 2 that were located among six counties shown in Figure 3. A database was assembled from the field test data pertaining to the house envelope, qualities of wind washing, and mechanical systems. The master database is organized in a spreadsheet format and contains all data collected from Phase 1 and Phase 2 with a total of 56 houses (32 Phase 1 homes and the 24 Phase 2 homes). For purposes of identification, the homes in Phase 1 are $\mathrm{H} 1$ through H32, and those in Phase 2 are H33 through H56 in sequence of testing order. Given the large size of the test spreadsheet, the data will not be shown in entirety in this report. However, a summary of some results is shared later in the report. The six Phase 2 homes that were monitored, repaired, and retested have an additional letter added to the home IDs (e.g. H23K or H39L).

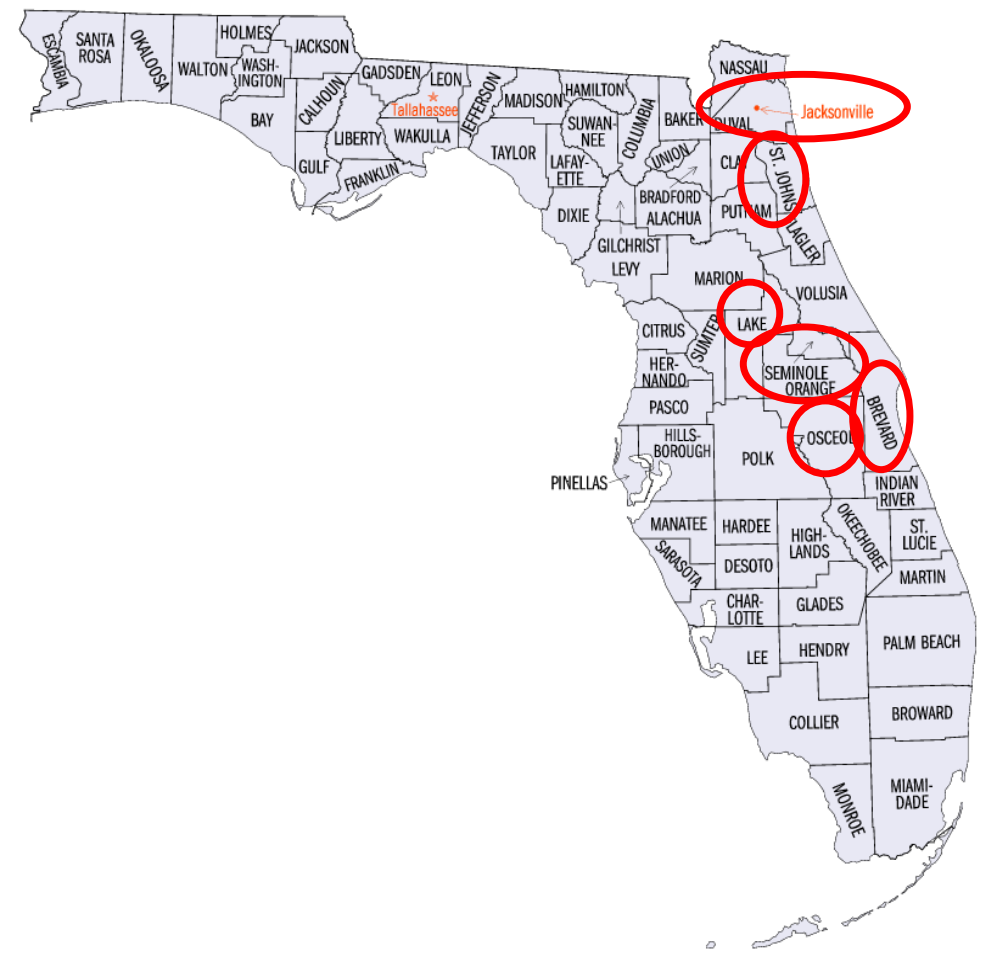

Figure 3. Florida counties where wind washing field tests were performed 
All Phase 2 homes were two-story construction averaging 26 years old (ranging from 7 years to 72 years). House size ranged from $1,329 \mathrm{ft}^{2}$ to $5,994 \mathrm{ft}^{2}$, with an average floor area of $3,016 \mathrm{ft}^{2}$. The second floor of each house represented from as little as $18 \%$ to as much as $51 \%$ of the total house floor area; on average, the second floor was 34\% of the house floor area. Therefore, $66 \%$ of the house floor area was, on average, on the first floor. All homes had central forced-air cooling. Nominal cooling capacity varied from 1.28 to 2.40 tons per $1,000 \mathrm{ft}^{2}$, with an average of 1.88 tons per $1,000 \mathrm{ft}^{2}$. Eight homes had just one space conditioning system serving the entire home. Ten of the 24 homes had two systems. Six homes had three systems. All but one of the homes had electric heat pump heating systems. Only one home had gas heating.

Wall construction was as follows: 17 homes were wood frame only, six were combined block and frame, and one was block only. Almost all homes (22 of 24) had composition asphalt shingle roofing, and the remaining two homes had tile roofs. Houses with unshaded asphalt shingle roofs had very hot attics. By contrast, tile roofs and some metal roofs resulted in a much cooler average attic temperature. The temperature of the attic had an important bearing on the energy impacts of wind washing.

\subsection{Test and Inspection Description}

Field evaluations consisted of testing and visual inspections. Testing consisted of the following:

A blower door test to characterize the airtightness of the house envelope.

Air boundary identification; during the blower door test with the house at $-50 \mathrm{~Pa}$, zone pressures in various interstitial cavities of the house were measured.

Pressure pan (Ppan) testing; during the blower door test with the house at $-50 \mathrm{~Pa}$, a pan with gasket was placed over supply and return registers/grilles (air handler units [AHUs] off), and the pressure in the duct was measured. This identified the relative size and location of duct leakage.

Pressure mapping; with the heating, ventilation, and air-conditioning (HVAC) system operating in normal mode, pressure differentials ( $\mathrm{dPs}$ ) were measured across interior partitions within the house with interior doors open and then again closed.

Infiltration and return leak fraction (RLF) tests with the AHUs operating using tracer gas techniques.

Heating or cooling system performance test. This was performed typically in the cooling mode (weather permitting) by measuring the system airflow rate, the return air temperature and relative humidity $(\mathrm{RH})$, and the supply air temperature and RH.

Field evaluation also included detailed visual inspections of attic spaces, floor cavities, and other locations that helped characterize and explain the potential for wind washing. The sequence of photos in Figures 4-16 illustrates some field inspection and testing activities. 


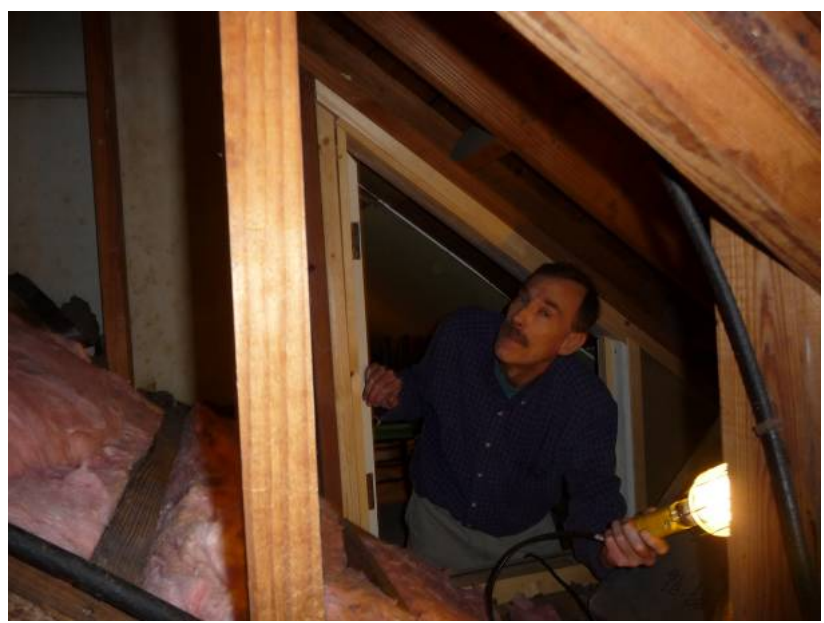

Figure 4. House H36M. Research team member performs a visual inspection in the attic space. Each accessible attic space is inspected to identify the presence and magnitude of wind washing characteristics.

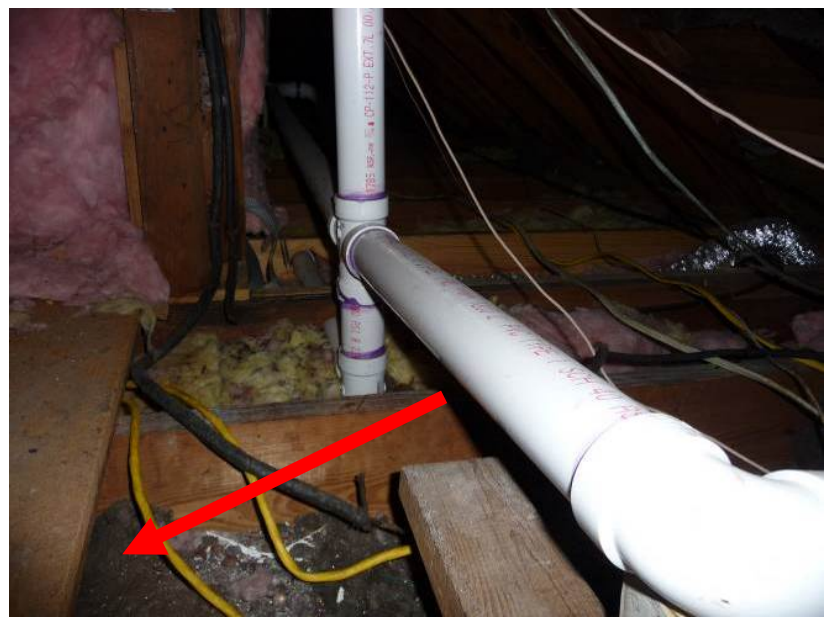

Figure 5. Photo from inside the east attic section at House H36M. The arrow points to the floor cavity opening. Attic vents are out of view on the right.

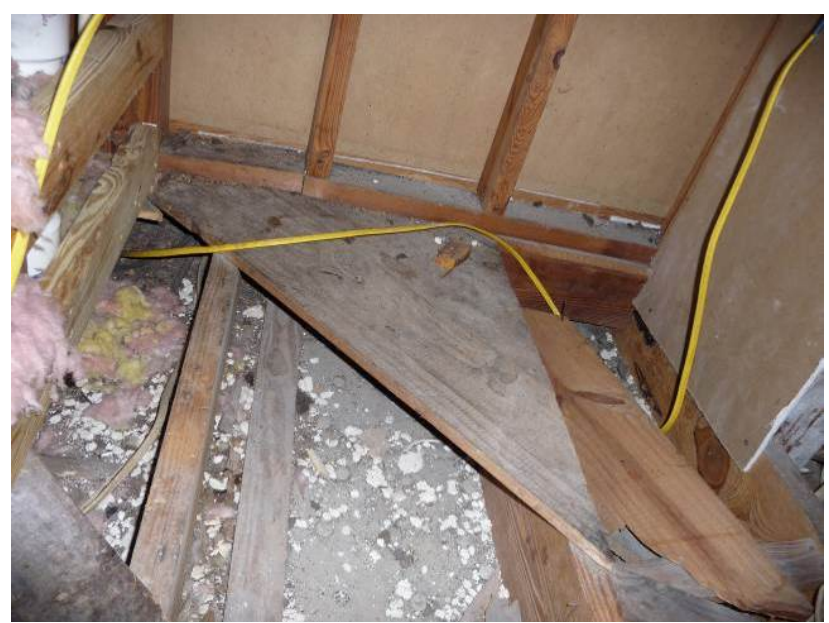

Figure 6. House H36M. View inside an east attic floor cavity section, with uninsulated knee wall area above. Complementary wind washing pathways are located at the other end of the floor cavity in the west attic. 


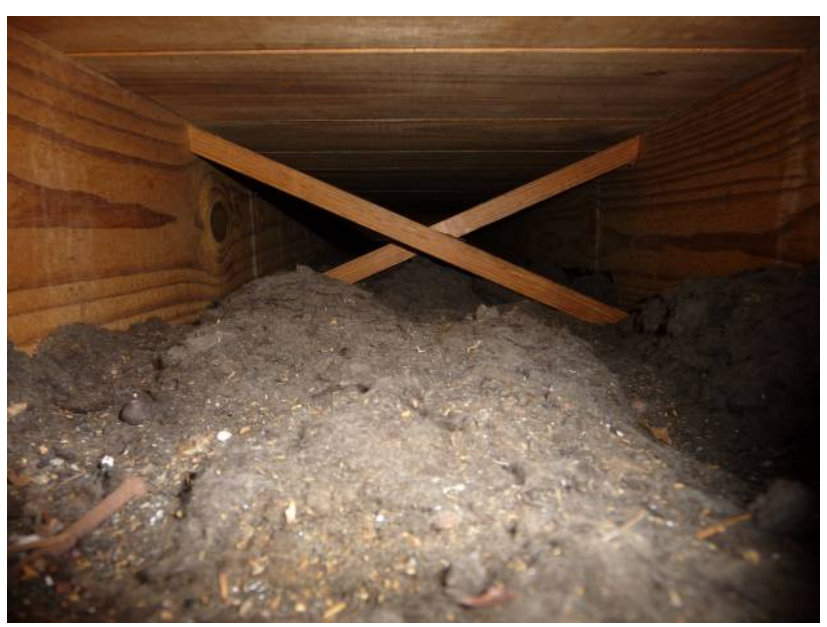

Figure 7. View inside one section of floor cavity from the east attic of House H36M. This floor cavity is wide open to the attic space.

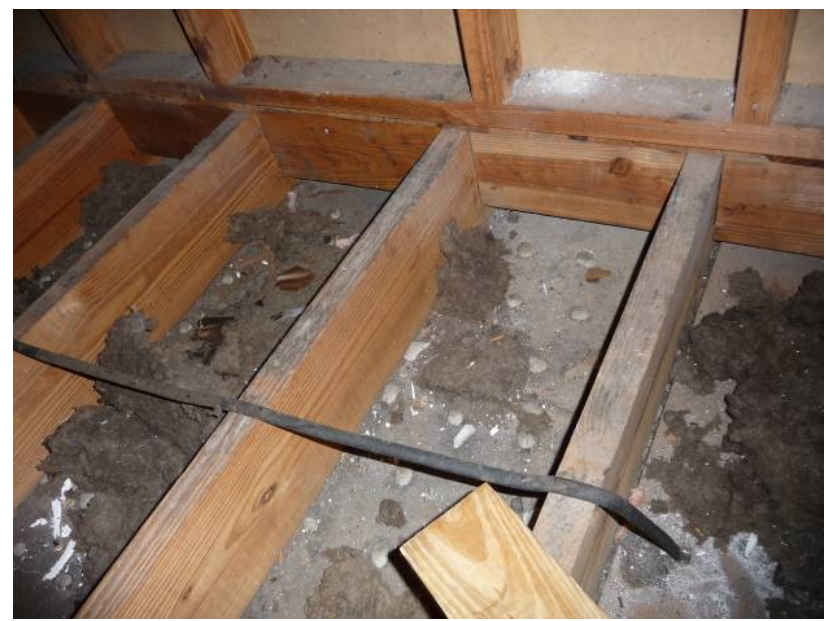

Figure 8. Most of the floor cavity openings from the west attic of House H36M are substantially blocked by frame members positioned between solid floor joists (see close-up in Figure 9).

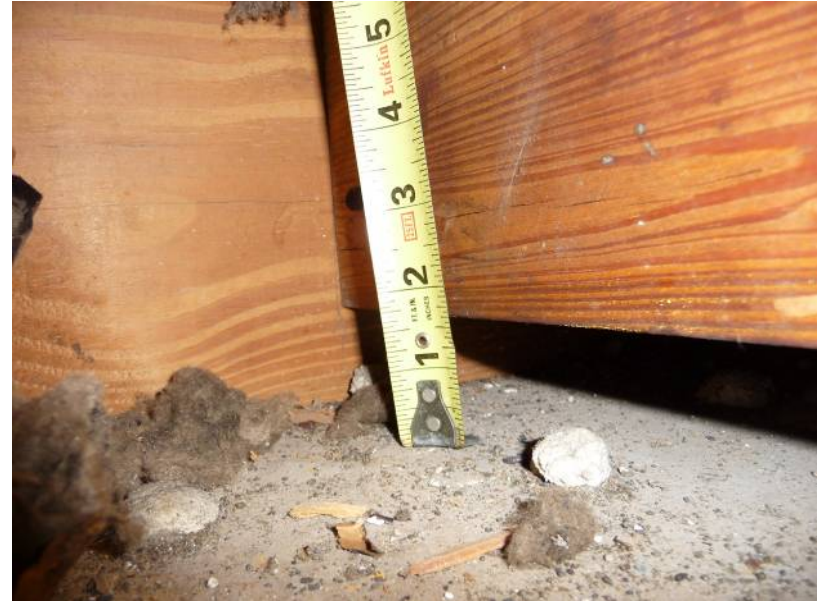

Figure 9. Most of the openings between the attic and floor cavities are blocked by frame members, leaving a $1-5 / 8-i n$. gap that occurs continuously. Pieces of original dirty insulation (R-11) have fallen from the roof deck above. 


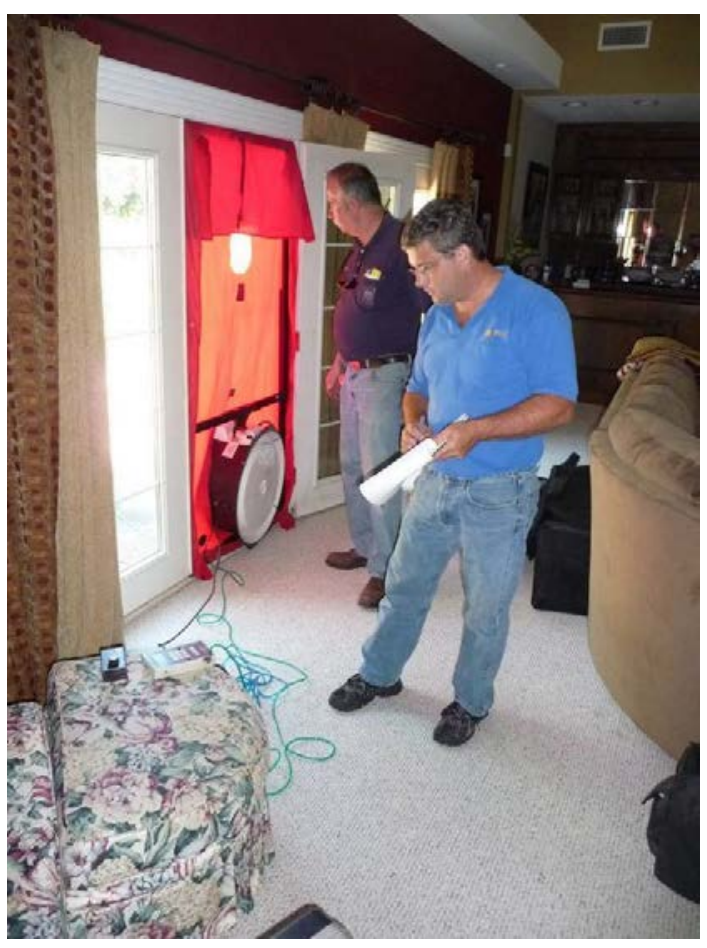

Figure 10. A baseline house pressure measurement is taken at the start of a blower door test at House H50.

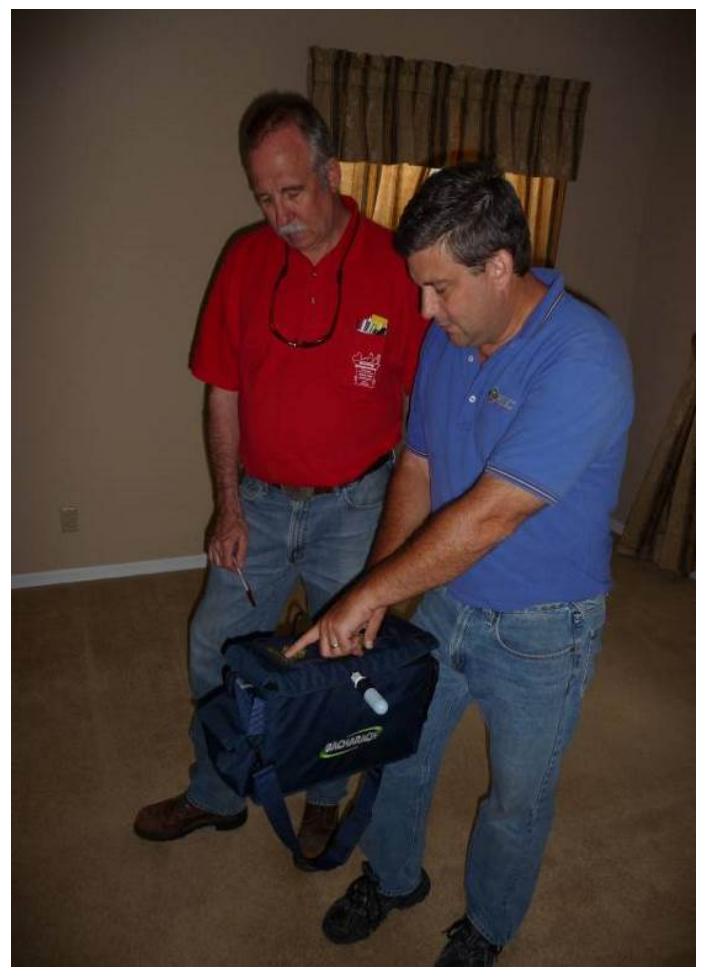

Figure 11. A house air infiltration test (with AHUs operating continuously) is performed at House H52 using a Bacharach specific gas analyzer. 


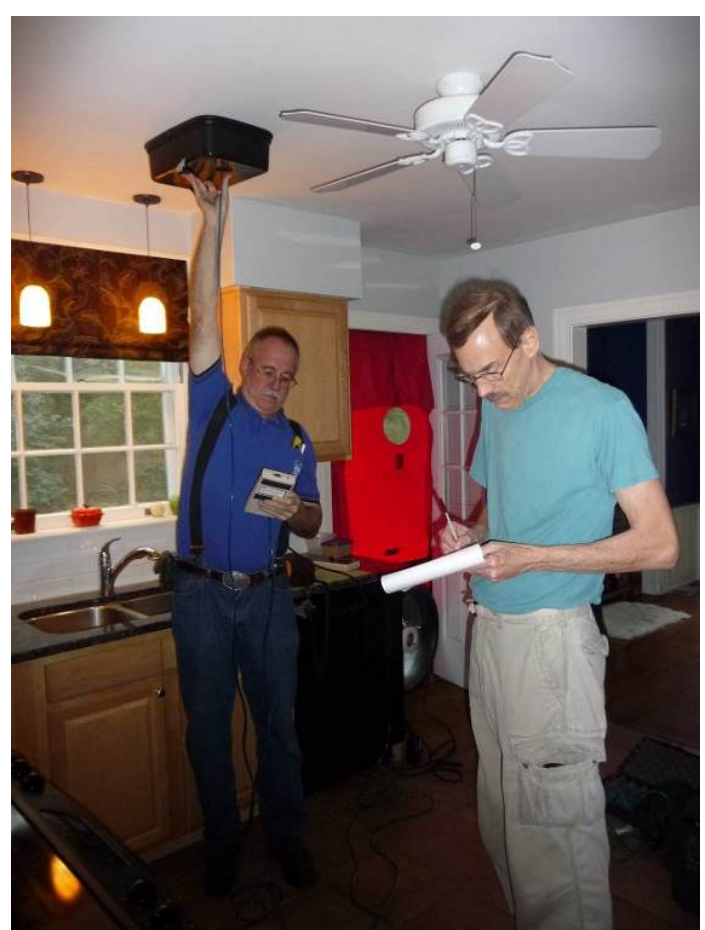

Figure 12. In House H36M, a Ppan test indicates both the magnitude and the general location of duct leaks with the air handling unit (AHU) off and the house depressurized to -50 $\mathrm{Pa}$. The blower door fan in the background is used for both the house tightness and Ppan tests.

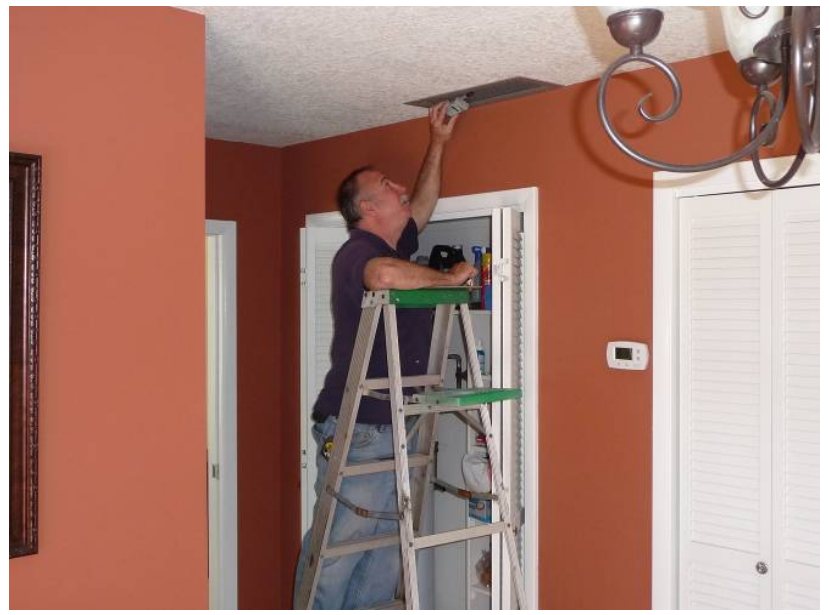

Figure 13. Air temperature and RH measurements were taken at House H51 using a Vaisala HM34 probe. 


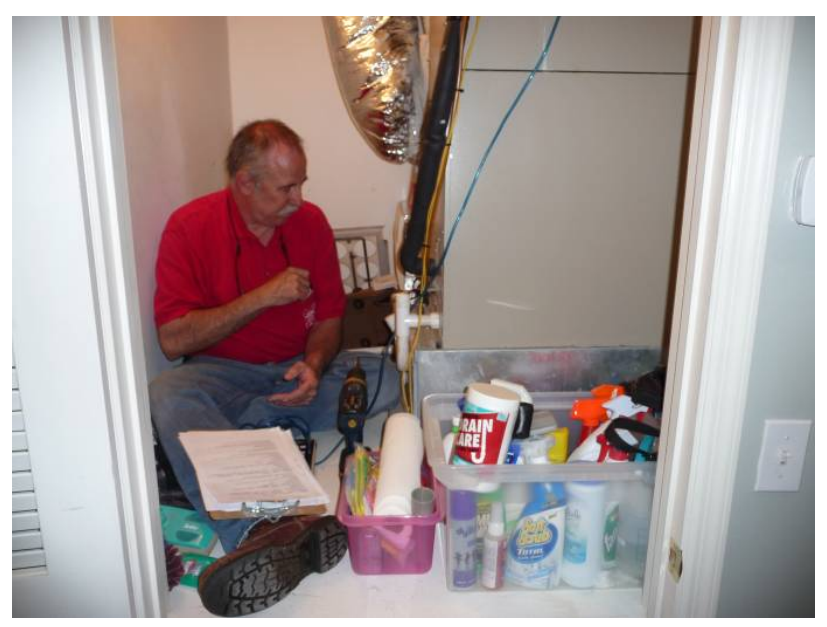

Figure 14. Preparing to measure the second-story AHU airflow rate at House H53 using a True Flow plate

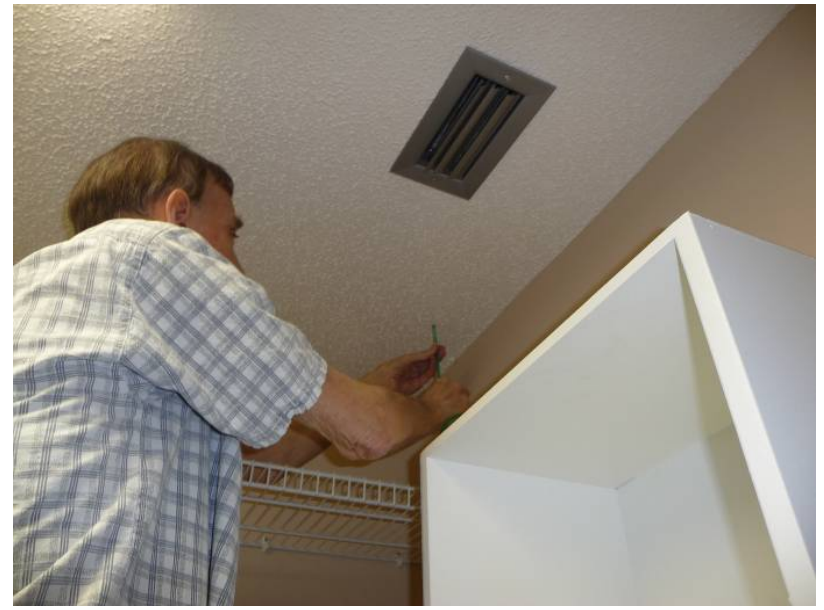

Figure 15. Floor cavity air pressure is measured by placing a tube into the floor cavity through a small drilled hole, with homeowner approval, at House H52.

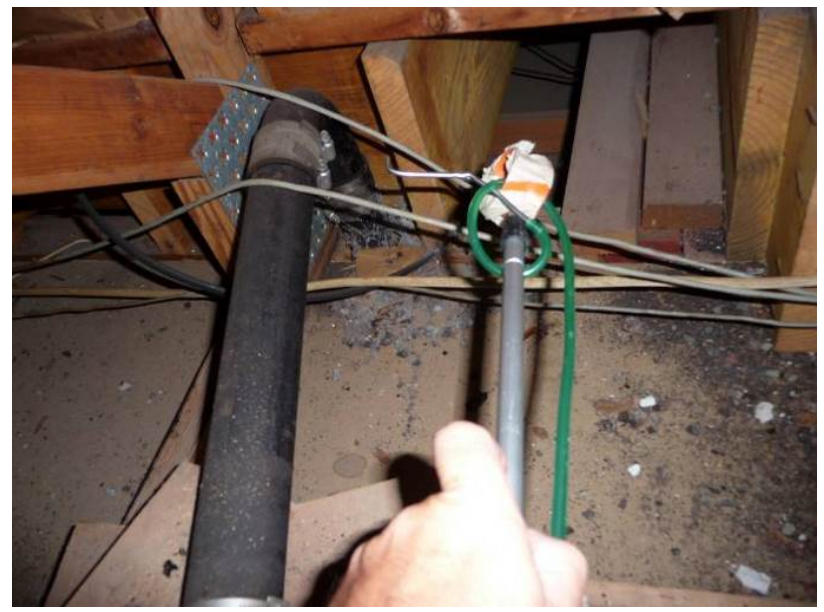

Figure 16. Floor cavity pressure is often measured by inserting a tube into the floor cavity using an extension pole at House $\mathrm{H} 50$. 
Infrared (IR) scans were used to identify temperature variations, which can reveal the operation of the wind washing phenomenon. Figures 17 through 25 illustrate some wind washing locations and IR signatures from House $\mathrm{H} 23 \mathrm{~K}$, the first Phase 2 repair home (this home was tested in Phase 1 but monitored and repaired in Phase 2). The first IR image (Figure 17) was taken during hot summer weather, and the following eight images were taken on a cool winter morning over a 20-minute period starting at 9:07 a.m. While the winter conditions during the IR images of Figures 18-25 are relatively chilly for Florida, it is recognized that they would seem spring-like in climate zones further north.

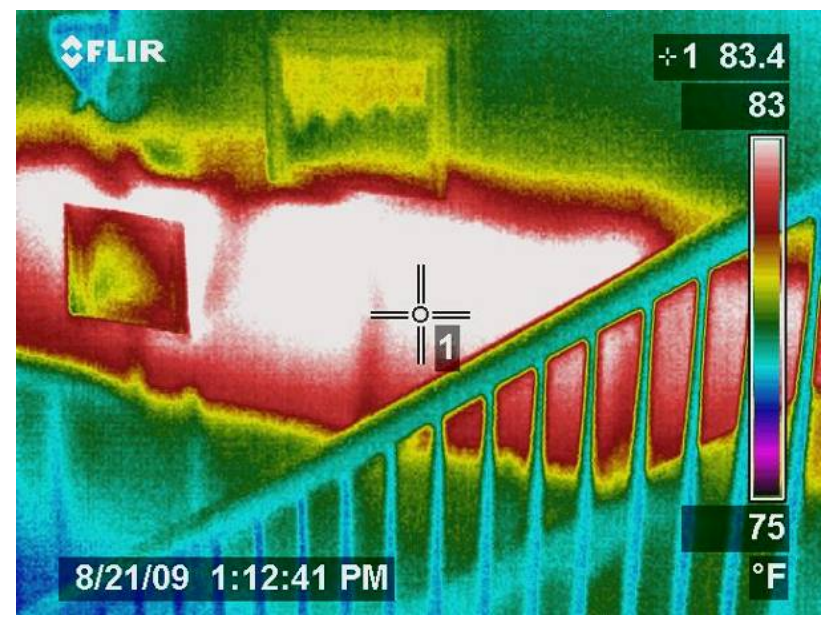

Figure 17. Summer IR image shows where hot attic air has penetrated into the floor cavity that lies behind the stairwell wall. The wall surface temperature at the floor cavity interface was $83^{\circ} \mathrm{F}$ compared to $77^{\circ}-78^{\circ} \mathrm{F}$ room air temperature.

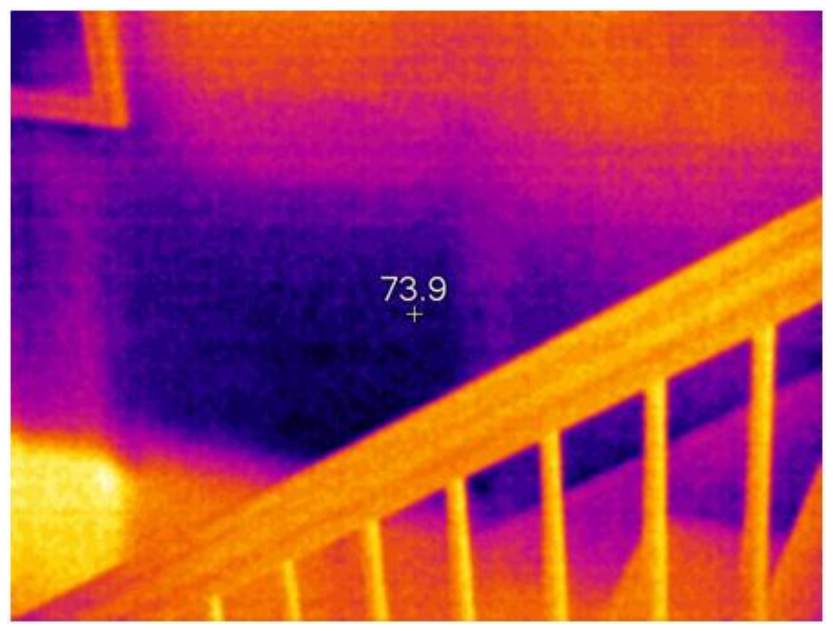

Figure 18. Winter IR image shows where cold outdoor air has penetrated into the floor cavity that lies behind the stairwell wall. The wall surface temperature at the floor cavity interface was $73.9^{\circ} \mathrm{F}$, about $1.5^{\circ} \mathrm{F}$ colder than the room air temperature. Overnight low outdoor temperature was about $44^{\circ} \mathrm{F}$ several hours prior to the image with calm wind conditions. 


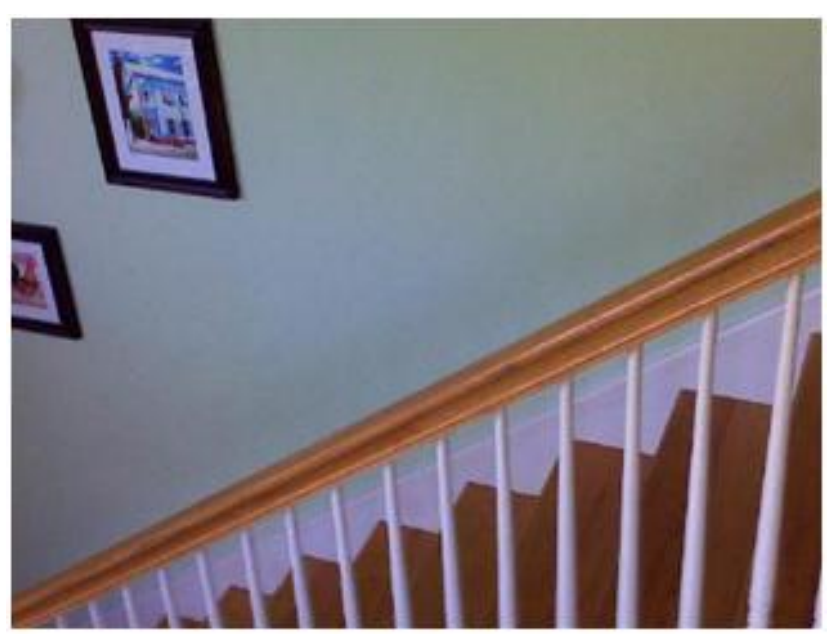

Figure 19. Stairwell where the thermal anomalies occurred

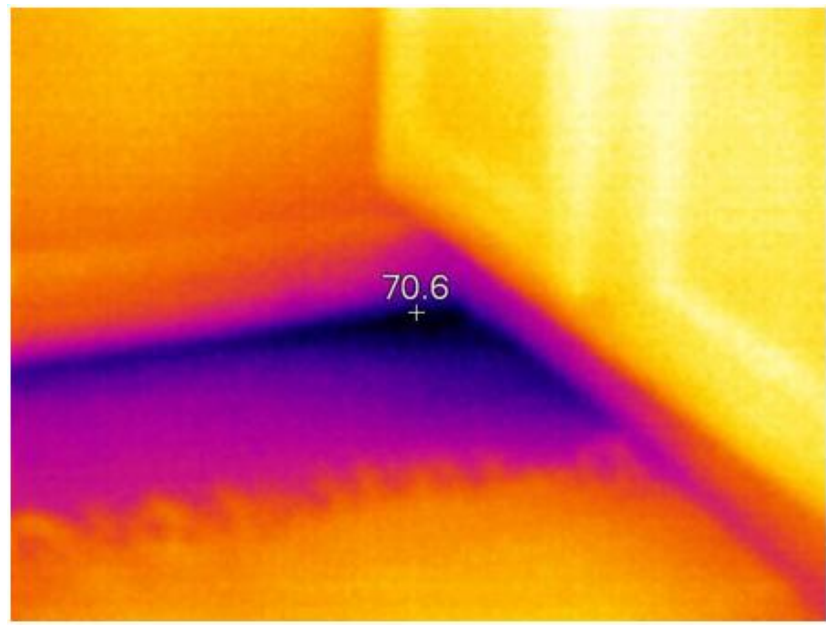

Figure 20. A bathroom floor had relatively cold surface temperatures compared to the heated area around it because of wind washing in the floor cavities below the floor.

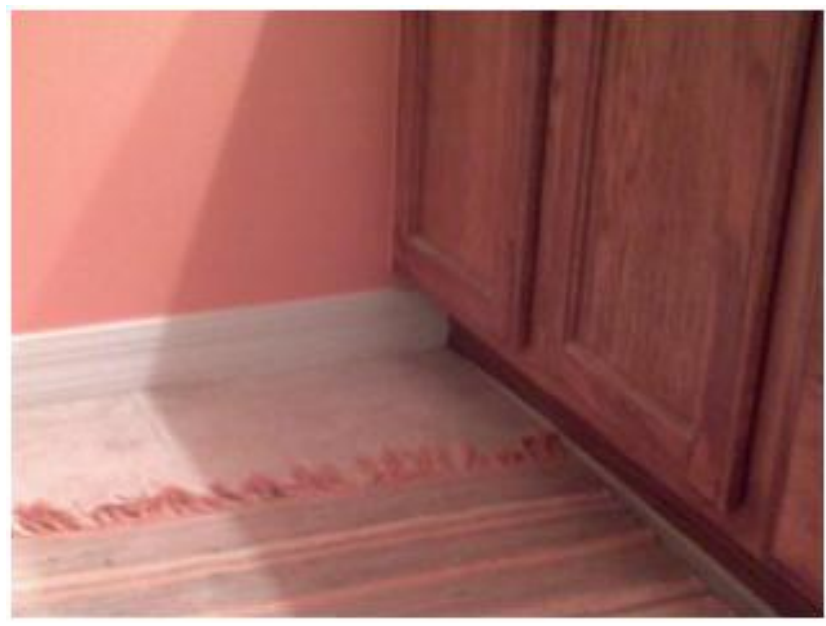

Figure 21. Photo of bathroom floor 


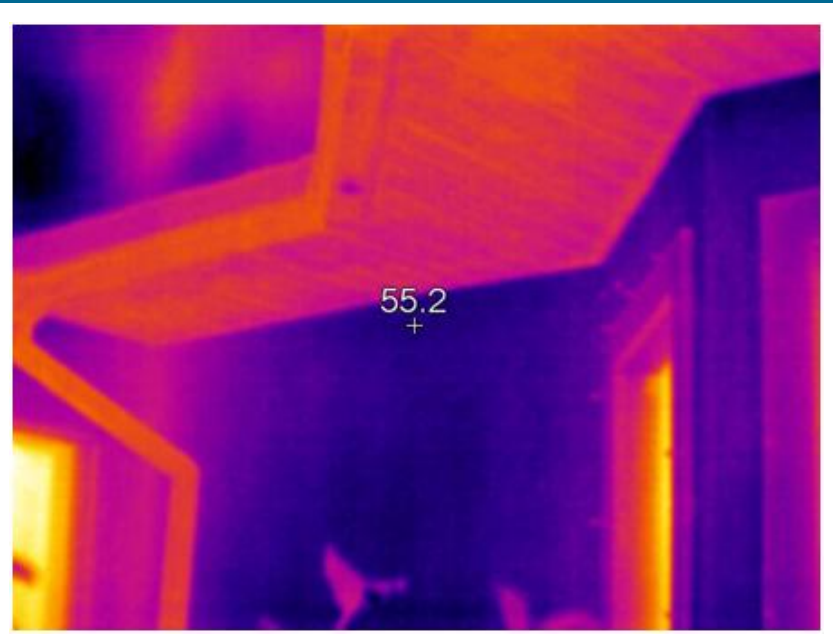

Figure 22. IR image of exterior west-facing wall. The soffit vent area is about $57.8^{\circ} \mathrm{F}$.

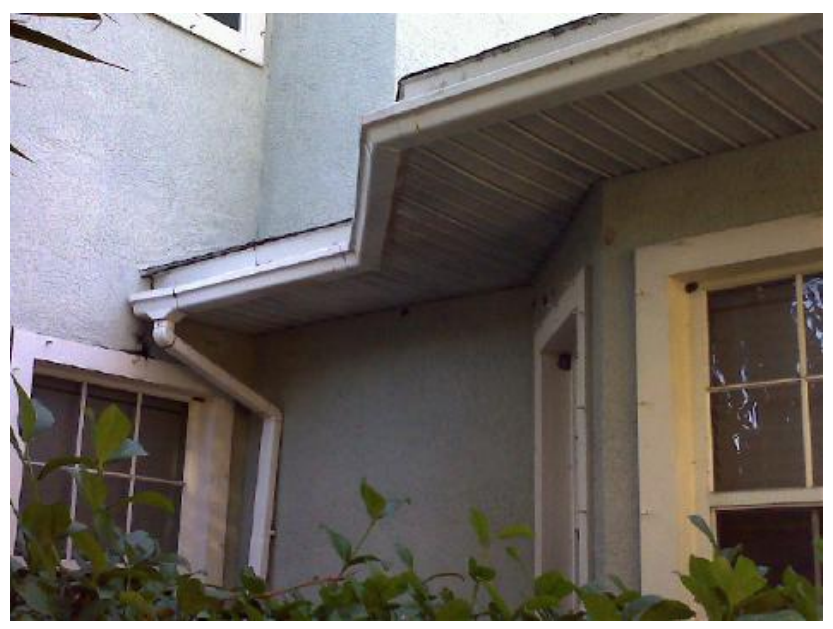

Figure 23. Photo of exterior west-facing wall

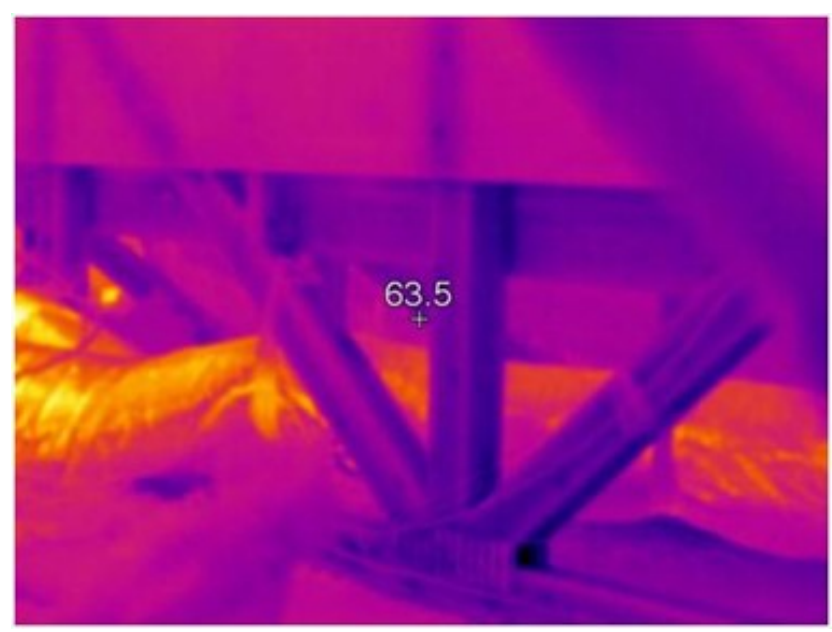

Figure 24. IR image of openings between the east attic and floor cavities near the second-floor bathroom 


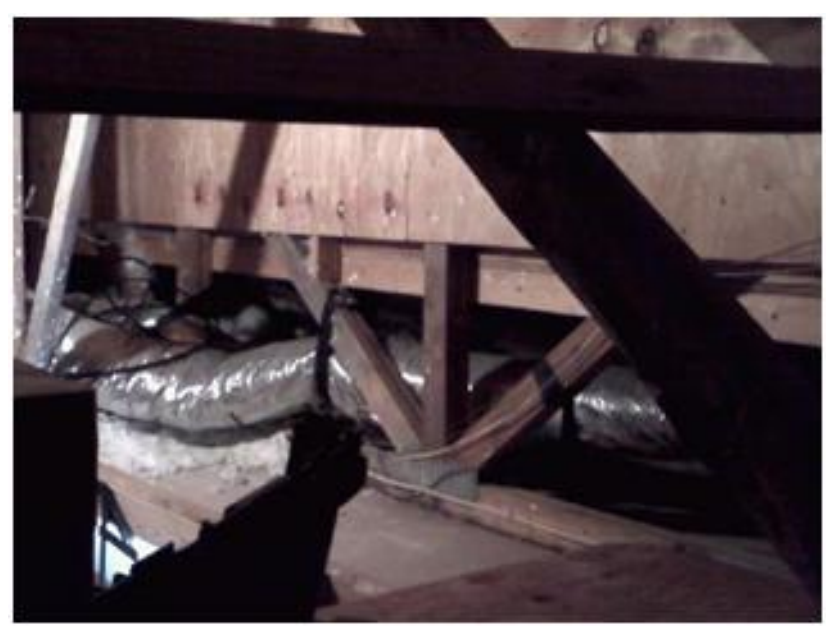

Figure 25. Photo of openings between the east attic and floor cavities near the second-floor bathroom

\subsection{Field Test Data Summary}

The field test performance-related data focused on house and duct tightness, unbalanced return air issues. Table 1 shows a summary of house- and duct tightness-related data. The average from all 24 homes is shown along with the range from lowest to highest in parentheses below the average. Field tests are described in more detail after Table 1.

Table 1. Summary Showing Average House Envelope and Duct Tightness Measurements With the Range of Lowest to Highest Value From 24 Tested Houses of Phase 2

\begin{tabular}{|c|c|c|c|c|c|c|}
\hline & ACH50 & $\begin{array}{c}\text { Estimated } \\
\text { Natural } \\
\text { Infiltration } \\
\text { (ach) }\end{array}$ & $\begin{array}{c}\text { Measured } \\
\text { Infiltration } \\
\text { Central on } \\
\quad(\text { ach })\end{array}$ & $\begin{array}{c}\text { Floor } \\
\text { Cavity } \\
\text { to House } \\
\left(\text { in }^{2}\right)\end{array}$ & $\begin{array}{c}\text { Floor } \\
\text { Cavity } \\
\text { to Attic } \\
\left(\text { in }^{2}\right)\end{array}$ & $\begin{array}{c}\text { House dP } \\
\text { wrt Floor } \\
\text { Cavity (pa) } \\
\text { house@-50 } \\
\text { Pa } \\
\end{array}$ \\
\hline $\begin{array}{c}\text { House } \\
\text { Tightness }\end{array}$ & $\begin{array}{c}9.7 \\
(6.2-22.1)\end{array}$ & $\begin{array}{c}0.243 \\
(0.155-0.553)\end{array}$ & $\begin{array}{c}0.429 \\
(0.115-0.797)\end{array}$ & $\begin{array}{c}12.0 \\
(0-34)\end{array}$ & $\begin{array}{c}2042 \\
(0-9677)\end{array}$ & $\begin{array}{c}-39.8 \\
(-27.9 \text { to }-49.5)\end{array}$ \\
\hline \multirow{2}{*}{$\begin{array}{c}\text { Duct } \\
\text { Tightness }\end{array}$} & RLF & Supply Ppan & Return Ppan & & & \\
\hline & $\begin{array}{c}5.4 \\
(0.0-23.4)\end{array}$ & $\begin{array}{c}1.0 \\
(0.1-3.4) \\
\end{array}$ & $\begin{array}{c}3.2 \\
(0.0-28.7) \\
\end{array}$ & & & \\
\hline
\end{tabular}

Note: $\mathrm{ACH}$, air changes per hour; wrt, with respect to; $\mathrm{dP}$, differential pressure

\subsubsection{House Tightness}

The house airtightness was measured using a blower door test assembly with the multipressure depressurization method of the American Society of Testing and Materials (ASTM) E779. The resulting measurement is the airflow from leakage in cubic feet per minute when the house is at a pressure of $50 \mathrm{~Pa}(0.2$ in. w.c.) with respect to (wrt) the outside. This value is known as CFM50. The average house tightness of 24 homes was 4,206 CFM50. For those interested in the flow variables, the average values for $\mathrm{C}$ and $\mathrm{n}$ were 344.8 and 0.66 , respectively. The leakage flow equation is as follows: 
$\mathrm{Q}=\mathrm{C} d \mathrm{P}^{\mathrm{n}}$

where $\mathrm{Q}=$ airflow leakage $(\mathrm{cfm})$

$\mathrm{C}=$ flow coefficient

$\mathrm{dP}=$ pressure differential from indoors wrt out $(\mathrm{Pa})$

$\mathrm{n}=$ flow exponent.

It is not surprising that larger homes tend to have greater leakage. Therefore, to compare the tightness of different homes, the CFM50 is normalized by house volume. The normalized leakage is shown as air changes per hour (ach) at $50 \mathrm{~Pa}$ of pressure (ACH50). This is calculated by (CFM50/house conditioned volume $\left.\mathrm{ft}^{3}\right) \times 60$. The average house leakage of these homes is quite high at 9.7 ACH50. By comparison, new International Energy Conservation Code building code (IECC 2012) requires new construction to have a tested airtightness not to exceed 5 ACH50 for climate zones 1 and 2. An even tighter restriction of 3 ACH50 is mandatory for climate zones 3 through 8. Florida has adopted this building code and, as such, will require tighter buildings. Eliminating floor cavity pathways will be an important step in being able to meet this requirement.

The natural infiltration rate in ach is estimated based upon the house ACH50. Based on previous research, the average natural infiltration rate (produced by wind and temperature differential [dT] effects alone) in Florida homes can be estimated by dividing the blower door test result (ACH50) by 40 (Cummings et al. 1990). Using this method, the average natural infiltration rate for these 24 homes would be 0.24 ach. This is nearly one-fourth of the house volume exchanged with outdoor air every hour, which based on the average house volume of $26,879 \mathrm{ft}^{3}$, could result in a natural ventilation rate of about $108 \mathrm{cfm}$.

While the natural ventilation rate has been estimated, the ventilation rate occurring during space heating and cooling was measured using the tracer gas decay method (ASTM E741-00 Reapproved 2006). A tracer gas decay test was performed in each house with the central ducted systems running continuously (interior doors open and exhaust fans turned off). The ach rate varied from 0.12 ach to $0.80 \mathrm{ach}$, with an average of $0.42 \mathrm{ach}$. Only one home had mechanical outdoor air. This home was tested with the ventilation air vents open as found and had a measured infiltration rate of 0.60 ach. The house with the highest measured infiltration rate of 0.80 ach was from a combination of leaky air envelope (16.8 ACH50) and large return duct leakage from a mechanical closet used as a return plenum. The closet had significant leakage to the floor cavity above, which also had large air pathways to an attic space abutted up against one side of the floor cavity. The return leakage ultimately allowed unconditioned air to be pulled from the attic space into the floor cavity and into the return of the central ducted heat pump. This home, H37M, was one of the six included in the retrofit study discussed later in the report.

A simplified estimate of the impact of duct leakage upon the infiltration rate can be made using the average estimated natural infiltration rate of 0.24 ach and the average measured infiltration rate with central ducted systems on of 0.42 ach. Based on this, the house infiltration rate increases by $75 \%$ (from 0.24 ach to 0.42 ach) as a result of air leakage from the air distribution system (duct leakage). The ducts in these homes are located primarily in vented attics and within the cavity between the first and second floors. The actual infiltration rate occurring at any given time will vary according to actual dTs between indoors and outdoors along with varying wind 
conditions. The comparison is best made when both the natural and mechanical infiltration tests can be measured under similar weather conditions. However, the magnitude of this impact is similar to hundreds of measured infiltration tests (ach natural versus ach ducted mechanical on) carried out under similar conditions by this primary author and others (Cummings et al. 1990). In fact, the average infiltration rates of this study ( 0.24 ach natural and 0.42 ach on) are very similar to the average of a 50-home study of (Cummings et al. 1990) that found 0.21 ach natural and 0.46 ach on.

The airflow rate of air exchange between indoors and outdoors with central systems operating continuously varied from $37 \mathrm{cfm}$ to $572 \mathrm{cfm}$, with an average of $194 \mathrm{cfm}$. This indicates that duct leakage provided air infiltration to the house on the order of three times that required for mechanical ventilation if the AHUs were, in fact, operated continuously (which of course they were not and should not be). If the central systems were operating, say, $33 \%$ of the time, the ventilation provided by the duct leakage would, on average, be equal to that required to meet ASHRAE Standard 62.2 ventilation. However, duct leakage is not a preferred means for meeting residential ventilation because duct leak air may be drawn from locations that are exceptionally hot or cold (vented attic) or contaminated (garage).

The house airtightness row in Table 1 shows an estimate of the floor cavity leakage pathway to the house as well as the floor cavity pathway to the attic. The pathway from the floor cavity to the house was typically very small and most often due to unsealed recessed can lights. The average leakage pathway from one unsealed recessed can light fixture was estimated to be about 1 in. ${ }^{2}$ or slightly larger if the fixture was not sealed well to the ceiling. The pathway from the floor cavity to the attic was measured and represents the net free area of the opening. As shown in Table 1, the controlling air barrier of the floor cavity occurs on the interior side from the finished drywall ceiling over the first floor and the finished floor deck of the second floor. The pathway on the attic side is about 180 times greater on average and demonstrates that the floor cavities (on average) are much more connected to the unconditioned attic than to the conditioned space.

\subsubsection{Duct Tightness}

The average results from duct leakage-related measurements and diagnostic tests are shown in Table 1. The first duct tightness measurement shown is the RLF and represents the return duct leakage as a percent of the total system airflow rate. The overall average RLF of all systems measured was $5.4 \%$ with a range of $0 \%$ to $23.4 \%$. RLF was measured during the tracer gas test. The RLF is calculated from:

RLF $=((A-B) /(A-C))($ Cummings 1989), where:

$\mathrm{A}=$ tracer gas concentration in the room at the return grille

$\mathrm{B}=$ gas concentration in the supply air stream

$\mathrm{C}=$ gas concentration in the unconditioned return duct leak zone (often zero in vented attics) 
For HVAC system 1 (serves the first floor), the average RLF was $6.6 \%$ and ranged from $0 \%$ to $23.4 \%$. For HVAC system 2 (serves the second floor), the average RLF was $3.7 \%$ and ranged from $0 \%$ to $11.0 \%$.

A second method of evaluating duct leakage was performed in all homes by means of a Ppan test. This diagnostic method provides an indication of significant leakage and approximately where it is located (Cummings et al. 1993). The Ppan method does not measure accumulated hole size or air leakage at $25 \mathrm{~Pa}$ (CFM25), which must be determined by direct duct leakage testing with a duct testing rig. The advantage of Ppan is that it is much quicker, adequate to determine if duct leakage is large enough to warrant repair, and can indicate the general area where the largest leaks are located. Duct repair was not a part of this project; however, it was important to know about this when considering the six house monitoring candidates.

With the house at $-50 \mathrm{~Pa}$, a pan (with gasket to create a tight seal to the gypsum board) was placed over supply registers and return grilles (AHU off) and a pressure in the duct (on the inside of the pan) was measured. Ducts sealed 100\% would have a Ppan reading of $0 \mathrm{~Pa}$, whereas a duct totally disconnected from the register boot would have a reading of $50 \mathrm{~Pa}$. It should be noted that the Ppan reading is related to the hole size and not to the actual system leakage. So, while a Ppan value of 1.5 Pa may not seem very large, the actual occurring leakage could be significant if this is in a high pressure area of the duct system. Generally, Ppan readings of $1 \mathrm{~Pa}$ or greater indicate slight to moderate duct leakage (cracks and seams), and Ppan readings of $3 \mathrm{~Pa}$ or greater indicate substantial duct leakage (typically small holes or long seams). Ppan readings greater than $5 \mathrm{~Pa}$ indicate large to very large duct leaks.

- For HVAC system 1 (serves the first floor), average supply Ppan readings ranged from $0.1 \mathrm{~Pa}$ to $3.4 \mathrm{~Pa}$, with an average of $1.1 \mathrm{~Pa}$. Average return Ppan readings ranged from $0 \mathrm{~Pa}$ to $28.7 \mathrm{~Pa}$, with an average of $4.3 \mathrm{~Pa}$.

- For HVAC system 2 (serves the second floor), average supply Ppan readings ranged from $0 \mathrm{~Pa}$ to $2.3 \mathrm{~Pa}$, with an average of $0.8 \mathrm{~Pa}$. Average return Ppan readings ranged from $0 \mathrm{~Pa}$ to $7.5 \mathrm{~Pa}$, with an average of $1.6 \mathrm{~Pa}$.

Repairing floor cavity leakage helps minimize duct leakage losses that occur within the floor cavity. Overall, 12 houses had floor cavity leakage repaired in Phase 1 and Phase 2. Two of the houses had return leakage that was repaired prior to wind washing repairs. Ten houses that only had wind washing repairs had reduced RLF duct leakage within the floor cavity by about $37 \%$ and supply Ppan reduction of 38\%. Measured tightness before and after Phase 2 repairs is shown in the Appendix, where six repairs are discussed.

\subsubsection{Floor Cavity Pathway Diagnostic Pressure Test}

This section describes a diagnostic test and some of its limitations. Understanding $\mathrm{dP}$ measurements impacted by series leakage can be difficult, so this section begins with an overview and moves into more detailed description and findings.

The purpose of the diagnostic test is to determine if significant leaks occur from the floor cavity to the vented attic space. This was based upon house wrt floor cavity pressure of about $-34 \mathrm{~Pa}$ when house pressure is at $-50 \mathrm{~Pa}$ wrt out.

Pros 
- Quick measurement (if already set up for house tightness test)

- Can be measured with house at $-50 \mathrm{~Pa}$ or at $+50 \mathrm{~Pa}$ wrt outdoors

- Can challenge the inspector to consider if leakage is occurring in some area not inspected and to consider additional inspection

- Works best in homes with little leakage to indoors and floor cavity with open truss design.

Cons

- Visual inspection still needed

- Not useful for determining thermal barrier integrity

- Not a good correlation of dP magnitude to pathway size of leakage to outside because $\mathrm{dP}$ is determined by the relative comparison between leaks to indoors and to the attic

- Single measurement does not represent the entire floor cavity in floors with solid wood joists (board joists or engineered structural wood panels).

Besides direct visual inspection for open floor cavity pathways, a diagnostic test was conducted to investigate the potential usefulness of a relatively easy measurement to determine the potential severity of floor cavities open to unconditioned spaces well connected to the outdoors. This could be useful in determining the relative airtightness of the cavity, but could not indicate anything about the thermal integrity. This is reason enough to always require visual inspection of all accessible floor cavity areas. However, the team thought that this diagnostic could provide enough information to warrant some disassembly of building components to view hard-to-access areas. Consider an example where a house has a floor cavity that abuts an accessible ventilated attic space and an inaccessible small vented roof/soffit area. Suppose inspection of the floor cavity from within the accessible area reveals that the air and thermal barrier are intact, and there is no significant leakage from the floor to the house, but the pressure diagnostic indicates there may still be a significant area of leakage. Based on this scenario, it may be worth some visual inspection of the small inaccessible area by removing a part of the soffit vent, or even a section of the floor cavity covering such as the floor deck or drywall. A borescope may be another less destructive option, but has very limited visual range.

The floor cavity diagnostic pressure test was completed as follows:

1. Place reference tubing inside the floor cavity. This can be done by drilling a small hole through the first-floor ceiling into the floor cavity (Figure 15), by pushing the tube well into the space by the extension pole from within the accessible attic (Figure 16), or by pushing the tube through the leaky can light or other ceiling fixture located in the floor cavity.

2. Set up the blower door and bring the house to -50 Pa wrt outdoors, all HVAC off.

3. Measure house wrt to floor cavity pressure.

With the house depressurized by the blower door to $-50 \mathrm{~Pa}$, the house pressure was measured wrt floor cavity. The house pressure wrt floor cavity will be negative (less than zero) as long as 
the floor cavity has some connection to a vented attic space. (This test could also be done in the pressurization mode if preferred.) If the floor cavity is much more connected to a vented attic space, the reading will be closer to $-50 \mathrm{~Pa}$. If the floor cavity is relatively tight to the attic and leakier to the indoor space, the reading will be closer to 0 Pa. Figure 26 shows the measured floor cavity area plotted versus the measured house wrt floor pressure. This figure includes data from Phase 1 and Phase 2. The first series shown is only for homes that had at least visual-sized openings large enough to be measured. The $\mathrm{dP}$ ranges from $-27.9 \mathrm{~Pa}$ to $-49.5 \mathrm{~Pa}$. Pressures that are less negative are generally those with smaller leak areas. The least negative $-27.9 \mathrm{~Pa}$ also had a good amount of leakage from house to floor cavity through several can lights. This is an example of what was previously mentioned, where less negative pressure can be expected as the leakage increases to the house. Because the Y-axis scale is so large, the leakage areas for the first series smaller than 150 in. $^{2}$ appear to be about zero in Figure 26.

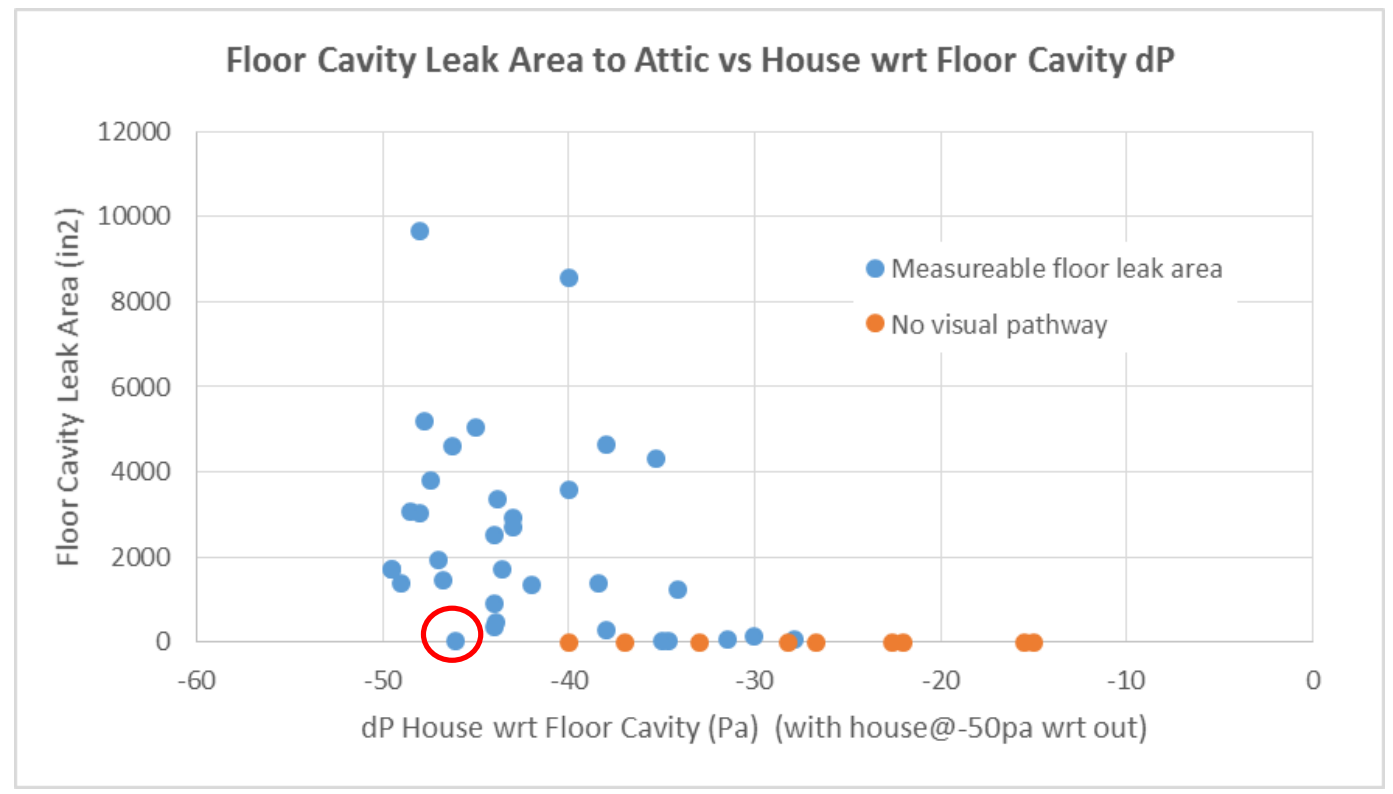

Figure 26. The measured floor cavity area plotted at the measured house pressure wrt floor cavity

This test method may also not work as well for homes with solid wood floor joists. The solid boards create compartmental spaces not well connected to one another compared to open floor truss construction. In any inspection, there may be long seams out of view and not easily noticed that provide ample connectivity to the attic. One compartmental floor cavity may be better connected to the house through ceiling-mounted recessed can lights or other leaky fixtures than other floor cavity compartments with no ceiling penetrations. The point highlighted with a red circle in Figure 26 is one example of a compartmental floor cavity pressure of $-46 \mathrm{~Pa}$ that indicates a floor cavity much better connected to the attic compared to the house, except there is a very small indication of visually observed leak area to the attic of only about $25 \mathrm{in}^{2}$. One might expect very obvious open pathways to the attic based on this pressure. However, in this particular case, the floor cavity compartment tested was very tight to indoors relative to the attic leakage consisting of long, narrow cracks. While the pressure in this case of $-46.1 \mathrm{~Pa}$ is indicative of the floor cavity being much more connected to the attic than to the house, the leakage pathway is still relatively small. 
Because the pathway to the attic is smaller relative to the pathway to the indoors, this will have more influence on the $\mathrm{dP}$ measurement and a greater likelihood of error in interpretation. The second series shows results for homes where no visual sized pathways were observed (observed cavity leakage area $=0$ in. ${ }^{2}$ ). The second series with no visually observed leakage would be expected to have pressures lower than $-20 \mathrm{~Pa}$, but clearly most of the readings exceed this. In cases where the $\mathrm{dP}$ is lower than $-20 \mathrm{~Pa}$ (indicating better connection to the attic than expected), some leakage may have occurred, but was not visible. Knowing how and when to trust this measurement is complicated because the pressure is dependent on the series leakage pathway (from house to floor to attic to outdoors). This is dependent on the relative size of the pathway from cavity to indoors and from cavity to outdoors. The overall usefulness of this measurement as a diagnostic test requires some general knowledge about the leakage from the floor cavity into the home as well as leakage to unconditioned space outside the primary air barrier of the home.

The results indicate that this diagnostic is clearly not adequate on its own to be a replacement of visual inspection to determine if a floor cavity has a significant potential for wind washing. The house wrt floor cavity dP diagnostic measurement could be considered a simple and quick measurement to determine if more detailed visual investigation of the floor cavity is warranted, particularly if the measurement is $-34 \mathrm{~Pa}$ or lower. It could be useful to prompt a more careful visual inspection and perhaps consideration of leakage to areas not easily accessible.

Among the 24 homes of Phase 2, the floor cavity pressure varied from $-49.5 \mathrm{~Pa}$ to $-27.9 \mathrm{~Pa}$, with an average of $-39.8 \mathrm{~Pa}$ (Table 1). With an understanding that the floor cavity pathway to the attic is about 182 times larger than to the indoors (2,022 in. ${ }^{2}$ attic leak/11.1 in. ${ }^{2}$ house leak), an average house wrt floor pressure of $-39.8 \mathrm{~Pa}$ indicates that, on average, the floor cavities of Phase 2 homes were much more connected to outside than inside the air boundary of the house. 


\section{Selecting Homes for Monitoring and Wind Washing Repair}

Long-term monitoring of energy and indoor environment (temperature and $\mathrm{RH}$ ) was completed in six homes of Phase 2. These homes were monitored for a period of 6-12 months, before and after wind washing repair, to obtain sufficient data to evaluate cooling and heating season energy impacts. Four of the six homes were located in the northern region of Florida around the Jacksonville area, where the heating season is generally longer and colder. This area was chosen to increase the chances of effectively evaluating heating season energy and demand savings. The Jacksonville area has typical heating degree days of 1355 compared to only 598 heating degree days in Orlando (Normal Monthly Heating Degree Days [Base 65] 2013).

The 24 field-tested homes were assessed to identify likely impacts from wind washing. Generally, those with the greatest energy savings potential were sought for the repair study, taking into account various factors such as likelihood that the occupants would remain in the house for 2 years and that no major house renovations were expected. Homes were considered for the retrofit study if there were adequate access to repair locations, measurable leak pathways from floor cavity to attic space, ventilated attic, space conditioning equipment in good condition, and owner/occupant willingness to participate. A home with anticipated high savings potential was one with large floor cavity openings to attic space occurring on opposing sides that create complementary pathways. The complementary pathways would enhance the likely movement of unconditioned air in and through the floor cavity. Other factors considered likely to improve savings potential were unshaded roof, black asphalt composite shingle, distributed attic ventilation around all soffits, and good wind exposure particularly oriented into floor cavity openings. The homes selected for repairs were considered to have moderately low to moderately high energy savings potential based on the house qualities. 


\section{Monitoring of Six Repair Homes}

Monitoring equipment was installed in six homes. Each house was monitored for representative summer and winter periods to characterize space conditioning energy use and space conditions before and after repair. Campbell Scientific CR10 or CR1000 data loggers were used to read sensors and complete intermediate data processing data storage. Data were collected in 15minute time steps and stored in the memory of the onsite data loggers. A central server located at the Florida Solar Energy Center was used to download data daily, screen for errors, process data, and permanently store data in a secure database account. Researchers could then regularly access data to review any potential indications of bad sensors or unusual data.

Monitoring consists of the following channels of data:

- Power use of the space conditioning system(s) (typically two) that serve(s) the house.

- Temperature measurements (type T thermocouple) indoors, in the attic, in the floor cavity between the first floor and the second floor of the house, and in the return and supply air streams of the space conditioning systems.

- RH measurements (Vaisala HMP50,60 or APT-RH1500 series sensors) indoors, in the attic, and in the floor cavity between the first floor and the second floor of the house.

- Monitoring varies slightly from one house to another. A typical channel map is shown in Table 2.

- Onset HOBO temperature and humidity data loggers were used in two cases where sensor wiring could not readily be run to a location.

Table 2. Typical Data Monitoring Channel Map for Repair Homes

\begin{tabular}{c|c|c}
\hline Acronym & Description & Units \\
\hline BATVOL & CR10 battery voltage average & $\mathrm{V}$ \\
\hline TFLOR1 & Temperature first floor & ${ }^{0} \mathrm{~F}$ \\
\hline TFLOR2 & Temperature second floor & ${ }^{0} \mathrm{~F}$ \\
\hline TATTIC & Temperature in an attic space adjacent to a floor cavity average & ${ }^{0} \mathrm{~F}$ \\
\hline TRFDEC & Roof deck temperature in attic average & ${ }^{0} \mathrm{~F}$ \\
\hline TFLSPC & Temperature inside the second-story floor space average & ${ }^{\circ} \mathrm{F}$ \\
\hline TOUTDR & Temperature outdoors average & ${ }^{\circ} \mathrm{F}$ \\
\hline RHOUTD & RH outdoors average & $\%$ \\
\hline RHATIC & RH in attic average & $\%$ \\
\hline RHFLR2 & RH on first or second floor average & $\%$ \\
\hline RHFLSP & RH inside second-story floor space average & $\%$ \\
\hline ACWHR1 & Energy first-floor heat pump total & ${ }^{\%}$ \\
\hline ACWHR2 & Energy second-floor heat pump total & $\mathrm{Wh}$ \\
\hline TRETF1 & Temperature return second-floor heat pump average (when AHU on) & ${ }^{\circ} \mathrm{F}$ \\
\hline TSUPF1 & Temperature supply air first-floor heat pump average (AHU on) \\
\hline TRETF2 & Temperature return air second-floor heat pump average (AHU on) & ${ }^{\circ} \mathrm{F}$ \\
\hline TSUPF2 & Temperature supply air second-floor heat pump average (AHU on) & ${ }^{\circ} \mathrm{F}$ \\
\hline
\end{tabular}


Figures 27 through 32 highlight some of the elements of monitoring installations. The Phase 2 homes that were monitored, repaired, and retested have an additional letter added to the home IDs such as H39L or H36M.

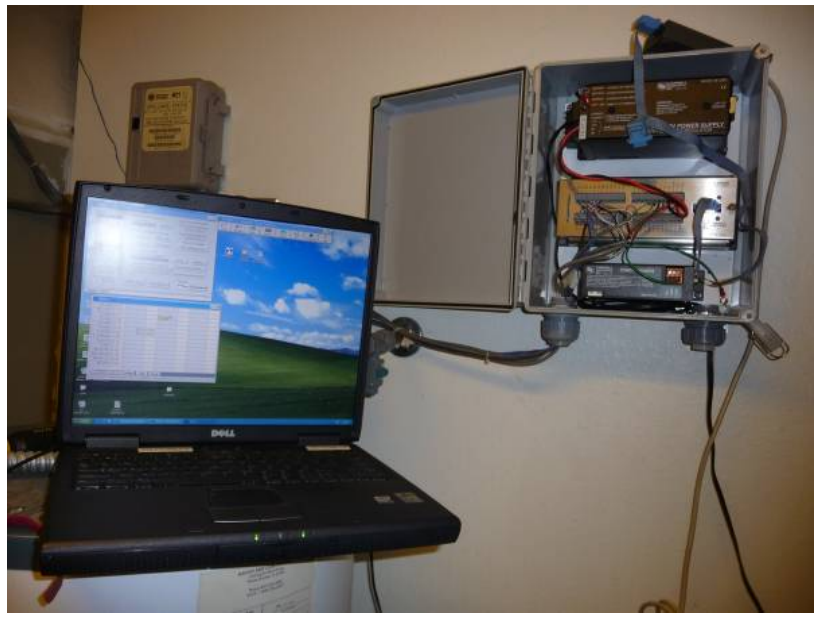

Figure 27. Installed data logger shown connected to sensor wires and to laptop at House H39L

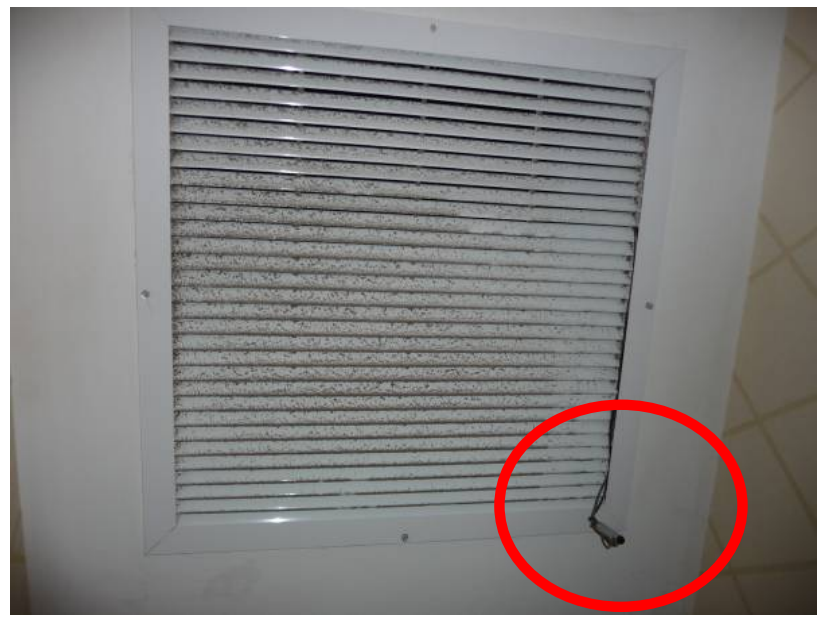

Figure 28. Temperature and RH measurement of first-floor return air at House H36M

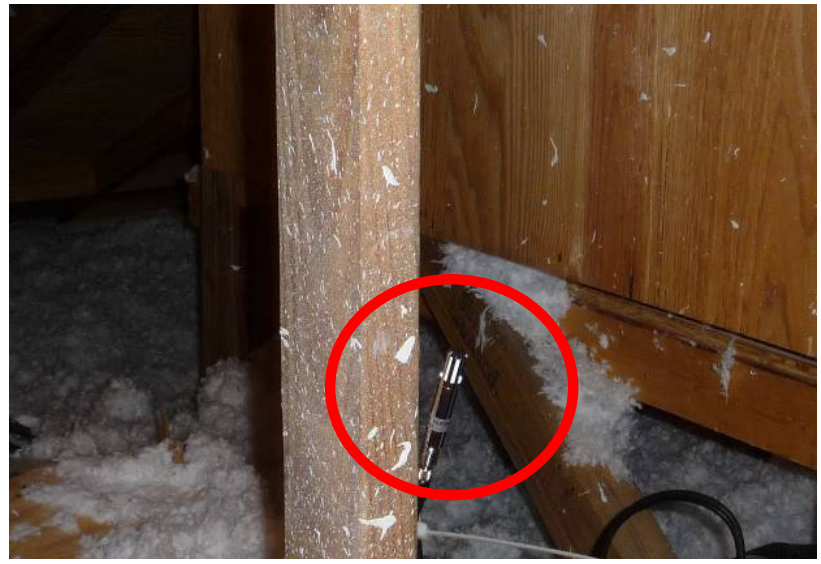

Figure 29. Vaisala temperature and RH probe in attic space near open floor cavity of House H23K 


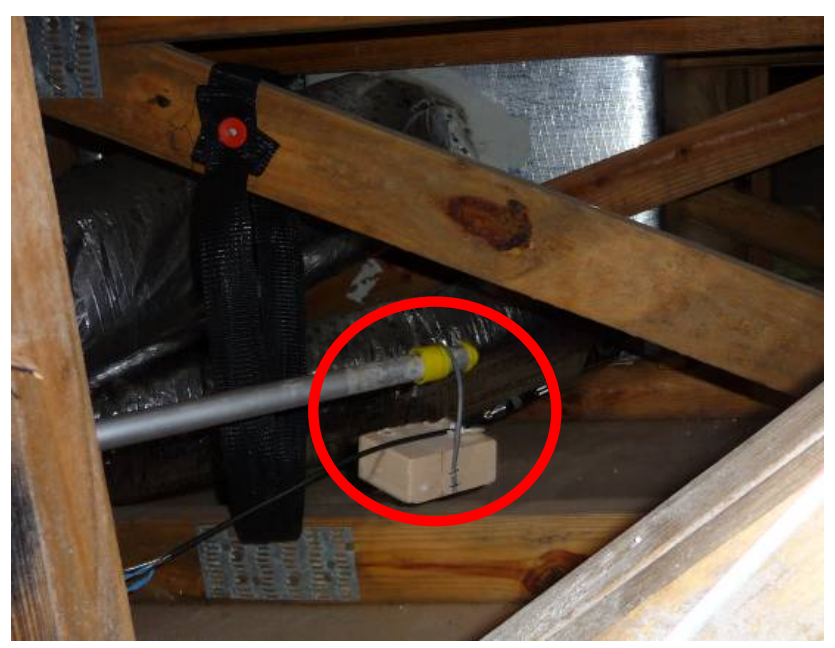

Figure 30. A telescoping pole was used with a portable mounting block to place a Vaisala temperature/RH probe inside the floor cavity at House H23K. Sensors were located away from ducts and duct leaks.

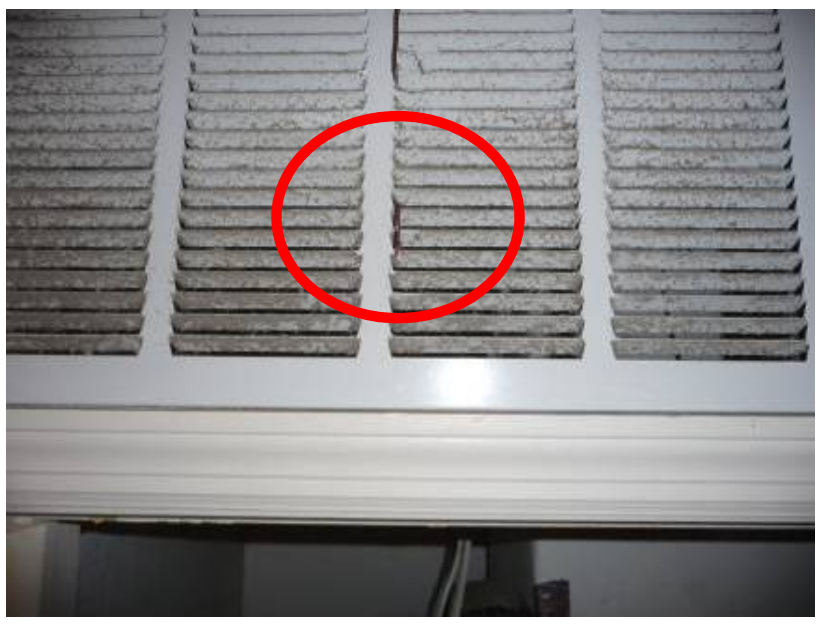

Figure 31. A copper-constantan (type $\mathrm{T}$ ) thermocouple was used to sample return air temperature on the second floor of House H39L.

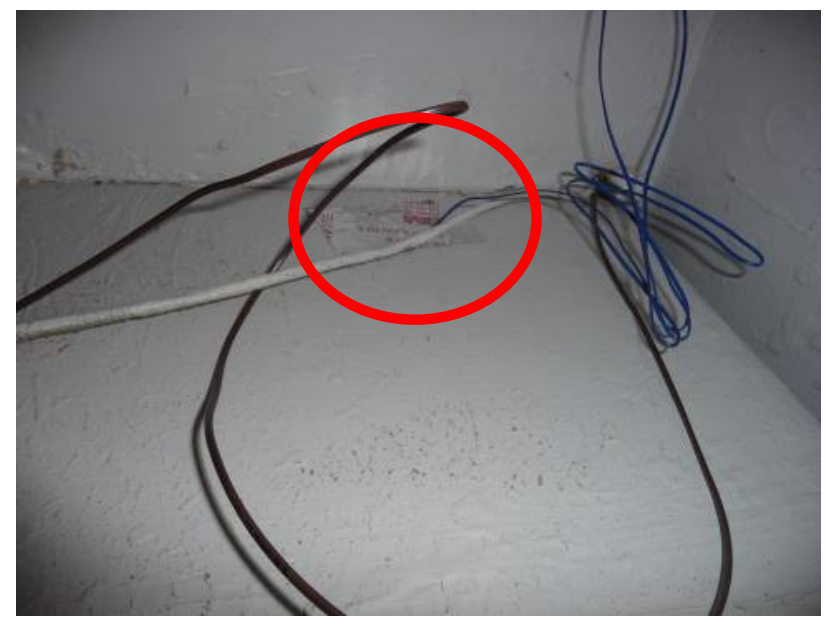

Figure 32. A thermocouple was inserted into the supply plenum (through the side wall of the plenum behind the foil tape) of the second-floor heat pump system to sample supply air temperature at House H39L. 


\section{Discussion of Wind Washing Repair Considerations}

A repair plan was developed for each home selected for wind washing repair. In developing the plan, the team considered a number of variables, including ease of access to repair locations in the attic, obstructions to sealing wind washing openings (such as ducts, plenums, junction boxes, and framing members), and the estimated effectiveness of various repair materials and methods of installation. A Florida Solar Energy Center research staff member was present during all repairs in Phase 1 and Phase 2 and inspected each job after completion before contractors left the work site.

Two types of repairs are considered for implementation:

- Sealing the openings between attic space and floor cavities. This repair type was implemented in all homes, though the types of sealing materials varied.

- Applying insulation materials to adjacent knee walls.

In Phase 1, two of the six homes had repairs that involved sealing the floor cavity opening and covering the knee wall area directly above it. Knee walls were improved if the knee wall area had either less than R-19 insulation, significant voids, or framing issues making it difficult to improve with batts. Approximately 3-1/2-4 in. of foam insulation material was applied over the knee wall to reduce heat flux from a hot attic to conditioned space on the other side of the wall (Figures 33 and 34). Knee walls above open floor cavities were insulated in five of the six Phase 2 repair homes. One of the knee wall insulation repairs was done with fiberglass batts instead of foam.

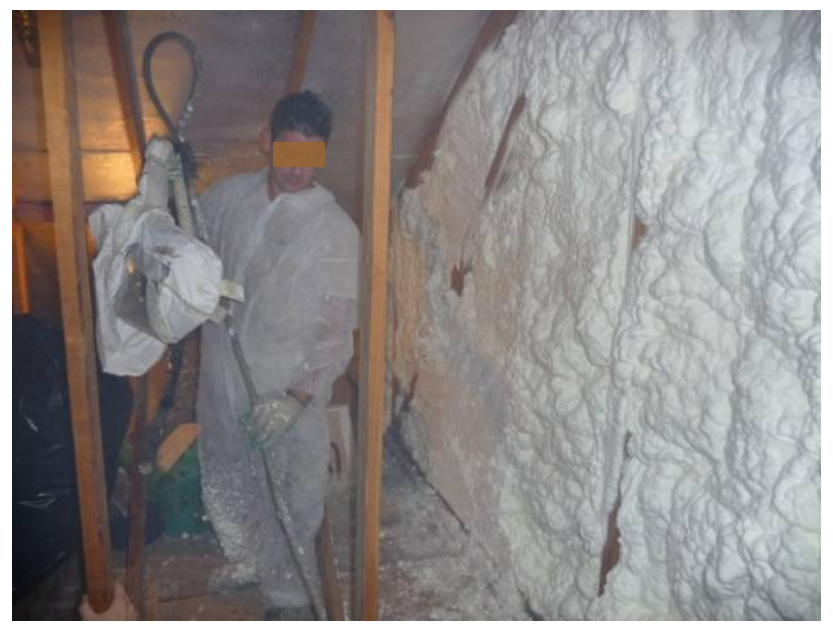

Figure 33. Foam insulation was used to seal the attic-to-floor cavity opening and insulate the knee wall above the floor cavity opening in Phase 1 House H16B. 


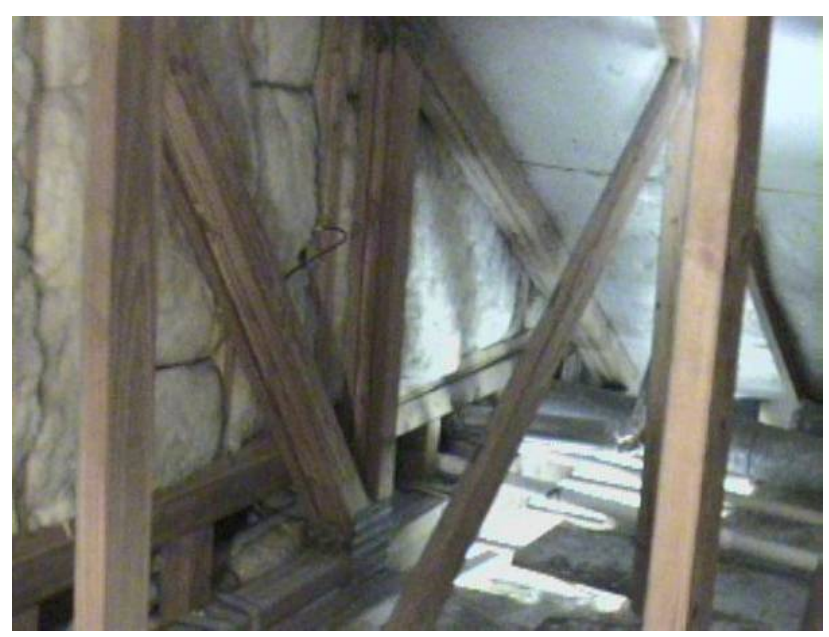

Figure 34. Floor cavity opening and knee wall can be seen in House H16B prior to foam insulation application.

In Phase 1, it was determined that open-cell spray foam worked well in sealing wind washing openings. The foam application is quite versatile in its ability to quickly expand to seal off openings of a wide range of sizes and shapes, even around a variety of obstructions (ducts, construction materials, etc.). The primary concern associated with the open-cell foam was (and is) about moisture condensation, which could occur on cool surfaces of supply air ducts that pass between the floor cavity and the attic space. The relatively high vapor permeability of the opencell foam would likely allow water vapor in the attic air to migrate (slowly) through the material and come into contact with cooler surfaces of the supply ducts. Moisture could accumulate on the exterior jacket of the supply duct and drain down onto the ceiling gypsum board. A successful solution to this problem was achieved by wrapping supply ducts with a semirigid but flexible (approximately $1 / 2$-in. thick) insulation with vapor barrier prior to spray foam application, thus preventing the open-cell foam from contacting the duct.

Open-cell spray foam was used in all six Phase 1 repair homes. Some consideration was given to alternative repair materials and methods, but alternatives were feasible in only two of those at the time. Furthermore, because the Phase 1 monitoring period occurred over one summer and repairs had to be completed quickly, spray foam was the better choice at the time to ensure quick repair. The spray foam contractor could, in some cases, finish three to four homes in 1 day. For Phase 2, the team made an effort to examine a broader range of repair options in an attempt to discover the lowest cost options.

Prior to wind washing repairs in Phase 2, the research team spoke with two contractors that use both open-cell and closed-cell foams. Both were asked about the suitability of open (low-density) or closed (higher density) cell foam for sealing and insulating open floor cavities in attics. The greatest drawback to closed-cell foam is that it may cost twice as much for comparable R-values. Thus, the research team determined that closed-cell foam would not be used in Phase 2 .

In Phase 2, four homes were repaired using low-density foam (LDF) and two were repaired using kraft paper-faced fiberglass batts. Repair using batt insulation was implemented by placing R-19 or R-30 kraft paper-faced insulation batts into floor cavity openings. The paper facing must be carefully attached to the surrounding frame structure of the floor cavity to provide an effective 
air barrier. This repair uses low-cost materials and can be implemented with little or no training of insulation professionals. It should be noted, however, that repair using batts was practicable because the floor cavity openings were of generally symmetrical dimensions, easily accessible, and unimpeded by various obstructions (ducts, junction boxes, dimensional lumber, etc.).

Seven of 12 repaired homes were completed using the same brand of LDF. This open-cell foam brand was Demilec, which is also identified as "SEALECTION 500" polyurethane foam. The following information was provided by the manufacturer:

"SEALECTION 500 is a two-component, open celled, spray-applied, semi-rigid polyurethane foam system." The product is water-blown, meets off-gassing requirements of CGSB 51.23-92, has been approved by the EcoLogo Program of Canada, and is listed as a Certified Green Product.

It is low density $\left(0.45-0.50 \mathrm{lb} / \mathrm{ft}^{3}\right)$.

It has thermal resistance of $3.81 \mathrm{ft}^{2}-\mathrm{h}-{ }^{\circ} \mathrm{F} / \mathrm{Btu} / \mathrm{in}$. of product thickness at $76^{\circ} \mathrm{F}$.

Air leakage of $3 \frac{1}{2} 2$-in.-thick product at $75 \mathrm{~Pa}$ is $0.001 \mathrm{~L} / \mathrm{s}-\mathrm{m}^{2}$.

Water vapor permeability of $3 \frac{1}{2}$-in.-thick product is 6.6 perms.

Three other homes used another brand of expanding open-cell, polyurethane-based LDF. The exact characteristics of these three are not known, but are reported to have similar thermal resistance performance.

As previously indicated, knee walls adjacent to the floor cavity openings are sometimes included in the wind washing repair. Knee walls are considered a target for this repair program for three reasons:

- The largest part of the repair task/cost is getting the contractor and his equipment into place. Thus, it often makes economic sense to address other adjacent airflow and insulation issues while the contractor is there.

- Knee walls often have inadequate insulation (poor effective R-value relative to the large delta temperatures across these knee walls) and therefore represent a thermally compromised pathway for heat to enter the conditioned space.

- In some cases the insulation batts are not in complete contact with the wallboard materials (this has been observed using an IR camera), thus allowing a type of wind washing to occur where hot attic air gets into the gap between the insulation batts and the wallboard. Because the air in that gap is cooled by the gypsum wallboard, it becomes denser and spills out into the attic, only to be replaced by additional hot attic air, in a recurring cycle.

Knee wall insulation, as already suggested, sometimes has compromised R-value. In Phase 1 House H16B, for example, R-11 batts had been installed when the house was built. However, because of the significant amount of framing (about $20 \%$ of face area), the effective R-value of the knee wall is about 8 . When one considers that the delta temperature across the knee wall is high (with attic temperatures peaking at about $125^{\circ} \mathrm{F}$ ), heat gain to the house through the knee wall is high. Not only does this create an energy waste problem, but it may cause a significant 
rise in the mean radiant temperature of the conditioned space on the other side of the wall. The result is either comfort problems or occupant adjustments to the thermostat to achieve comfort. Adding 3-1/2 in. of open-cell foam to that knee wall increases the effective R-value by a factor of about 2.65 , from about 8 to about 21 . To the extent that buoyancy-driven wind washing may have been occurring between the batts and the wallboard, and to the extent that attic radiant heat may have been penetrating into the outer layers of the fiberglass batts, the wall assembly may experience an improvement in overall thermal resistance by a factor that is greater than 2.65.

One of the Phase 2 homes had no insulation on the knee wall. In this case, it was cost effective to apply an insulation system to those knee wall surfaces. Even in cases where the knee wall has R19 batts with typical voids and compression, application of a layer of foam insulation is likely to be a cost-effective activity, especially because the contractor is already there sealing floor cavity openings. 


\section{The Cost of Wind Washing Repairs}

The actual cost of repairing wind washing can vary greatly. The greatest factors affecting cost involve the level of difficulty to access repair areas and the total area required to be sealed. One of the project goals was to seek lower cost options for repairs based on using different repair materials. Two primary types of materials were used: open-cell spray LDF and fiberglass batt insulation with kraft paper facing. Only two contractors were used during Phase 1 and Phase 2.

The six repaired homes in the Phase 1 study (summer 2009) were all sealed using a blown, expanding open-cell LDF. Other options such as sealing some with batt insulation or rigid board stock were considered, but were not used because repairs needed to be completed in a timely manner to avoid starting post-retrofit periods too late in the summer. Foam application is fast. For example, one two-person crew was able to implement three wind washing repairs in three homes in one 8 -hour day, including travel time and about $2-1 / 2$ hours downtime from equipment failure. The foam insulation contractor that was selected for the Phase 1 repairs charged a flat rate of $\$ 650$ per house. This company had a provision to charge a minimum of $\$ 650$ or $\$ 1.45 / \mathrm{ft}^{2}$, whichever was greater. This may indicate that jobs smaller than $448 \mathrm{ft}^{2}$ were not large enough to cover expenses, overhead, and profit at $\$ 1.45 / \mathrm{ft}^{2}$. In fact, the typical cost of professionally applied LDF at about R-13 to R-14 is in the range of \$2.05-\$2.50 (ABT 2014).

Of the six repaired homes from the Phase 2 study, the four located in Jacksonville were repaired by the same company. Several companies were contacted and invited to provide estimates on repairs. While three indicated initial interest, only one maintained interest in staying involved. Those that lost interest did not provide any indication of why they later did not pursue the work. It is assumed that perhaps the nature of the work was too small to become involved. The insulation company that maintained contact was presented with a description of each repair and a request for an estimate. This company had an estimator make a site visit to each home to inspect it and then provided a formal estimate. The cost of repair from this company ranged from $\$ 365$ to $\$ 642$. One of the six homes from Phase 2 was repaired by another contractor for $\$ 800$, and one other home with a very small repair area was repaired by research staff using batt insulation.

Summaries of repair costs are provided in Table 3 and Table 4. Table 3 shows the actual cost to the research project along with the area repaired, time in total person-hours, and the repair material used. The work rate is also shown as square feet repaired per person-hour worked. The repair material is shown in each table as LDF or kraft paper-faced batt (batt). The first six houses were completed in Phase 1 by the same contractor. The last six houses were completed in Phase 2 (four by the same Jacksonville company, one by another contractor, and one by research staff). The average project cost of 12 homes was $\$ 573$ per home, which is within the estimated range reported in the Phase 1 report; however, it is believed that these costs could be much lower if materials other than foam are considered. 
Table 3. Wind Washing Repair Areas, Labor Time, and Research Project Costs

\begin{tabular}{|c|c|c|c|c|c|c}
\hline House & $\begin{array}{c}\text { Repair } \\
\left(\mathbf{f t}^{2}\right)\end{array}$ & $\begin{array}{c}\text { Time } \\
(\mathbf{h})\end{array}$ & $\begin{array}{c}\text { Research } \\
\text { Cost } \mathbf{( \$ )}\end{array}$ & $\begin{array}{c}\text { Cost } \\
\left(\mathbf{\$} / \mathbf{f t}^{\mathbf{2}}\right)\end{array}$ & $\begin{array}{c}\text { Coverage } \\
\left(\mathbf{f t}^{\mathbf{2}} / \mathbf{h}\right)\end{array}$ & $\begin{array}{c}\text { Repair } \\
\text { Material }\end{array}$ \\
\hline H10H & 113 & 2.25 & 650 & 5.75 & 50.2 & LDF \\
\hline H7G & 510 & 4.6 & 650 & 1.27 & 110.9 & LDF \\
\hline H14Y & 209 & 4 & 650 & 3.11 & 52.3 & LDF \\
\hline H8Hd & 108 & 10 & 650 & 6.02 & 10.8 & LDF \\
\hline H16B & 103 & 3.75 & 650 & 6.31 & 27.5 & LDF \\
\hline H11C & 48 & 3.1 & 650 & 13.54 & 15.5 & LDF \\
\hline H23K & 148 & 6.75 & 800 & 5.41 & 21.9 & LDF \\
\hline H36S & 442 & 6.75 & 483 & 1.09 & 65.5 & Batt \\
\hline H37M & 81 & 1.5 & 365 & 4.51 & 54.0 & LDF \\
\hline H39L & 53 & 2.5 & 50 & 0.95 & 21.0 & Batt \\
\hline H45H & 143 & 5.5 & 634 & 4.43 & 26.0 & LDF \\
\hline H47W & 73 & 3 & 642 & 8.79 & 24.3 & LDF \\
\hline Average & 169 & 4.48 & 573 & 5.10 & 40.0 & \\
\hline
\end{tabular}

Table 4. Estimated Cost of Wind Washing Repairs Using Project and National Cost Data

\begin{tabular}{|c|c|c|c|c|c|c|c|c|c|}
\hline House & $\begin{array}{c}\text { Repair } \\
\text { Area } \\
\left(\mathrm{ft}^{2}\right)\end{array}$ & $\begin{array}{c}\text { Foam } \\
\text { Time } \\
\text { (h) }\end{array}$ & $\begin{array}{c}\text { Batt } \\
\text { Time } \\
\text { (h) }\end{array}$ & $\begin{array}{c}\text { Foam } \\
\text { Cost } \\
(\$)\end{array}$ & $\begin{array}{c}\text { Batt } \\
\text { Cost } \\
(\$)\end{array}$ & $\begin{array}{c}\text { Lowest } \\
\text { Potential } \\
\text { Cost }(\$)\end{array}$ & $\begin{array}{c}\text { Lowest } \\
\text { Cost } \\
\text { Material }\end{array}$ & $\begin{array}{c}\text { Lowest } \\
\text { Cost } \\
\left(\$ / \mathbf{f t}^{2}\right)\end{array}$ & $\begin{array}{c}\text { Lowest } \\
\text { Cost Cover } \\
\text { Rate }\left(\mathrm{ft}^{2} / \mathrm{h}\right)\end{array}$ \\
\hline H10H & 113 & 2.25 & 2.75 & 373 & 177 & 177 & Batt & 1.57 & 41.1 \\
\hline H7G & 510 & 4.6 & 14.00 & 1275 & 806 & 806 & Batt & 1.58 & 36.4 \\
\hline H14Y & 209 & 4 & & 683 & & 683 & LDF & 3.27 & 52.3 \\
\hline H8Hd & 108 & 10 & & 671 & & 671 & LDF & 6.21 & 10.8 \\
\hline H16B & 103 & 3.75 & 2.50 & 408 & 161 & 161 & Batt & 1.57 & 41.2 \\
\hline H11C & 48 & 3.1 & & 244 & & 244 & LDF & 5.09 & 15.5 \\
\hline H23K & 148 & 6.75 & 3.50 & 640 & 228 & 228 & Batt & 1.54 & 42.3 \\
\hline H36S & 442 & 5.75 & 6.75 & 1105 & 534 & 534 & Batt & 1.21 & 65.5 \\
\hline H37M & 81 & 1.5 & 3.25 & 263 & 178 & 178 & Batt & 2.20 & 24.9 \\
\hline H39L & 53 & & 2.50 & & 131 & 131 & Batt & 2.50 & 21.0 \\
\hline H45H & 143 & 5.5 & 3.50 & 578 & 225 & 225 & Batt & 1.58 & 40.9 \\
\hline H47W & 73 & 3 & 1.75 & 303 & 114 & 114 & Batt & 1.56 & 41.7 \\
\hline Average & 169 & 4.48 & 4.50 & 595 & 284 & 346 & & 2.49 & 36.13 \\
\hline
\end{tabular}

It is not known how representative the project costs may be for a mature wind washing retrofit program carried out in different regions, because only three contractors were used. In the authors' experience of observing repairs, it seems reasonable to believe that the costs could be significantly lower for companies familiar with this specific type of repair. Table 4 shows an estimated wind washing program cost based upon national cost estimates (RS Means Online 2014; ABT 2014) and research project data. This has been done in an attempt to evaluate the lowest likely cost option for each home. A cost analysis was completed by first estimating an average cost to complete the repair using LDF and then again for repair by kraft-faced batt insulation. There are blanks in Table 4 for a specific repair if it would not be considered likely or feasible. There is no estimate for foam repair for House H39L because the area to be repaired is so small that either a foam contractor would not consider doing this or the cost would not be 
reasonable. Batt cost estimates are missing primarily where access is too restrictive or application too difficult to facilitate effective repair.

The foam cost shown in Table 4 was figured at $\$ 2.50 / \mathrm{ft}^{2}$ for jobs involving at least $300 \mathrm{ft}^{2}$. Otherwise, it was $\$ 40.05 / \mathrm{h}+\$ 2.50 / \mathrm{ft}^{2}$ of repair area if it was smaller than $300 \mathrm{ft}^{2}$. The repair cost using faced batts was estimated using $\$ 40.05 / \mathrm{h}+\$ 0.596 / \mathrm{ft}^{2}$ (insulation + air sealant). From Table 4, the lowest cost indicated by the estimates occurs from using the batt insulation with some caulk or can foam sealant $75 \%$ of the time. Foam repair is indicated as the most feasible or lowest cost method $25 \%$ of the time. The average lowest cost of repair is $\$ 2.49 / \mathrm{ft}^{2}$ with a range of $\$ 1.21-\$ 6.21 / \mathrm{ft}^{2}$. Considering batt insulation for more of the repairs has dropped the estimated cost in half with less variability in range compared to the research project costs. The estimated batt repair method averages $\$ 1.70 / \mathrm{ft}^{2}$ with a range of $\$ 1.21-\$ 2.50 / \mathrm{ft}^{2}$. The estimated foam costs are less predictable because this method is more likely to be used when access is tighter or when additional work may be required in gaining access to repair areas. Estimated foam costs average $\$ 3.87 / \mathrm{ft}^{2}$ with a range of $\$ 2.50-\$ 6.21 / \mathrm{ft}^{2}$.

Generally, the foam sealed method is expected to require fewer hours, except for cases where extra effort is required to protect the home. The greater variability in foam cost is also related to whether additional work is required to protect the home from soiling or overspray, as well as whether additional effort is needed to access repair areas. Indoor furnishings need to be protected when spray lines must be run through the home, as shown in Figure 35. In some cases, the outdoor walls and windows may need to be protected from overspray if work occurs within nearby outdoor soffit areas, as shown in Figure 36. Extra preparations can easily add 1-2 personhours. Labor can thus vary significantly for different repair methods.

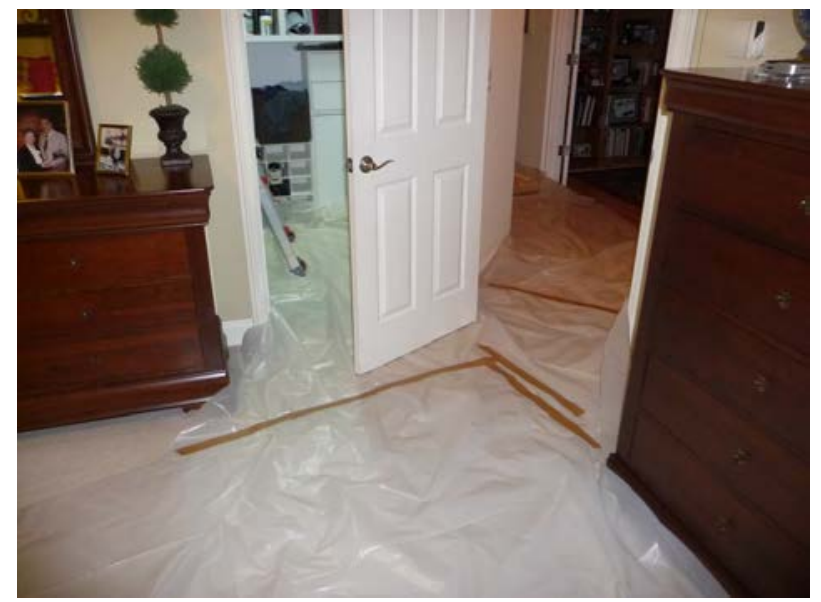

Figure 35. About $30 \mathrm{ft}$ of plastic drop sheet was placed down to protect floor in House $\mathrm{H} 45 \mathrm{H}$ from spray foam line prior to being run through the home and up through the attic access port in the closet. 


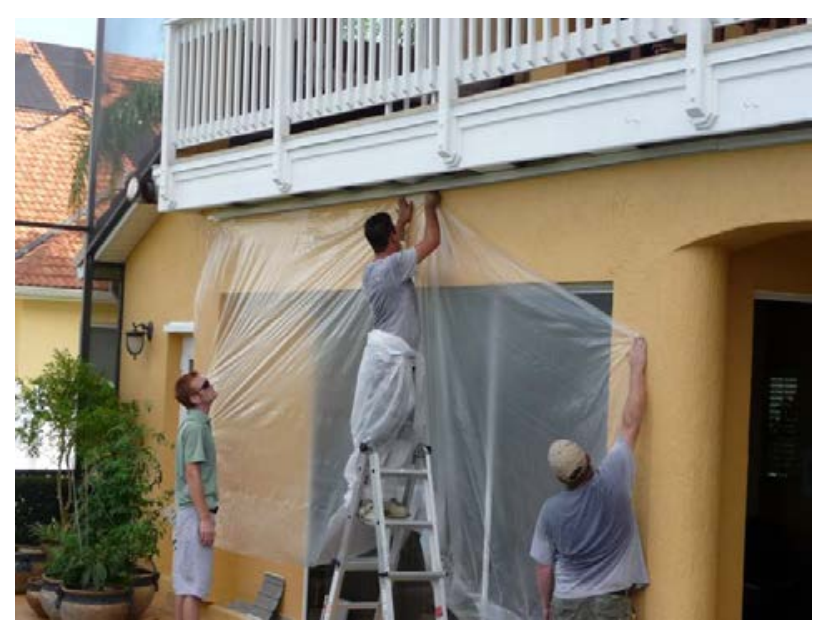

Figure 36. Exterior wall and window area was protected from potential overspray of foam applied within the soffit area above

Unlike spaces with easy access, homes with open floor construction into very small attic or soffit areas take much more time. Working in these tight spaces can also limit the options of material used. For example, a very small attic area at a great distance from attic access would make working with rigid board stock very time consuming and difficult. While the rigid board stock might be inexpensive, the labor would be very expensive and require considerable skill and agility.

Based on estimates made in Table 4, the average wind washing program repair cost could be about $\$ 350$ per house; however, many homes with an open floor cavity easily accessed through a garage attic could cost about half this. Homes with garage attic spaces next to second-story floor spaces (the most common location) generally have easy access and often require less than $40 \mathrm{ft}^{2}$ of material to seal and insulate the floor cavity from the attic. If the knee wall is also insulated, the total area typically increases to $70-100 \mathrm{ft}^{2}$. Repair cost of an easy-to-access floor cavity and knee wall area of about $100 \mathrm{ft}^{2}$ and 2.8 person-hours could likely cost as little as $\$ 173$ and even less at about $\$ 85$ if only the floor cavity is sealed with faced batt and sealant.

Fifty-four percent of homes in the combined Phase 1 and 2 study (30 of 56) had at least some small part of the floor cavity open to a garage or other attic space with no other complementary pathway to another attic area. Of this group, 25\% (14 of 56) had an open area of $5 \mathrm{ft}^{2}$ or smaller with the nature of the opening typically about 15-20 ft long and only a few inches high. Openings only a few inches high could be simply repaired for as little as $\$ 20-\$ 40$ (often by capable do-it-yourself homeowners) using materials such as caulking, canned foam, and faced batt insulation.

Phase 2 energy and demand analysis is presented in Section 8 of this report. Based on the average annual wind washing repair energy savings of $\$ 121$ per house and the average estimated cost of repair of $\$ 350$ per house from Phases 1 and 2, the average simple payback period would be about 2.9 years. 


\section{Measured Energy Impacts of Wind Washing Retrofits}

Six homes were selected to monitor the energy impacts of wind washing retrofits in Phase 2. This section provides a summary of the seasonal cooling and heating energy as well as cooling and heating peak energy impacts of these homes. Details about general house characteristics and how the repair was made in each home are provided in the Appendix.

Occupants of study homes were asked to not make any changes to the home that would impact energy use during the study period. They were also asked to keep a log of events that would likely impact space conditioning energy use. Noteworthy items may be a significant change in occupancy (vacation or guests stay over), a change in thermostat setting habit, and heating or cooling service work. Unusual event periods were noted during the analysis and periods of data were not used if deemed inappropriate.

\subsection{Seasonal Cooling Impacts}

Seasonal cooling was evaluated based on a least-squares best-fit regression analysis of daily total space cooling energy versus the daily average dT between outdoors and indoors. Polynomial best-fit was used where P-values indicated significance at 95\% confidence in using them; otherwise, linear best-fit least-squares regression was used.

Figures $37-42$ show the measured daily cooling data before and after repairs for six homes.

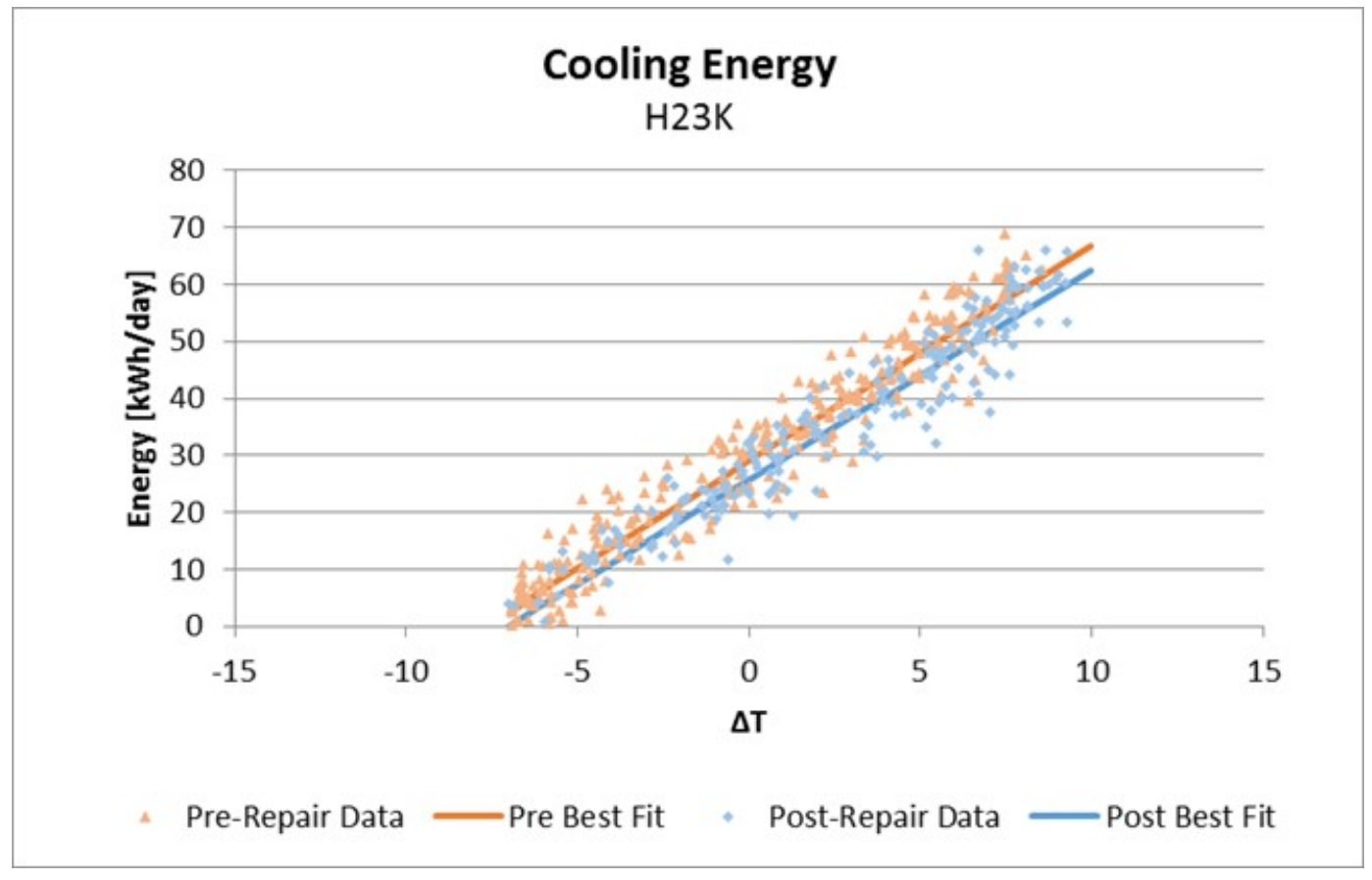

Figure 37. Daily cooling energy and daily average dT between outside and inside for House H23K 


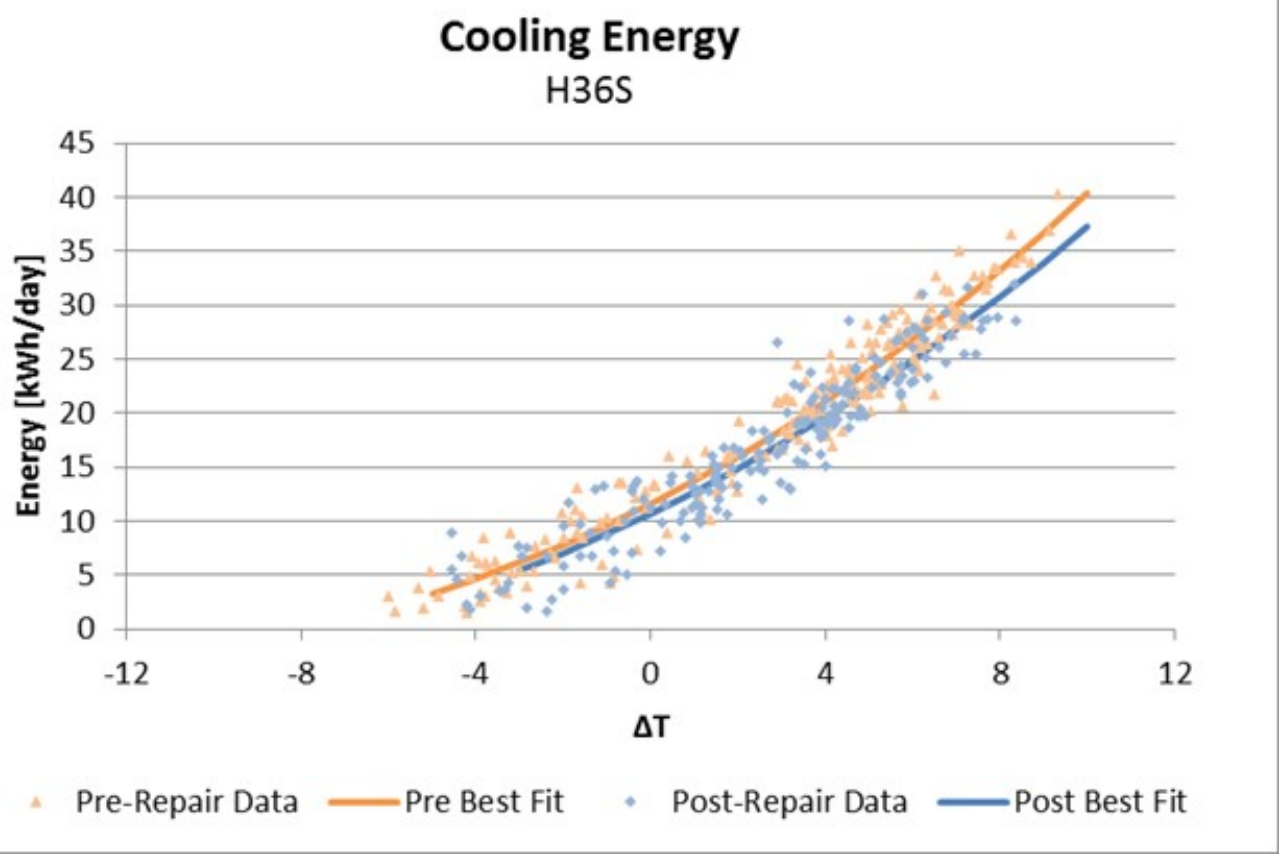

Figure 38. Daily cooling energy and daily average dT between outside and inside for House H36S

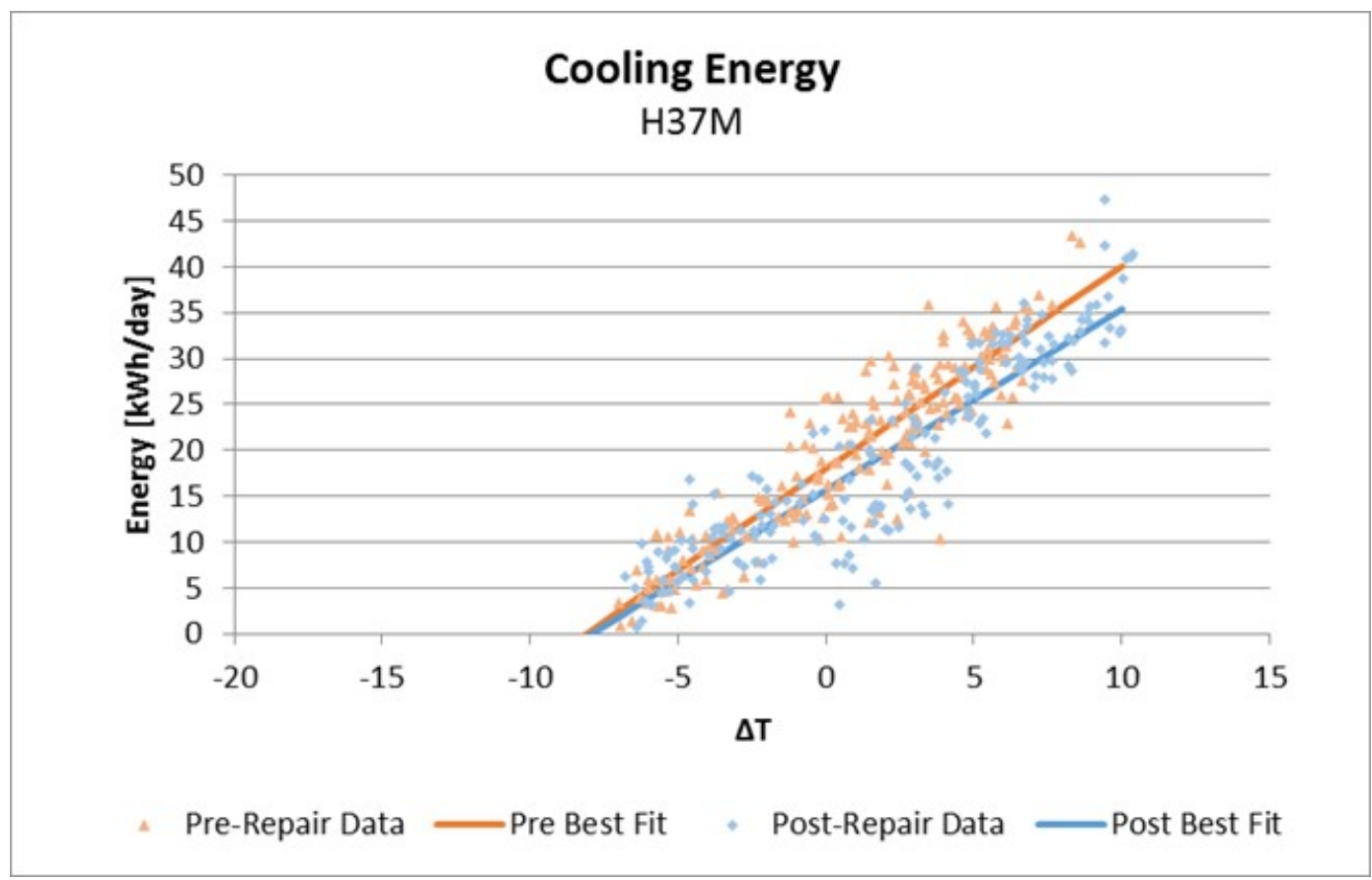

Figure 39. Daily cooling energy and daily average dT between outside and inside for House H37M 


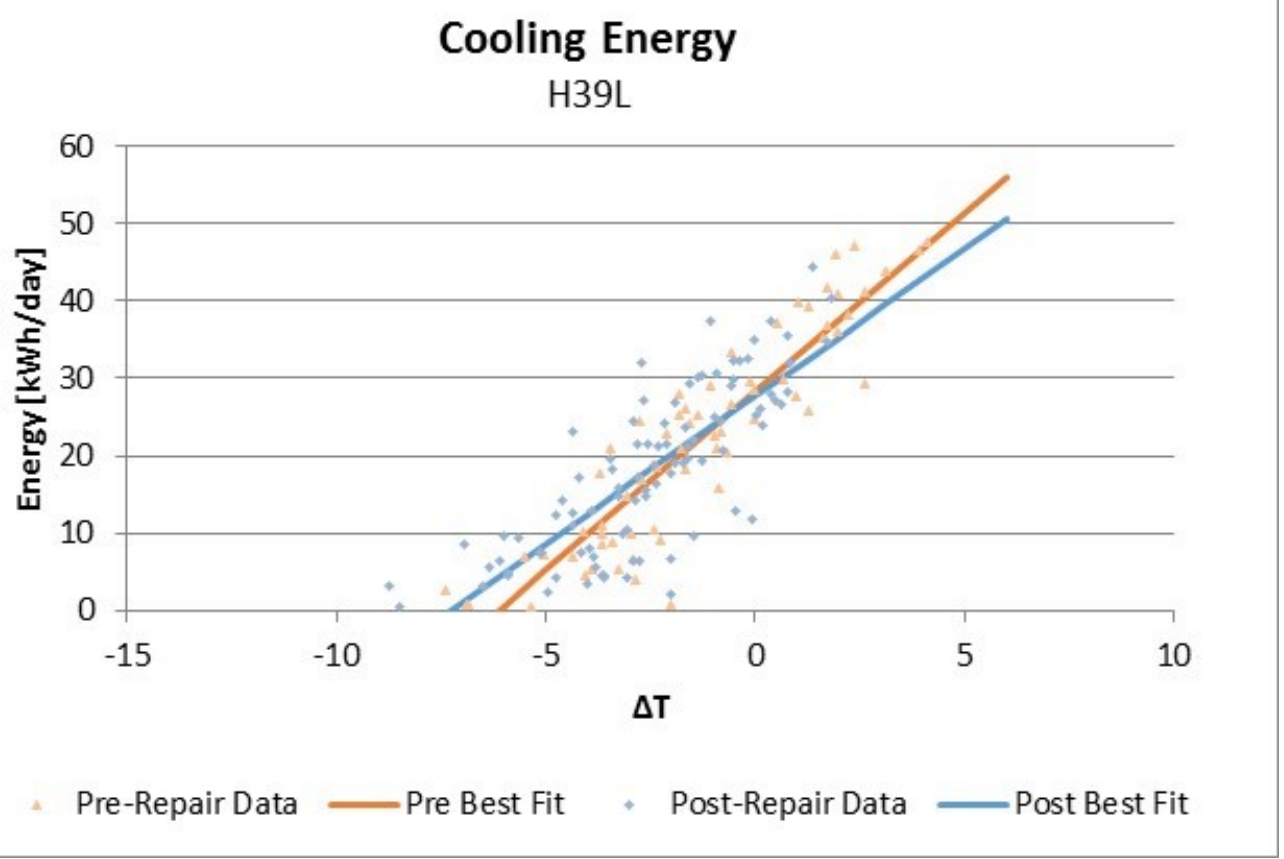

Figure 40. Daily cooling energy and daily average dT between outside and inside for House H39L

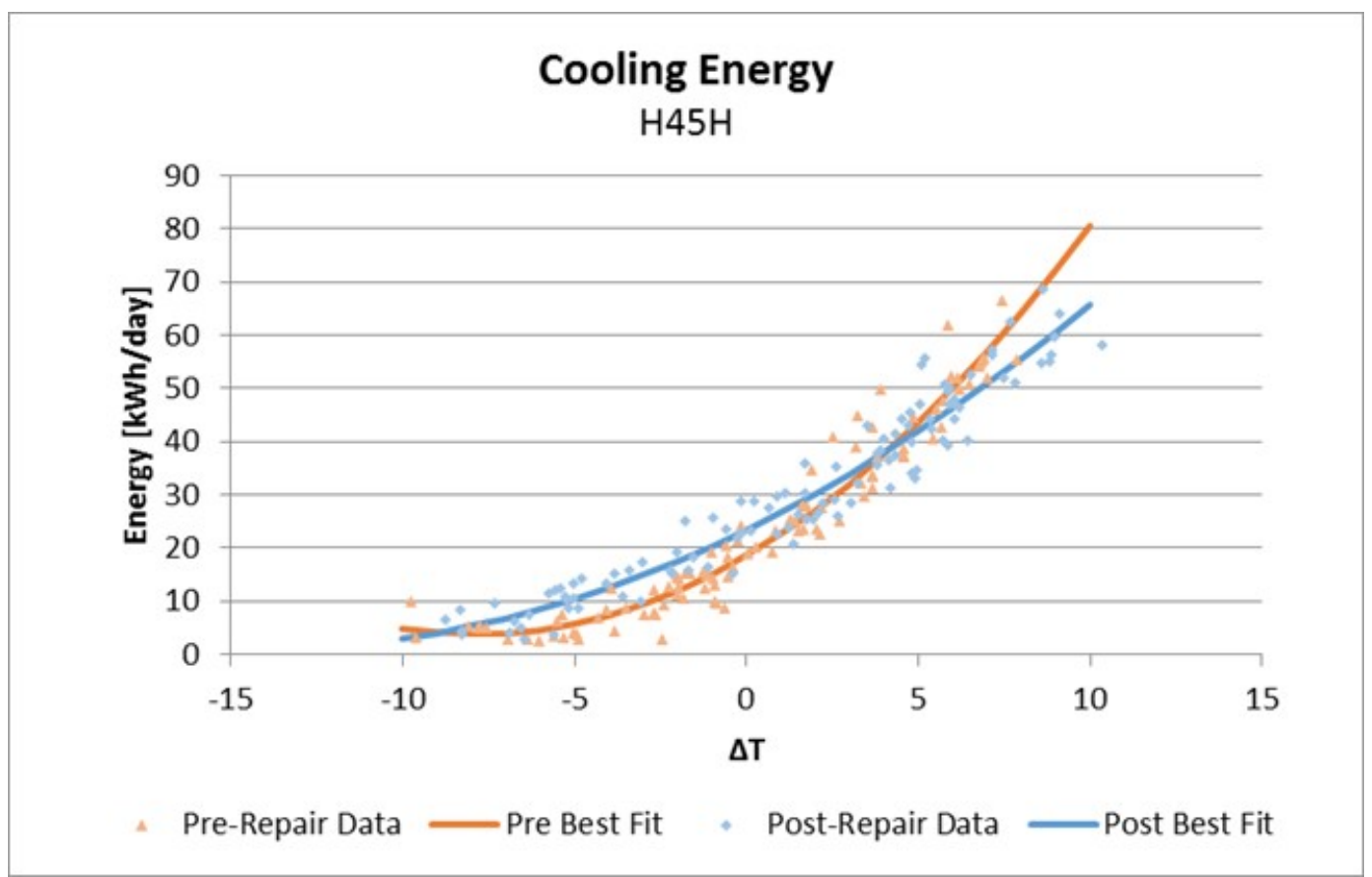

Figure 41. Daily cooling energy and daily average dT between outside and inside for House H45H 


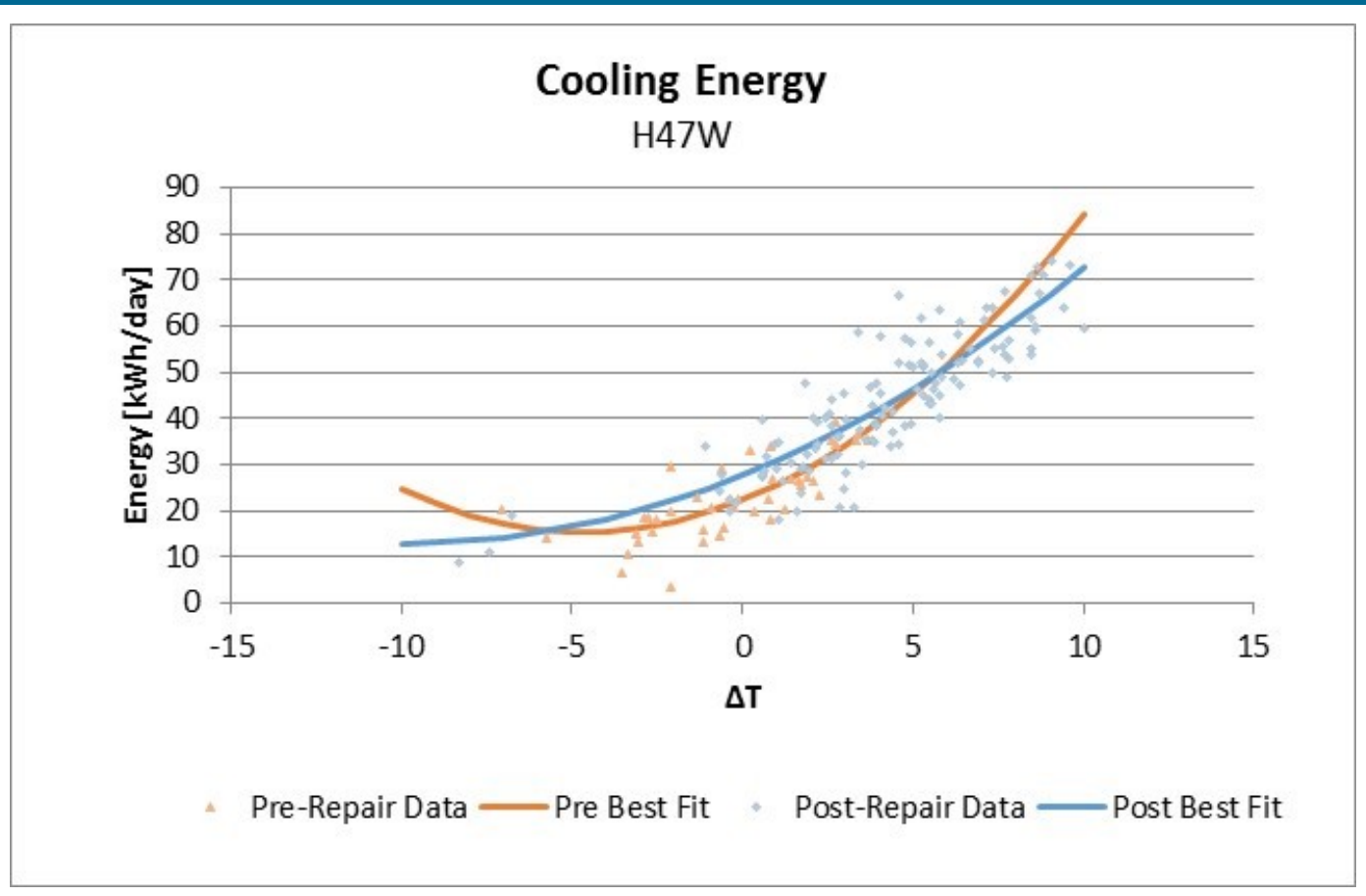

Figure 42. Daily cooling energy and daily average dT between outside and inside for House H47W

Figure 43 shows a composite plot of outdoor, attic, and floor cavity temperatures $\left({ }^{\circ} \mathrm{F}\right)$ for all summer days from June 1 to August 27, 2013 for House H36S. This is during the pre-repair period. Red is the attic space temperature, green is the attic roof deck temperature between plywood and deck insulation, blue is inside the floor cavity, and pink is the outdoors. These data show that the peak temperatures in the lower attic area near the floor cavity averaged only about $83^{\circ} \mathrm{F}\left(5^{\circ} \mathrm{F}\right.$ cooler than the peak outdoor temperature) even though the roof deck temperature peaked at $127^{\circ} \mathrm{F}$. The post-repair profile is very similar to the pre-repair profile. The floor cavity temperature has a fairly flat profile and had a peak of only about $78^{\circ} \mathrm{F}$, which does not suggest a large wind washing influence on average. 


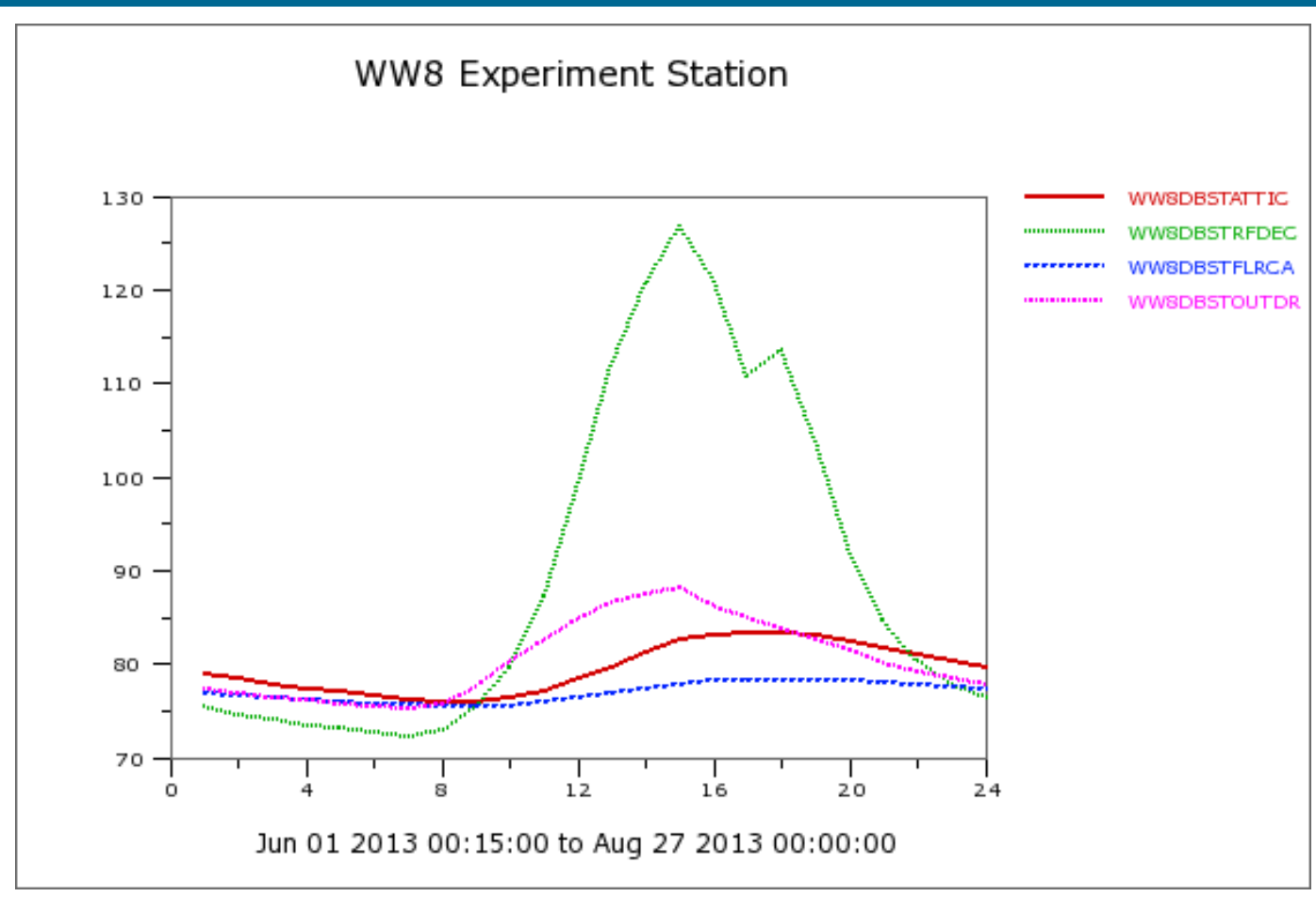

Figure 43. Pre-repair composite of attic and outdoor temperatures for House H36S

The annual cooling savings from wind washing repairs was calculated using the best-fit equations from daily cooling versus dT (daily average outdoor temperature - indoor temperature). Typical Meteorological Year 3 (TMY3) data were used to represent weather conditions for a typical year. TMY3 data were chosen for four Florida cities weighted by service distribution within the Florida Power \& Light Company service area. The cities used were Daytona, West Palm Beach, Miami, and Fort Myers. The dT was calculated by subtracting the average indoor cooling temperature of $76.5^{\circ} \mathrm{F}$ from the daily average outdoor temperature. The average indoor cooling temperature is based on the average of the first and second floors of the houses in the study. After the dT was calculated for each day of the year for each of the four cities, the best-fit equations were used to calculate the daily cooling before and after repair.

Calculated negative cooling values were set to zero and no cooling was permitted to be calculated beyond $\mathrm{dT} \leq 18^{\circ} \mathrm{F}$. Some homes with higher internal generated heat sources will have cooling loads on relatively cool days and can use a small amount of cooling even on a day when it is $68^{\circ} \mathrm{F}$ outside. After the cooling energy was calculated for each day of the year, the total cooling was summed for the year before and after the repair. The annual cooling savings was calculated as the difference between the calculated annual energy before repair and after repair.

Table 5 shows the predicted annual cooling energy kilowatt-hours before and after repairs along with the annual savings. The savings of the Phase 2 study homes range from $0.5 \%$ to $11.0 \%$ with an average of $7.1 \%$. 
Table 5. Average Annual Cooling Energy Before and After Repairs With Savings From Six Phase 2 Homes

\begin{tabular}{c|c|c|c|c}
\hline House ID & $\begin{array}{c}\text { Pre-Repair } \\
\mathbf{k W h}\end{array}$ & $\begin{array}{c}\text { Post-Repair } \\
\mathbf{k W h}\end{array}$ & $\begin{array}{c}\text { Savings } \\
\mathbf{k W h}\end{array}$ & $\begin{array}{c}\text { Savings } \\
\mathbf{\%}\end{array}$ \\
\hline H23K & 10087 & 9195 & 893 & $8.8 \%$ \\
H36S & 4622 & 4268 & 354 & $7.7 \%$ \\
H37M & 6126 & 5455 & 671 & $11.0 \%$ \\
\hline H39L & 10132 & 9556 & 576 & $5.7 \%$ \\
H45H & 8843 & 8802 & 41 & $0.5 \%$ \\
\hline H47W & 11555 & 10466 & 1089 & $9.4 \%$ \\
\hline Average & 8561 & 7957 & 604 & $7.1 \%$ \\
\hline
\end{tabular}

\subsection{Seasonal Heating Impacts}

Seasonal heating was evaluated with the same method as used for seasonal cooling, based on a least-squares best-fit regression analysis of heating energy versus the dT.

Figures 44-48 show the daily heating data before and after repairs for five homes. House H47W had insufficient post-heating data to support a heating savings evaluation.

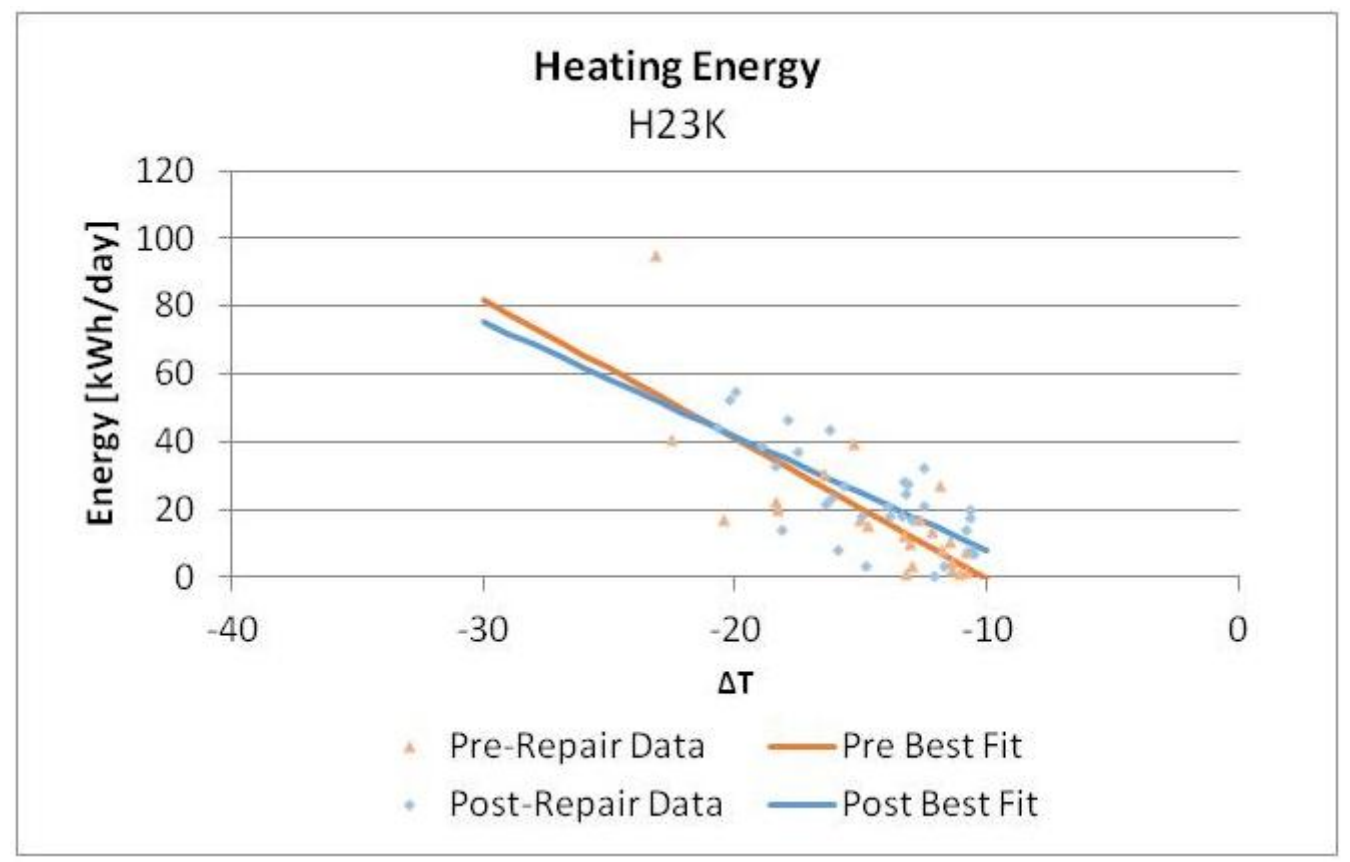

Figure 44. Daily heating energy and daily average dT between outside and inside for House H23K 


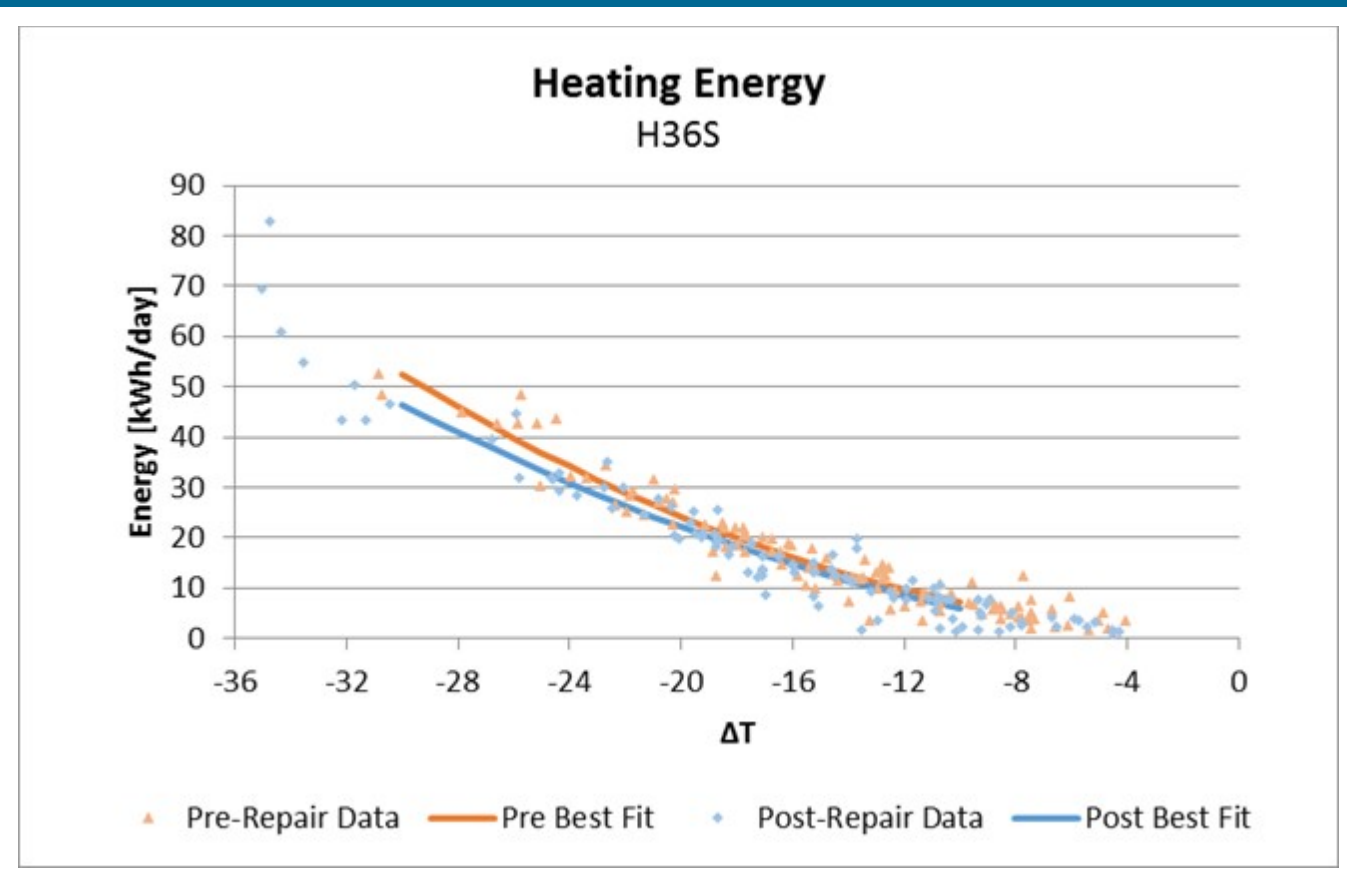

Figure 45. Daily heating energy and daily average dT between outside and inside for House H36S

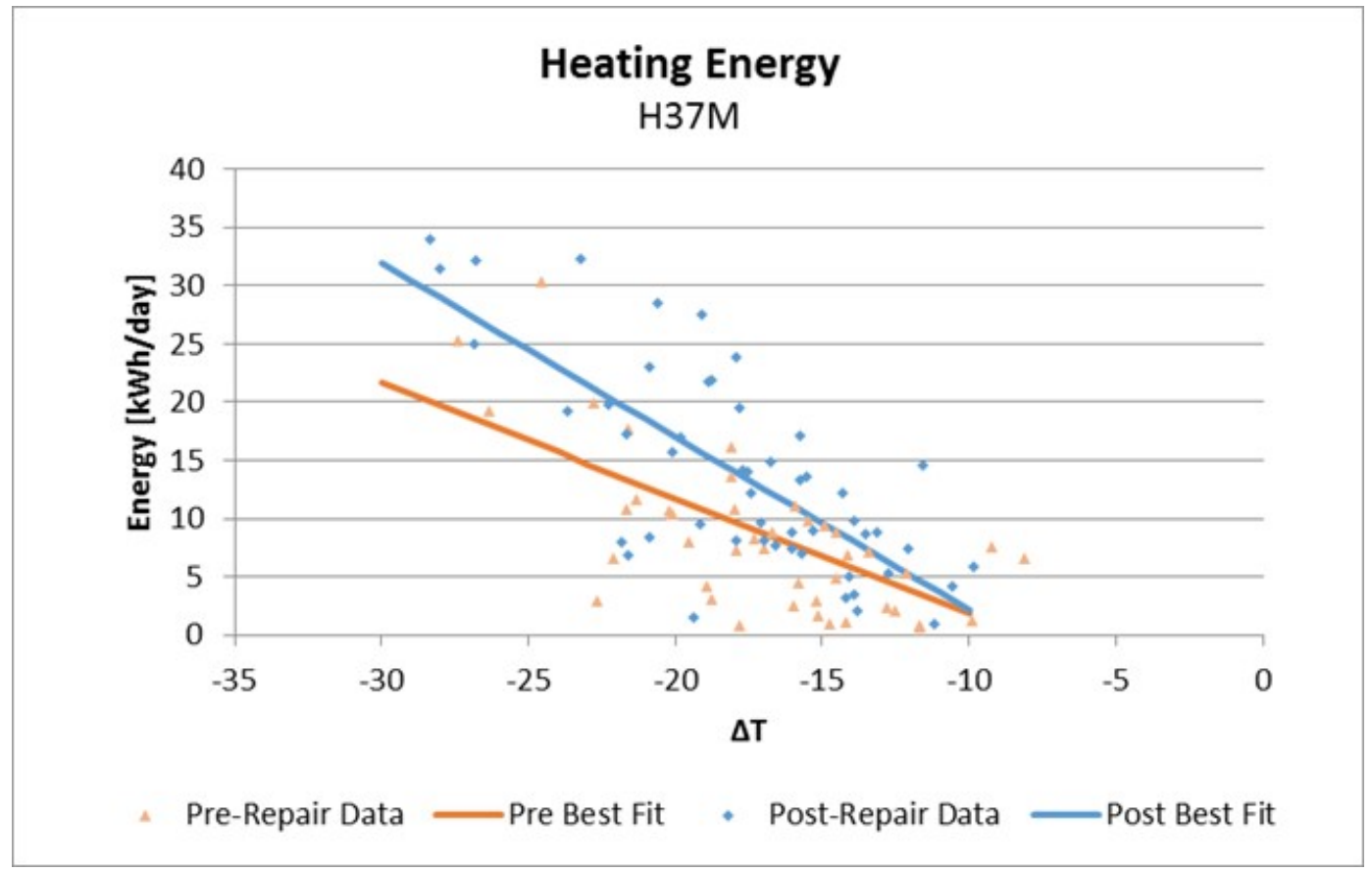

Figure 46. Daily heating energy and daily average dT between outside and inside for House H37M; the post-repair period was period higher because of equipment problem 


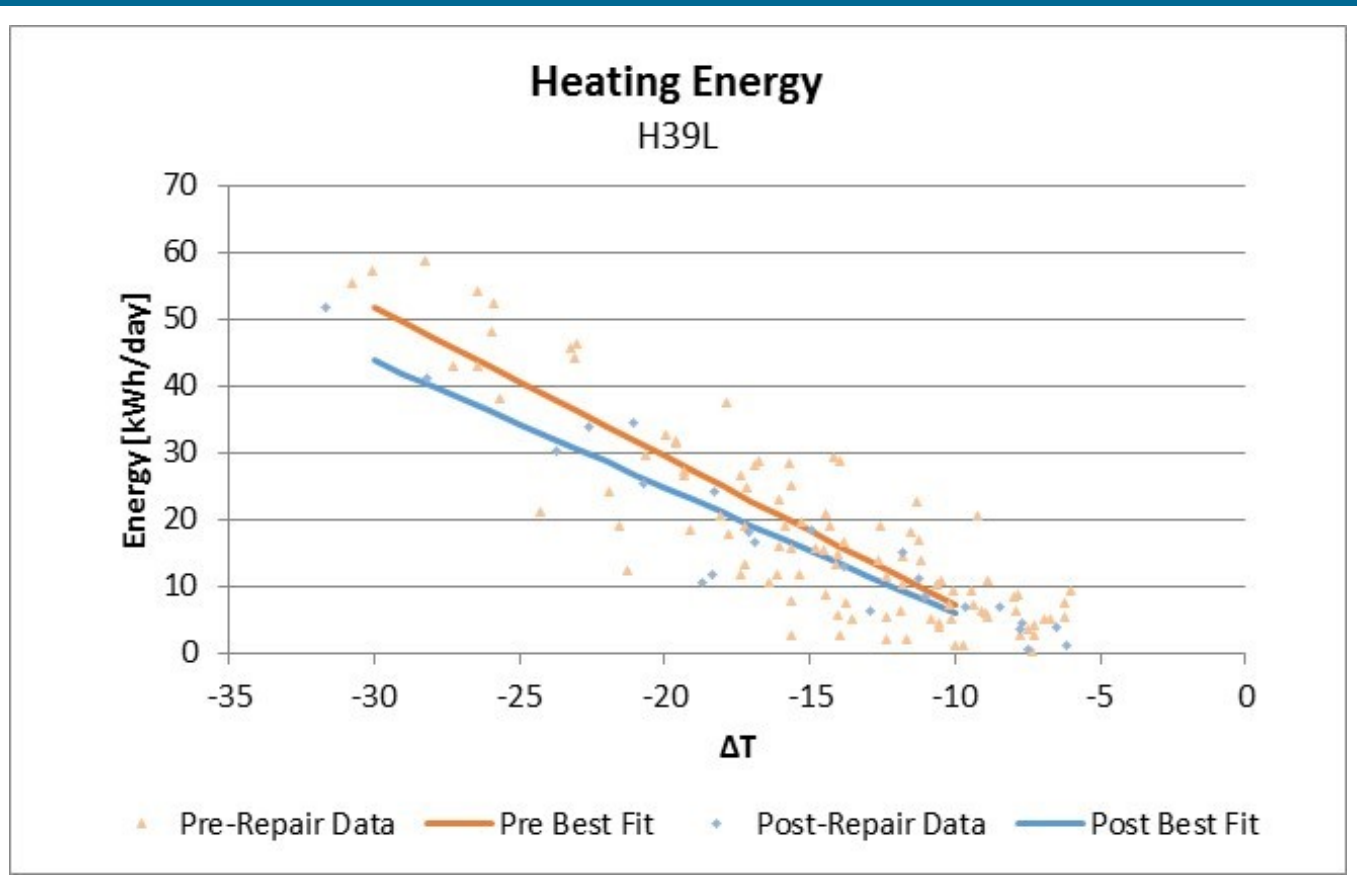

Figure 47. Daily heating energy and daily average dT between outside and inside for House H39L

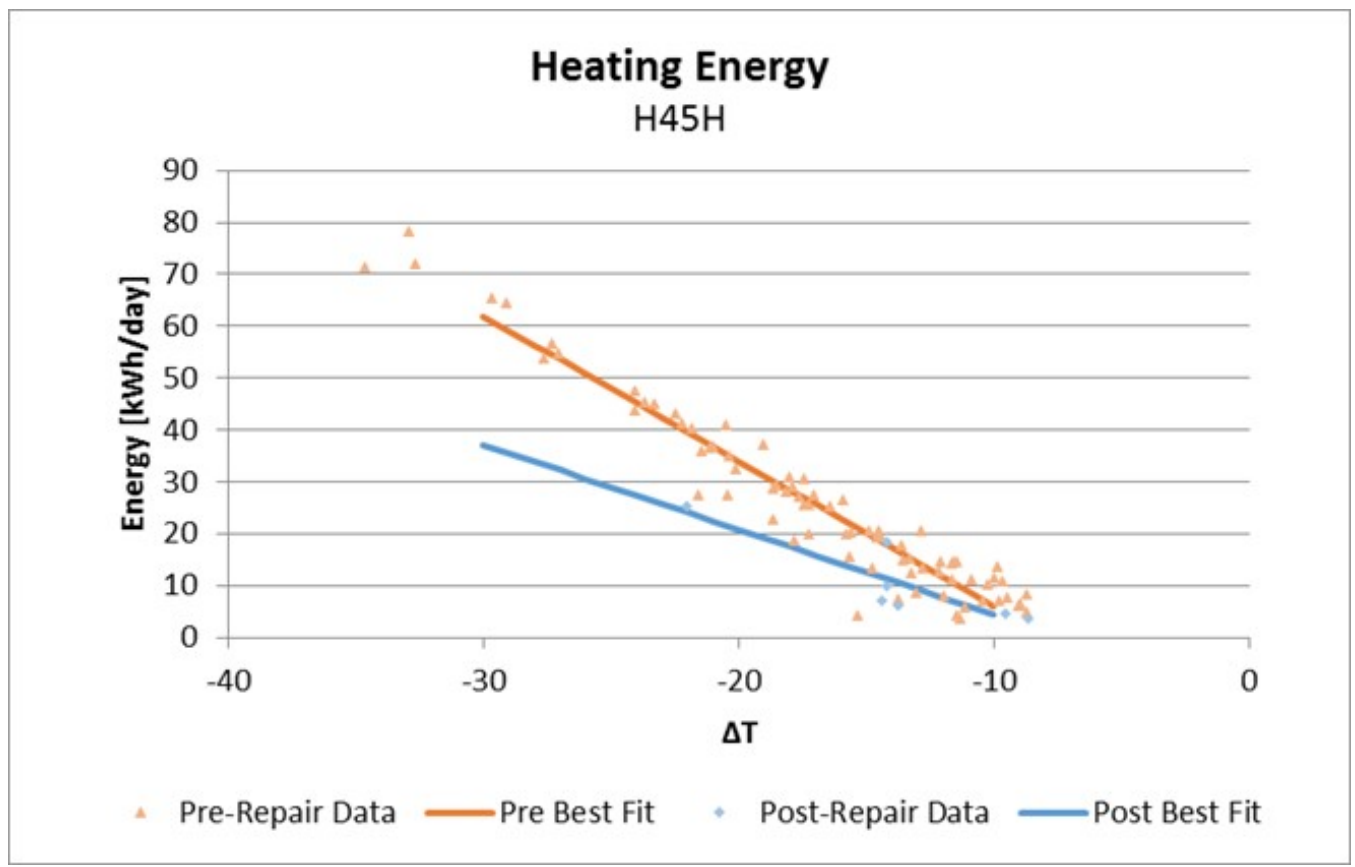

Figure 48. Daily heating energy and daily average dT between outside and inside for House $\mathrm{H} 45 \mathrm{H}$

The annual heating savings from wind washing repairs was calculated using the best-fit equations from daily heating versus dT (daily average outdoor temperature - indoor temperature). TMY3 data were used to represent weather conditions for a typical year. TMY3 data were chosen for four Florida cities within the Florida Power \& Light Company service area. The cities used were Daytona, West Palm Beach, Miami, and Fort Myers. The dT was calculated by subtracting the average indoor heating temperature of $71.5^{\circ} \mathrm{F}$ from the daily average outdoor temperature. The average indoor heating temperature was based on the average of the first and 
second floors of the houses in the study. After dT was calculated for each day of the year for each of the four cities, the best-fit equations were used to calculate the daily heating before and after repairs. The daily calculated heating values were reviewed to ensure that negative heating was not permitted and that cooling and heating were not calculated for the same day of the year.

Table 6 shows the predicted annual heating energy kilowatt-hours before and after repairs along with the annual savings. The savings are shown for only four of the six homes and range from $10.1 \%$ to $38.7 \%$ with an average of $24.8 \%$. House $\mathrm{H} 47 \mathrm{~W}$ had inadequate heating weather data to evaluate heating savings. The large negative savings at house H37M appears to be related to a drop in the heating output that developed sometime during the post-repair heating period. Service work was required as reported by the homeowner, but he could not recall the exact nature of the repair. Monitoring data also indicate a drop in the heating performance. The average dT between the return and supply air dropped about $2.3^{\circ} \mathrm{F}$ in the postheating period compared to the preheating period. A lower supply air temperature indicates less heating was delivered and resulted in a longer runtime to meet load. If this house is left out of the average, the average heating savings is about $6.1 \mathrm{kWh} /$ day $(16.1 \%)$.

Table 6. Average Annual Heating Energy Before and After Repairs With Savings From Four Phase 2 Homes

\begin{tabular}{|c|c|c|c|c|}
\hline House ID & $\begin{array}{c}\text { Pre-Repair } \\
\mathbf{k W h}\end{array}$ & $\begin{array}{c}\text { Post-Repair } \\
\mathbf{k W h}\end{array}$ & $\begin{array}{c}\text { Savings } \\
\mathbf{k W h}\end{array}$ & $\begin{array}{c}\text { Savings } \\
\mathbf{\%}\end{array}$ \\
\hline H23K & 801 & 581 & 220 & $27.5 \%$ \\
\hline H36S & 341 & 306 & 35 & $10.1 \%$ \\
\hline H37M & 157 & $\mathrm{NA}^{*}$ & $\mathrm{NA}$ & $\mathrm{NA}$ \\
\hline H39L & 405 & 341 & 64 & $15.9 \%$ \\
\hline H45H & 462 & 283 & 179 & $38.7 \%$ \\
\hline H47W & 859 & $\mathrm{NA}$ & $\mathrm{NA}$ & $\mathrm{NA}$ \\
\hline Average 4 Homes & 502 & 378 & 125 & $24.8 \%$ \\
\hline
\end{tabular}

* Post-repair energy was higher because a refrigerant leak developed during postheating repair period.

\subsection{Peak Cooling Impacts}

Peak cooling analysis was completed to identify peak cooling demand that occurred before and after the wind washing repairs. Several days from each period were chosen for having as similar outdoor conditions as possible. The days were also chosen to be as hot as possible. A composite of cooling energy use over a 24-hour day was developed from the pre-repair and also a second composite day for the post-repair days. Then, the energy use during the utility peak period between 4 p.m. and 5 p.m. was compared to determine the peak energy impact. Examples of profiles of total cooling energy per hour at each hour of the composite day are shown in Figures 49-51. The analysis is sensitive to changes in occupant behavior and weather conditions and required substantial review of days used. Even with careful review, variability still occurred and some of the before and after profiles do not follow similar patterns such as in Figure 50. Occupants were requested to maintain similar thermostat set points throughout the monitoring periods, but adjustments to thermostats seemed apparent based on interior temperatures. Most homes have two central heating/cooling systems. The energy plots show the combined energy of both systems. Two systems will have different cycle times that add to the variability in this measurement. This means that having several similar days is important to help smooth out the variability in the profile and peak. 


\section{Composite Cooling Energy \\ $\mathrm{H} 23 \mathrm{~K}$}

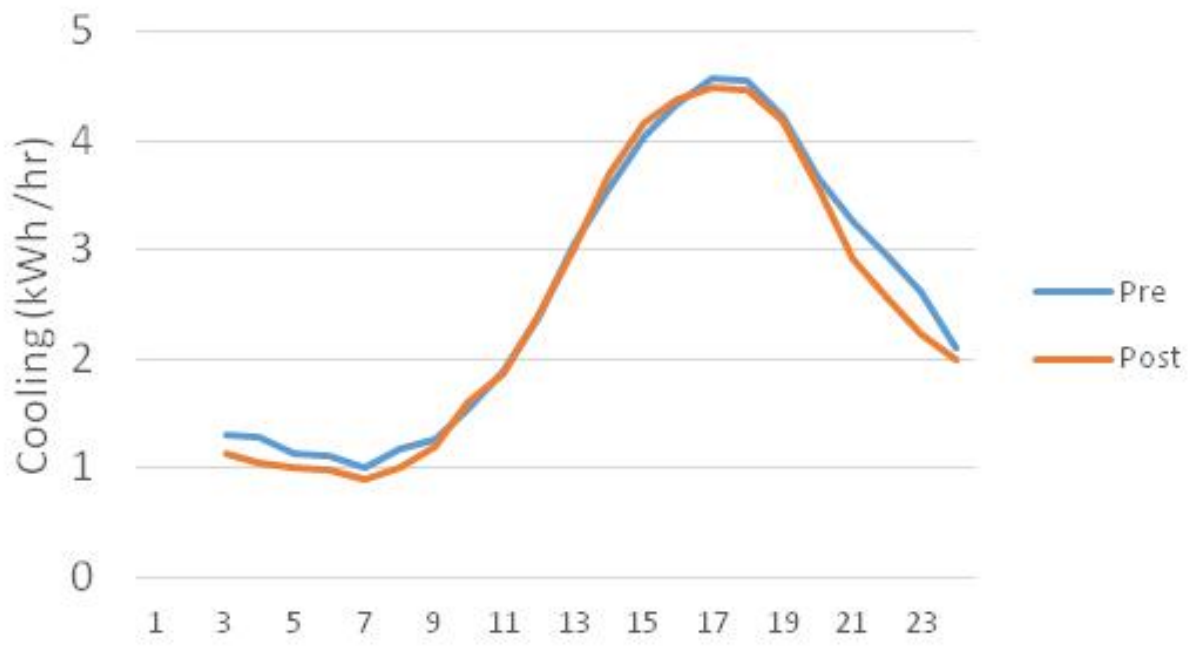

Figure 49. Cooling energy before and after repair of House H23K with hour of day shown on the X-axis

\section{Composite Cooling Energy}

$$
\text { H37M }
$$

$$
3.0
$$

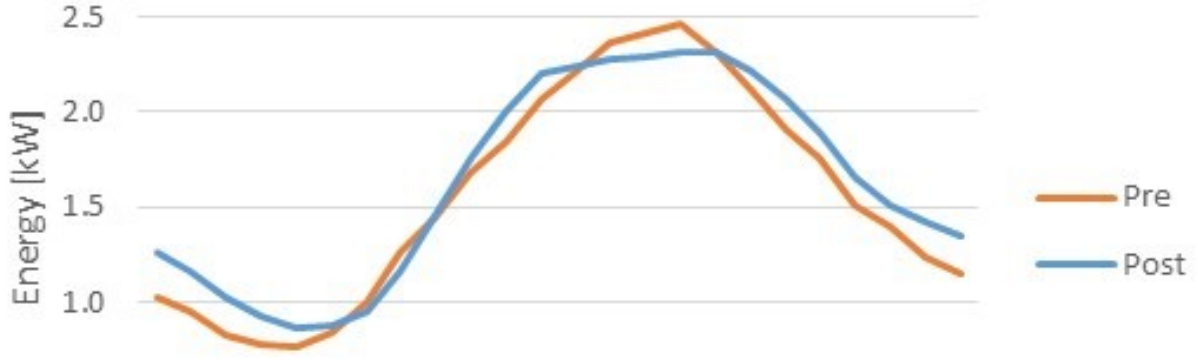

0.5

0.0

$$
\begin{array}{llllllllllll}
1 & 3 & 5 & 7 & 9 & 11 & 13 & 15 & 17 & 19 & 21 & 23
\end{array}
$$

Figure 50. Cooling energy before and after repair of house H37M with hour of day shown on the $x$-axis 


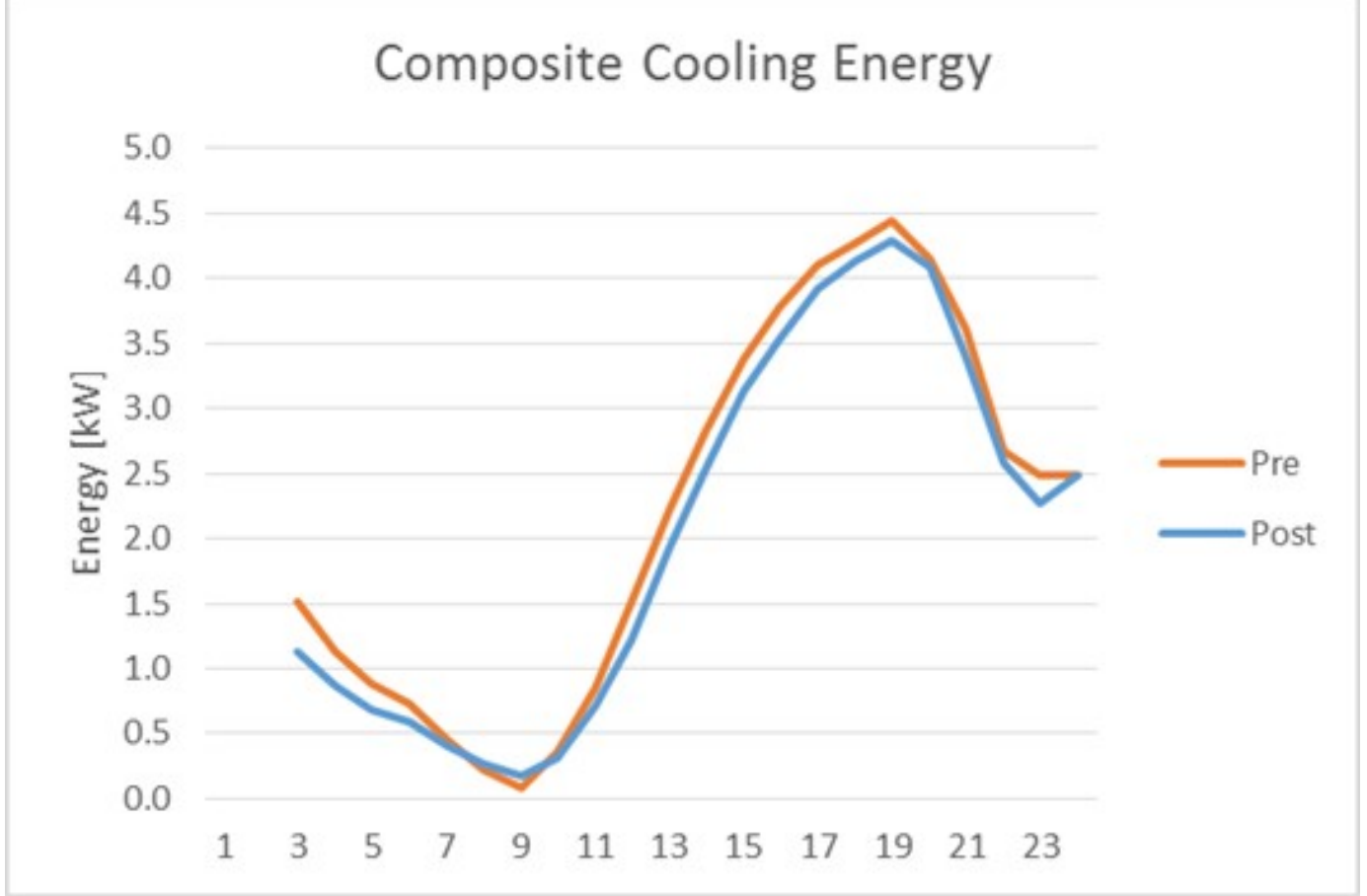

Figure 51. Cooling energy before and after repair of house $\mathrm{H} 45 \mathrm{H}$ with hour of day shown on the $\mathrm{x}$-axis

Table 7 shows the peak cooling $\mathrm{kW}$ savings resulting from wind wash repairs in the six Phase 2 homes. The average peak cooling savings is $0.27 \mathrm{~kW}(7.7 \%)$.

Table 7. Peak Cooling Energy Savings for Six Homes of Phase 2

\begin{tabular}{c|c|c|c|c}
\hline House ID & $\begin{array}{c}\text { Pre-Repair } \\
\mathbf{k W}\end{array}$ & $\begin{array}{c}\text { Post-Repair } \\
\mathbf{k W}\end{array}$ & $\begin{array}{c}\text { Savings } \\
\mathbf{k W}\end{array}$ & $\begin{array}{c}\text { Savings } \\
\mathbf{\%}\end{array}$ \\
\hline H23K & 4.70 & 4.45 & 0.26 & 5.4 \\
\hline H36S & 2.49 & 2.01 & 0.47 & 19.0 \\
H37M & 2.39 & 2.35 & 0.04 & 1.7 \\
H39L & 3.92 & 3.45 & 0.47 & 12.1 \\
H45H & 4.24 & 4.06 & 0.18 & 4.2 \\
\hline H47W & 3.26 & 3.04 & 0.22 & 6.9 \\
\hline Average & 3.50 & 3.23 & 0.27 & 7.7 \\
\hline
\end{tabular}

Another method of peak hour analysis was used where the hourly total energy use was plotted against the hourly average dT between outdoors and indoors. A least-squares best-fit regression analysis was used to develop a linear equation. The equation can then be used to predict peak electricity demand at a specific dT.

\subsection{Peak Heating Energy Impacts}

Peak heating energy analysis was completed to determine peak heating demand that occurred before and after the wind washing repairs. Several days from each period were chosen for having as similar outdoor conditions as possible. The days were also chosen to be as cool as possible. A composite of heating energy use over a 24 -hour day was developed from the pre-repair and a 
second composite day for the post-repair days. Then the energy use during the utility peak period between 6 a.m. and 7 a.m. is compared to determine the peak energy impact. Examples from two houses are shown in Figures 52-53. As discussed in Section 8.3, it can be difficult to use this method to find comparable periods at the more extreme weather conditions where occupant impacts have not increased variability. Thus, the team recommends using the least-squares bestfit regression method previously described at the end of Section 8.3 of this report. Figure 52 shows a comparison of the pre- and postheating profiles for fairly similar days, but for unknown reasons, the owners permitted the house to stay cooler in many of the coldest pre-repair days. It should be noted that this home did not experience many cold days and the typical pattern of heating was to adjust the thermostat on occasion to increase heat for a few hours.

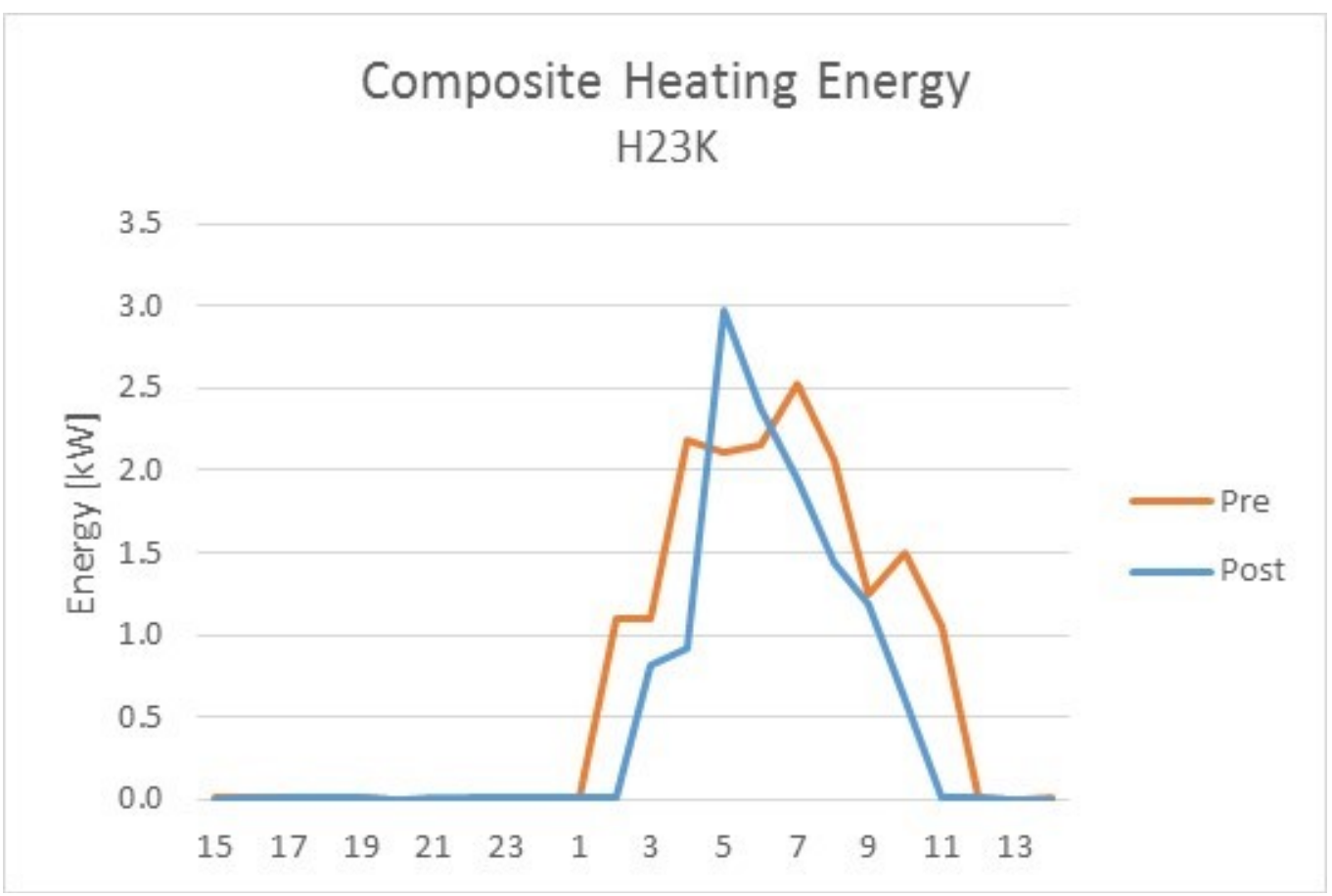

Figure 52. Heating energy before and after repair for House H23K with hour of day shown on the $\mathrm{x}$-axis 


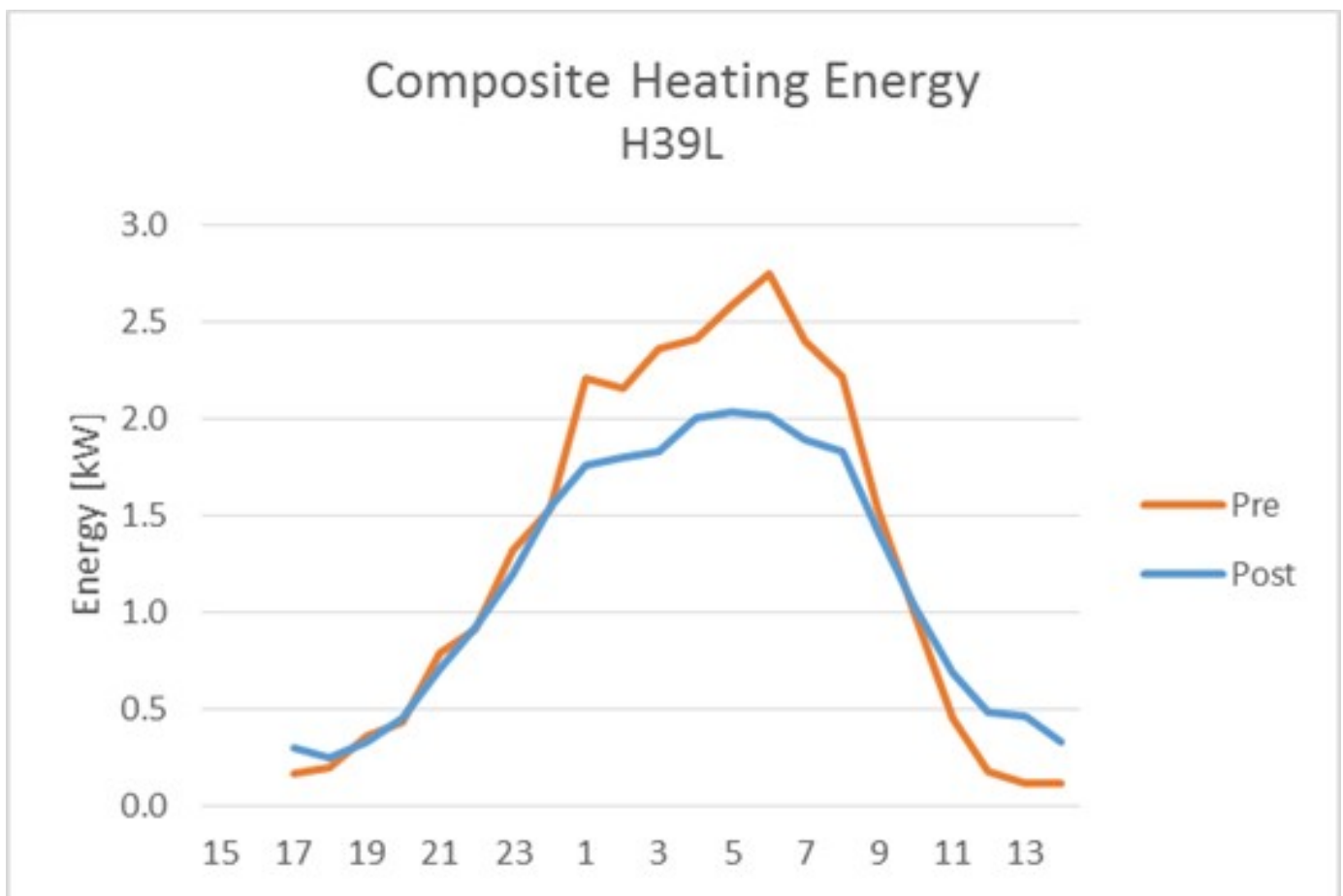

Figure 53. Heating energy before and after repair for house H39L with hour of day shown on the $x$-axis

Table 8 shows the peak heating kilowatt savings resulting from wind wash repairs in the five Phase 2 homes. The average peak heating savings is $0.28 \mathrm{~kW}(13.7 \%)$.

Table 8. Peak Heating Energy Savings for Four Homes of Phase 2

\begin{tabular}{c|c|c|c|c}
\hline House ID & $\begin{array}{c}\text { Pre-Repair } \\
\mathbf{k W}\end{array}$ & $\begin{array}{c}\text { Post-Repair } \\
\mathbf{k W}\end{array}$ & $\begin{array}{c}\text { Savings } \\
\mathbf{k W}\end{array}$ & $\begin{array}{c}\text { Savings } \\
\mathbf{\%}\end{array}$ \\
\hline H23K & 2.25 & 1.92 & 0.33 & 14.7 \\
H36S & 1.72 & 1.67 & 0.05 & 2.9 \\
H37M & NA & NA & NA & NA \\
H39L & 2.61 & 1.92 & 0.69 & 26.4 \\
H45H & 1.62 & 1.55 & 0.07 & 4.2 \\
H47W & NA & NA & NA & NA \\
\hline Average & 2.05 & 1.77 & 0.28 & 13.7 \\
\hline
\end{tabular}




\section{Conclusion}

The impact of wind washing within floor cavities in multistory single-family homes was evaluated. Fifty-six homes were inspected and tested for the potential of floor cavity air and thermal leakage. At least 54\% were found to have some degree of wind washing potential. This sample of 56 homes is biased toward those more likely to have floor cavity leakage. A total of 12 homes using electric space heating and cooling were monitored before and after wind washing repairs using either spray LDF or paper-faced fiberglass batts. Based on results of Phase 1 and Phase 2 monitoring, the total annual estimated energy savings from repair is $1,034 \mathrm{kWh} /$ year, which at $\$ 0.115 / \mathrm{kWh}$ equates to $\$ 119 /$ year saved in consumer energy costs. It is believed that the average cost of repair may be $\$ 350$, assuming about $75 \%$ of homes can be sealed by professional contractors using off-the-shelf air and thermal barrier products and the other $25 \%$ are sealed using professionally applied spray LDF. The average simple payback would be about 2.9 years.

Wind washing repairs typically use much less insulation material than is common in more conventional insulation jobs. The average repair area in this project was $169 \mathrm{ft}^{2}$ with a range of $48-510 \mathrm{ft}^{2}$. The relatively small repair area and high mobilization cost of spray foam rigs can make repair by spray foam twice as costly as using batts or insulated board stock. Homes with garage attic space next to second-story floor space (the most common location) generally have easy access and often require less than $40 \mathrm{ft}^{2}$ of material to seal and insulate the floor cavity from the attic. If the knee wall is also insulated, the total area typically increases to $70-100 \mathrm{ft}^{2}$. Repair cost of an easy-to-access floor cavity and knee wall area of about $100 \mathrm{ft}^{2}$ and 2.8 person-hours could likely cost as little as $\$ 173$ and even less at about $\$ 85$ if only the floor cavity is sealed with faced batt and sealant. Of all homes having floor cavity pathways, about $25 \%$ of those inspected had very small leakage pathways (longitudinal seams) that could be sealed inexpensively using canned expansive foams for perhaps as little as $\$ 20-\$ 40$ in retail material costs.

While using relatively inexpensive materials (such as backed insulation batts) can result in lower installation costs, specific installation details must be carefully followed to ensure effective air and thermal barrier performance. Materials have to be carefully cut to fit within framing, be fastened mechanically, and have a functional air seal. Following these details is challenging in relatively easy installations and can be extremely challenging in tight attic spaces or where complex framing would require a laborious amount of custom material trimming. Such spaces would require much more labor to fit the inexpensive materials and the final results are less likely to be successful compared to spray foam. If duct leakage is known to exist within the floor cavity, an airtight seal is even more important. Therefore, spray-applied LDF may be the best choice in certain circumstances.

It is likely that peak demand reduction from wind washing repair will look attractive to electric utilities, which in turn may provide rebates and other incentives to homeowners to fix wind washing problems. In some cases, wind washing repair may also resolve occupant comfort complaints and diminish the impetus to install higher capacity HVAC equipment to achieve space comfort. 


\section{Recommendations}

The following points can help prevent wind washing issues in new construction:

Improve building code language and code enforcement. This is an obvious requirement to avoid wind washing problems in new construction. The average house leakage in 56 homes (average age of 25 years) is very high at $8.8 \mathrm{ACH} 50$. By comparison, the new building code (IECC 2012) requires new construction to have a tested airtightness not to exceed 5 ACH50 for climate zones 1 and 2. An even tighter restriction of $3 \mathrm{ACH} 50$ is mandatory for climate zones 3 through 8. Florida has adopted this building code and as such will require tighter buildings. Eliminating floor cavity pathways is an important part of being able to meet this requirement. IECC 2012 has language in Table R402.4.1.1 that may be interpreted to mean that floor cavities are required to be insulated and air sealed from unconditioned spaces; however, floor cavities are not specifically mentioned. Without more specific language to address floor cavities, code enforcement is more likely to be missed. Florida code has adopted more specific language that requires an "Air barrier on perimeter of floor cavities between floors" for multistory homes. This is more specific than IECC, but Florida code language could be improved to say "Air and thermal barrier on perimeter..." The IECC could be improved to add a table entry specifically for floor cavities such as Florida's code.

Use a continuous sheet of plywood or other air barrier material located on the attic side of knee wall and floor cavity framing to provide a durable air barrier.

Attach an air barrier against the plywood to stop air through plywood sheet seams if using an air-permeable insulation.

Avoid designs that place a roof truss within $18 \mathrm{in.}$ of the floor cavity. This allows some space for insulation to be placed on the outside plane of plywood or other air barrier material located on the attic side of knee wall and floor cavity framing.

Repairing wind washing in existing construction:

Inspection:

Begin with a careful visual inspection of all accessible areas of the floor cavity and its perimeter. This requires access into attic and other unconditioned spaces surrounding floor cavities. Some of these spaces may be very difficult and sometimes impossible to physically access.

Some building disassembly or borescope investigations may be needed. The house tightness test and house pressure wrt floor cavity pressure diagnostic test may help substantiate cause for more invasive investigations, especially when moisture-related damage has been occurring within the floor cavity.

Inspections should focus efforts on locating an effective air barrier over the floor cavity (such as wood or other rigid composite materials, faced batts, infiltration barrier house wrap) with no pathways or open seams at the perimeter of the floor cavity adjacent to attic space. There should also be an effective thermal barrier in the same location as the air barrier that does not permit air bypass. 
Repair:

Floor cavities can be effectively sealed and insulated using kraft-faced fiberglass batts (carefully installed) or open-cell spray foam insulation. Other material such as rigid board insulation could also work, but is not likely as cost effective at R-19 or higher.

Consider adding insulation to the existing knee wall areas above floor cavities. This can be cost effective when spray foam is used and the existing insulation is R-19 or lower with significant void and/or compression areas. If wall insulation has only a few problem areas, replace or reinstall areas of poorly installed R-19 wall insulation as needed during the floor cavity wind washing repair.

Fiberglass batts are likely to be more cost effective than other methods, particularly when repair areas are easily accessible and smaller than $100 \mathrm{ft}^{2}$. However, it is stressed here that an effective seal using kraft paper-faced batts can be accomplished only by careful installation that avoids rips and significant wrinkles of the paper facing. Some repairs cannot be made effective using fiberglass batts, but can be by the spray foam application.

Kraft paper should not only be mechanically fastened by staples, but also sealed with a caulking or construction adhesive to the perimeter floor cavity structure for the best measure of air restriction. In some cases, it may be easier to verify a complete seal by installing the batt insulation with the paper side facing the installer. This results in the paper being exposed to the attic space, which codes do not accept, and will require an additional thermal barrier to be placed over the paper facing. Another section of fiberglass batt with no paper facing exposed to the attic may be used as the added thermal barrier over the exposed paper.

Given the relative ease of application, expansive property, and nature of adherence, spray foam application is likely to result in a more effective, longer lasting air seal than other methods. Floor cavity perimeters having numerous pipe, duct, and wire penetrations as well as less planar geometry at the sealing plane of the floor cavity will be much easier to seal effectively with spray foam.

The spray foam method may be preferable when there are significant duct leaks into the floor cavity if sealing the faced batts or other material to isolate the floor cavity from the attic is difficult.

Building codes require a fire ignition barrier on foam insulation exposed in attic spaces "where entry is made only for service of utilities." This can most simply be accomplished by coating the exterior foam surface with a spray-applied fire ignition barrier, also referred to as an intumescent material.

Protect cold supply ducts from condensation whenever any insulation is placed against the duct surface. Condensation potential on supply ducts with existing R-6 insulation in the summertime can be limited by wrapping the duct with an additional layer of insulation that has a vapor barrier on its outside surface. No evidence of moisture issues was noticed for R-6 supply ducts wrapped with materials having at least an effective R-1 to R-3 thermal resistance and an effective vapor barrier. Ducts with insulation lower than R-6 were not in the study, but they would certainly require much higher added R-value to significantly reduce condensation potential. An added R-6 layer with vapor barrier should adequately limit condensation potential under normal circumstances. 
The recommendations for added duct insulation should limit condensation potential in vented attics in hot-humid climates under normal circumstances. These recommendations cannot guarantee that significant condensation would never occur. Poor installation, unexpected material failure, and excessively low cooling set points by occupants can all cause duct condensation.

Energy savings from wind wash repair may be limited for the following reasons:

Very small pathways from attic to floor cavity, except when significant duct leakage occurs within the floor cavity.

Relatively cool attic in summer from high mass roof such as tile, limited deck radiation into attic from radiant barrier or reflective metal roof, or very heavy shading from a tree canopy.

Limited natural driving force of wind either from limited wind magnitude or direction that does not align well to drive air into pathways, or limited attic ventilation pathways for wind to push air through the attic.

Occupant preference for higher interior temperatures during cooling or lower temperatures during heating.

Occupant preference for frequent ventilation by various means such as long operation of bathroom or kitchen exhaust fans, or opening of windows.

Failure to properly maintain space conditioning equipment. 


\section{References}

ABT. (2014). American Building Technologies online estimated insulation costs. Accessed August 2014:

http://www.americanbuildingtechnologies.com/weatherization/insulation/insulation-price-list/

ASTM E741-00. (Reapproved 2006). Standard Test Method for Determining Air Change in a Single Zone by Means of a Tracer Gas Dilution. ASTM International.

ASTM E779-03. (2003). Standard Test Method for Determining Air Leakage Rate by Fan Pressurization. ASTM International.

Cummings, J. (1989). Tracer Gas as a Practical Field Diagnostic Tool for Assessing Duct System Leaks. FSEC-PF-195-90. Cocoa, FL: Florida Solar Energy Center. Accessed September 2014: http://www.fsec.ucf.edu/en/publications/html/FSEC-PF-195-90/index.htm

Cummings, J.; Withers, C.; Lahiff, I. (2009). Investigating Solutions to Wind Washing Issues in 2-Story Florida Homes; Phase 1. FSEC-CR-1842-09. Cocoa, FL: Florida Solar Energy Center. Accessed September 2014: http://fsec.ucf.edu/en/publications/pdf/fsec-cr-1842-09.pdf

Cummings, J.B.; Moyer, N.; Tooley, J.J. (1990). Radon Pressure Differential Project, Phase II: Infiltration. FSEC-CR-370-90. Cocoa, FL: Florida Solar Energy Center. Accessed September 2014: http://www.fsec.ucf.edu/en/publications/pdf/FSEC-CR-370-90.pdf

Cummings, J.B.; Tooley, J.J.; Moyer, N. (1993). Duct Doctoring Diagnosis and Repair of Duct System Leaks. Cocoa, FL: Florida Solar Energy Center.

DOE (2000). Technology Factsheet: Ceilings and Attics: Install Insulation and Provide Ventilation. United States Department of Energy, Office of Building Technology, State and Community Programs, DOE/GO10099-771.

Lstiburek, J. (2005). Builder's Guide to Hot-Humid Climates. The Energy \& Environmental Building Alliance (EEBA).

"International Energy Conservation Code." (2012). International Code Council. Accessed June 2014: http://publicecodes.cyberregs.com/icod/iecc/2012/index.htm?bu=IC-P-2012000014\&bu2=IC-P-2012-000019

"Normal Monthly Heating Degree Days (Base 65)." (2013). National Climatic Data Center. Accessed September 2014: http://www.ncdc.noaa.gov/oa/climate/online/ccd/nrmhdd.html

RS Means Online. (2014). Version 5.0.6, 2014 Reed Construction Data Inc. Accessed August 2014: http://rsmeansonline.com/References/CREW/1-

Year\%202014\%20Crews/Crew\%20Residential.PDF

Swami, M.; Cummings, J.; Sen Sharrma, R., Withers, C.; Basarkar, M. (2006). Florida Building Code-Enhance Florida's Building To Next-Generation Energy \& Mechanical Codes and Enrich Compliance. FSEC-CR-1678-06. Cocoa, FL: Florida Solar Energy Center. Accessed September 2014: http://www.fsec.ucf.edu/en/publications/pdf/FSEC-CR-1678-06.pdf 


\section{Appendix: Description of Wind Washing Repairs in Six Homes}

Six homes were chosen to measure the energy impact of repairing wind washing related to open floor cavities in two-story homes. Two repair methods were evaluated. Four homes were repaired using open-cell spray LDF and two homes were repaired using kraft paper-faced fiberglass insulation. Specific details about the wind washing repairs for each home are provided in this appendix.

\section{House H23K}

This house, known as H23K, was tested in August 2009 and was considered to have a high wind washing potential. This home is located within a half mile of the Atlantic Ocean, has a vented attic, and had open floor cavities oriented east to west, which readily allowed the predominant east-to-west sea breeze to flow through these cavities. An exterior view of the attic section over the garage on the east side of home is shown in Figures A1 and A2.

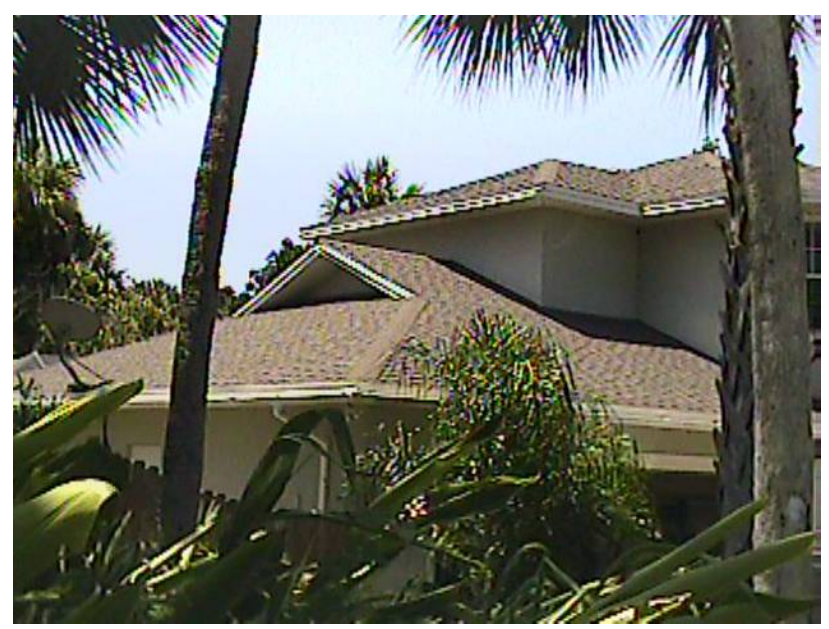

Figure A1. East and north sides of House H23K with garage attic adjacent to open floor cavities

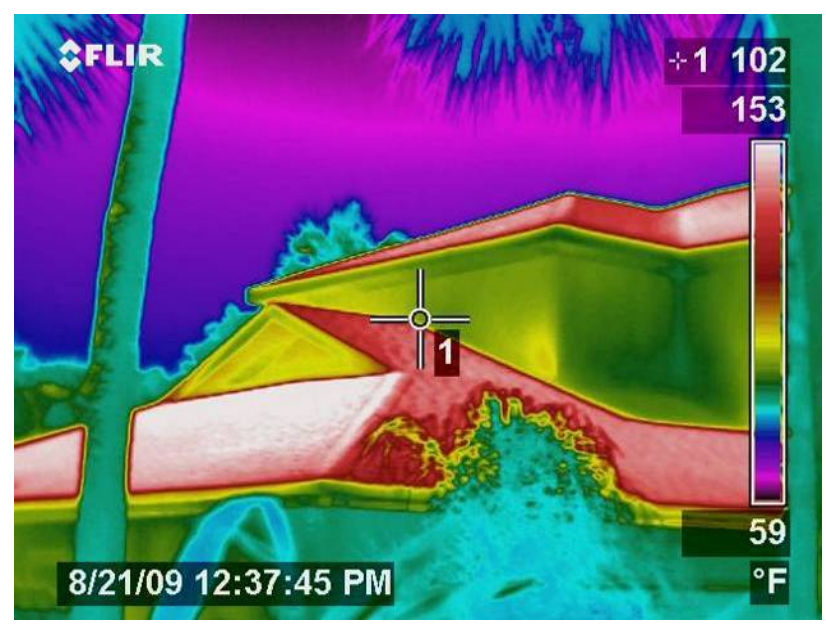

Figure A2. IR image of the house at midday after mostly sunny conditions all morning 
$\mathrm{H} 23 \mathrm{~K}$ is a two-story home built in 2002 with a total of $2,500 \mathrm{ft}^{2}$ of floor area served by two heat pumps: a 4-ton Goodman heat pump on the first floor and a 2-ton Goodman heat pump on the second floor. The second-floor total area is $933 \mathrm{ft}^{2}$. All of the second-story floor space is positioned over the conditioned first floor and has two areas where floor space is next to attic space. The attic space is very hot in the summer because the roof has black asphalt shingles and little shading.

Inspection of the garage attic revealed that the floor cavities between the first and second floors were open to the garage (east) attic space and to the west attic space (above the master bedroom; see Figures A3 and A4). Evidence that hot attic air has flowed into the interstitial floor cavity can be seen in Figures A5-A8. These IR images show evidence that hot attic air has been pushed into the floor cavity that intercepts the stairway and balcony areas. The first-story ceiling and secondstory floor surfaces also have elevated temperatures; IR images indicate that floor space surfaces of about $3^{\circ}-6^{\circ} \mathrm{F}$ warmer than other interior temperatures. This heat results when attic air is pushed into interstitial floor cavities. The added heating of floor and ceiling surfaces adds considerable cooling load to the heat pump system. Figures A9 and A10 show the floor layout and the locations of floor cavity openings to adjacent attics.

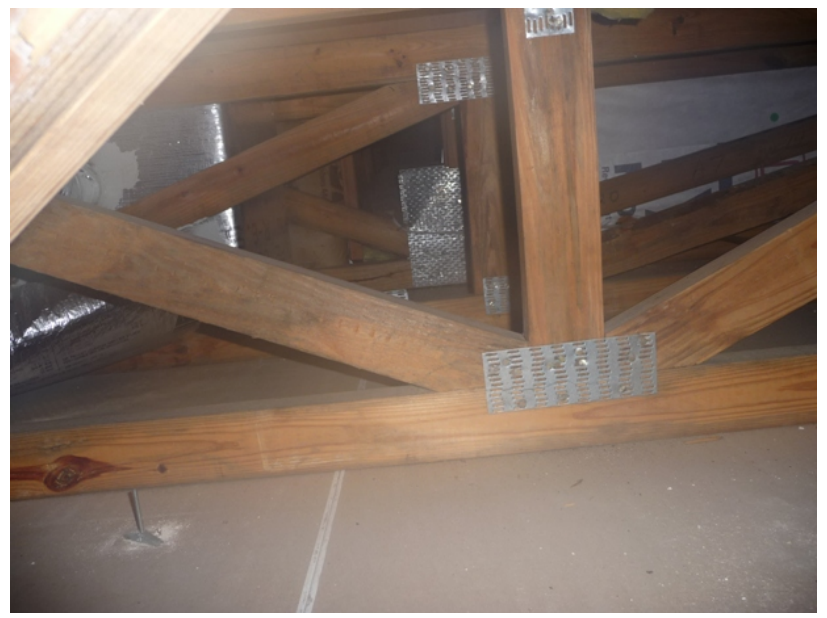

Figure A3. Looking from east attic space into open floor cavity (view toward the west)

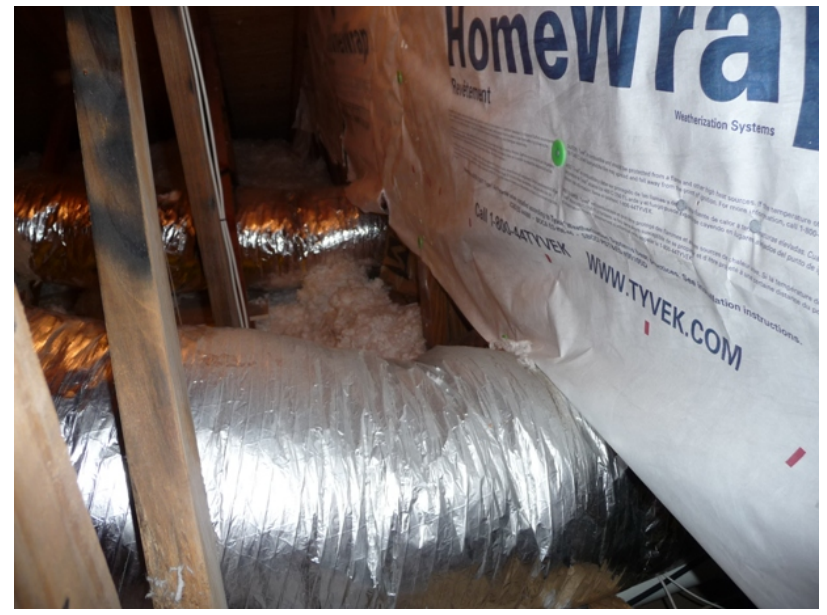

Figure A4. Looking at ducts passing from west attic into an open floor cavity 


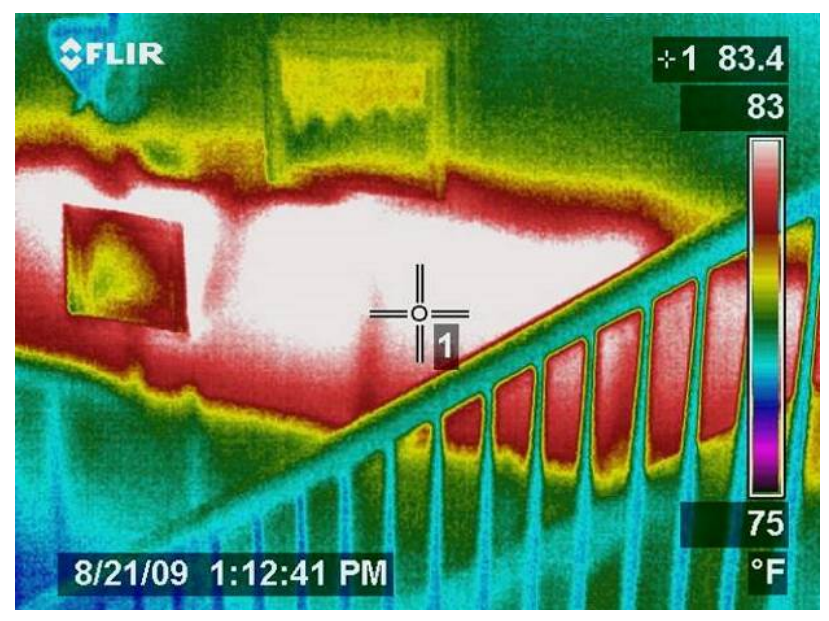

Figure A5. IR image shows where hot attic air has penetrated into the floor cavity that lies behind the stairwell wall.

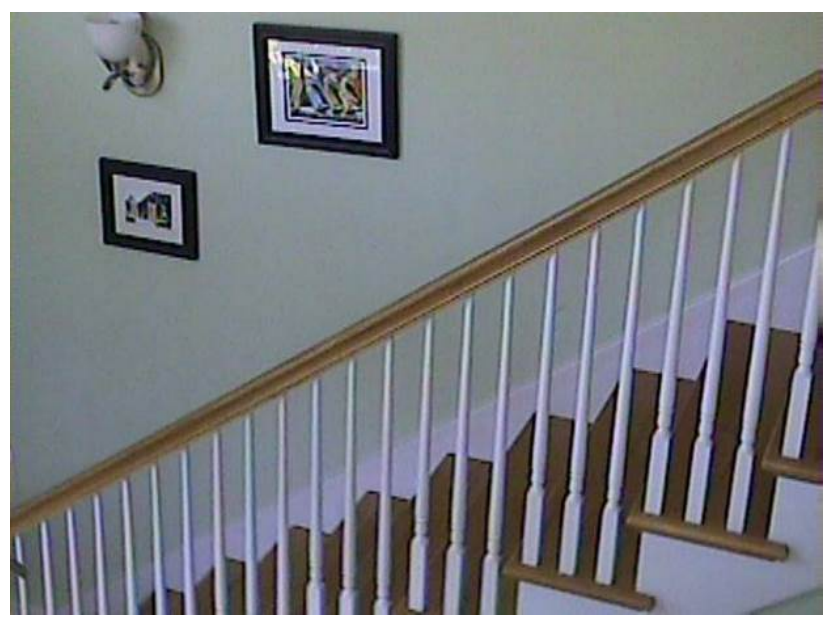

Figure A6. Stairwell where the wind washing thermal impacts is occurring

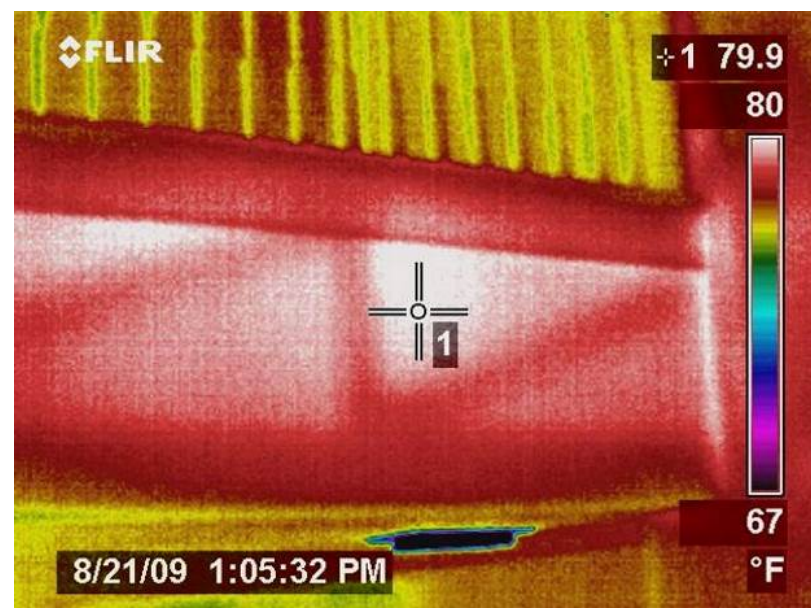

Figure A7. Thermal image of second floor landing. The heat signature indicates flow of attic air far into the interstitial cavities of the house. 


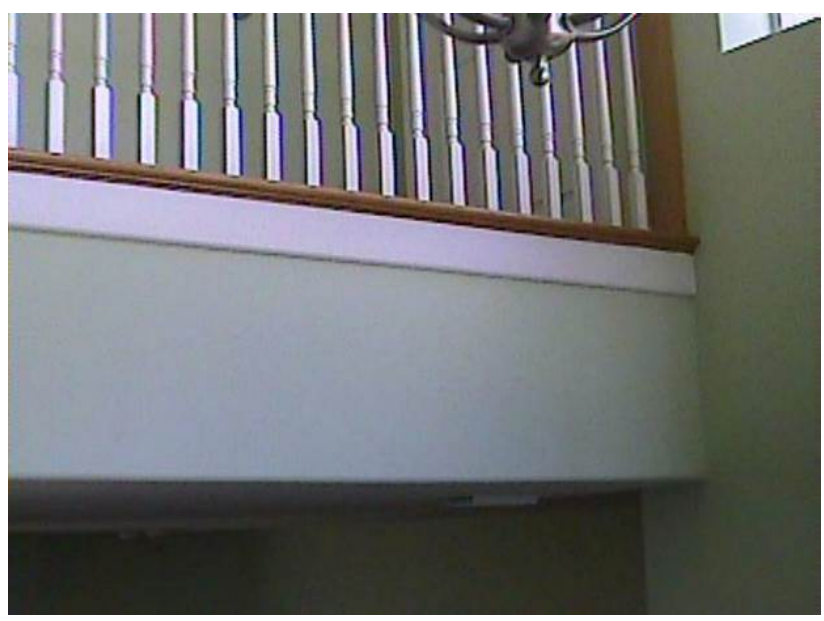

Figure A8. Photo of second-floor landing

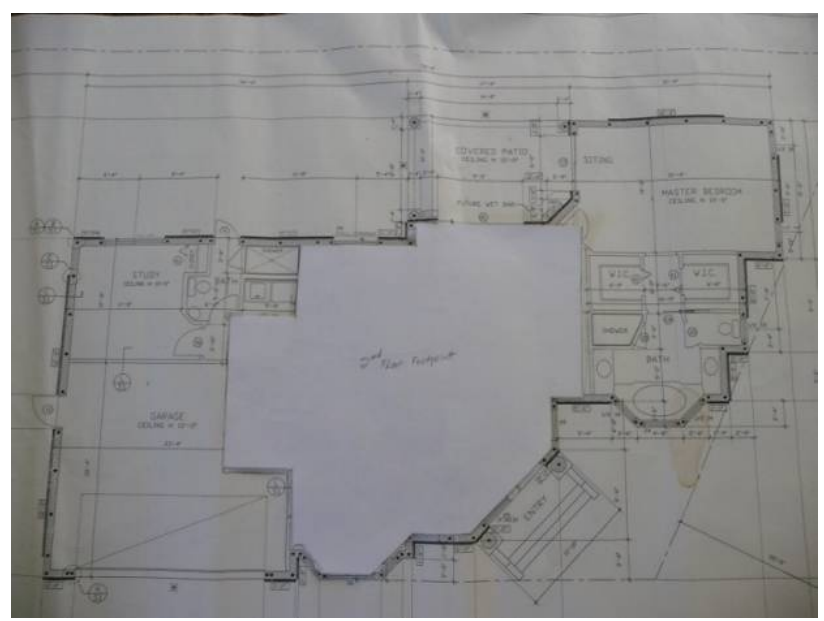

Figure A9. First-floor plan with second-floor plan footprint placed on top. Left side faces east toward the prevailing wind.

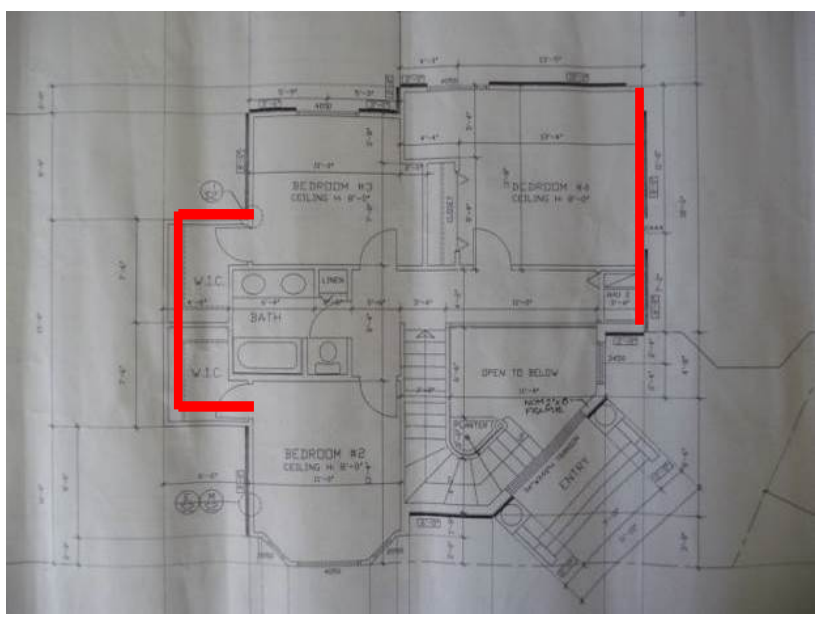

Figure A10. Second-story floor plan. Red lines indicate areas of openings from attics into floor cavities. 
Prior to repair, the floor cavities were wide open to the adjacent attic spaces, with total openings of $26.8 \mathrm{ft}^{2}$ on the east (windward) side of the home and $9.2 \mathrm{ft}^{2}$ on the west (leeward) side of home. Because of the large floor cavity openings, and the orientation to the predominant sea breeze to which this house is fully exposed, this house was considered to have a high wind washing potential.

There was also a large area of east knee wall that was void of insulation. Knee walls should, according to the Florida code, be insulated to at least R-19. However, code officials permit R-11 insulation when plywood is installed on the attic side of $2 \times 4$ frame walls. This practice seems to have been used sporadically by a variety of builders in older and newer homes in the wind washing study. In this case, however, even the R-11 insulation was missing. Evidence of the missing insulation can be seen in Figure A11. Figure A12 shows an area of the floor cavity open to the east attic just before and during the spray foam repair. The foam insulation crew stapled a plastic sheet over the floor cavity opening. This was done primarily to create a backstop for the spray foam. The crews in the Phase 1 study did not put up a backstop and simply constructed a foam barrier by spraying around the cavity perimeter and letting the foam expand toward the center until it sealed. This process observed in Phase 1 effectively sealed the opening. While the spraying effort may take just a little longer without a backstop, no time was involved in putting up a backstop. There was no obvious difference in the total time to complete the job. Many of the floor cavity opening heights are about 14 in. high and seal quickly with the expansive foam.

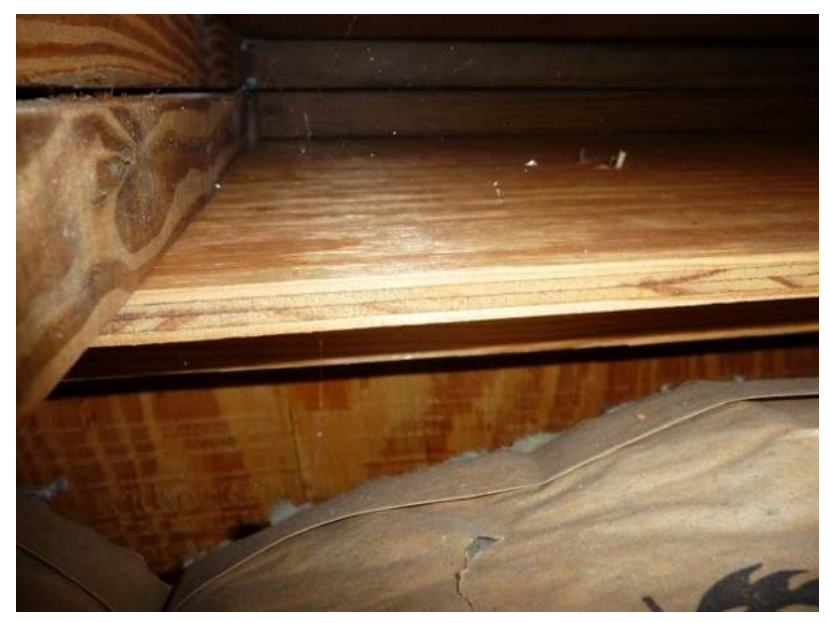

Figure A11. View looking up into a vacant wall cavity from within the east attic shows no insulation in this wall next to a walk-in closet. 

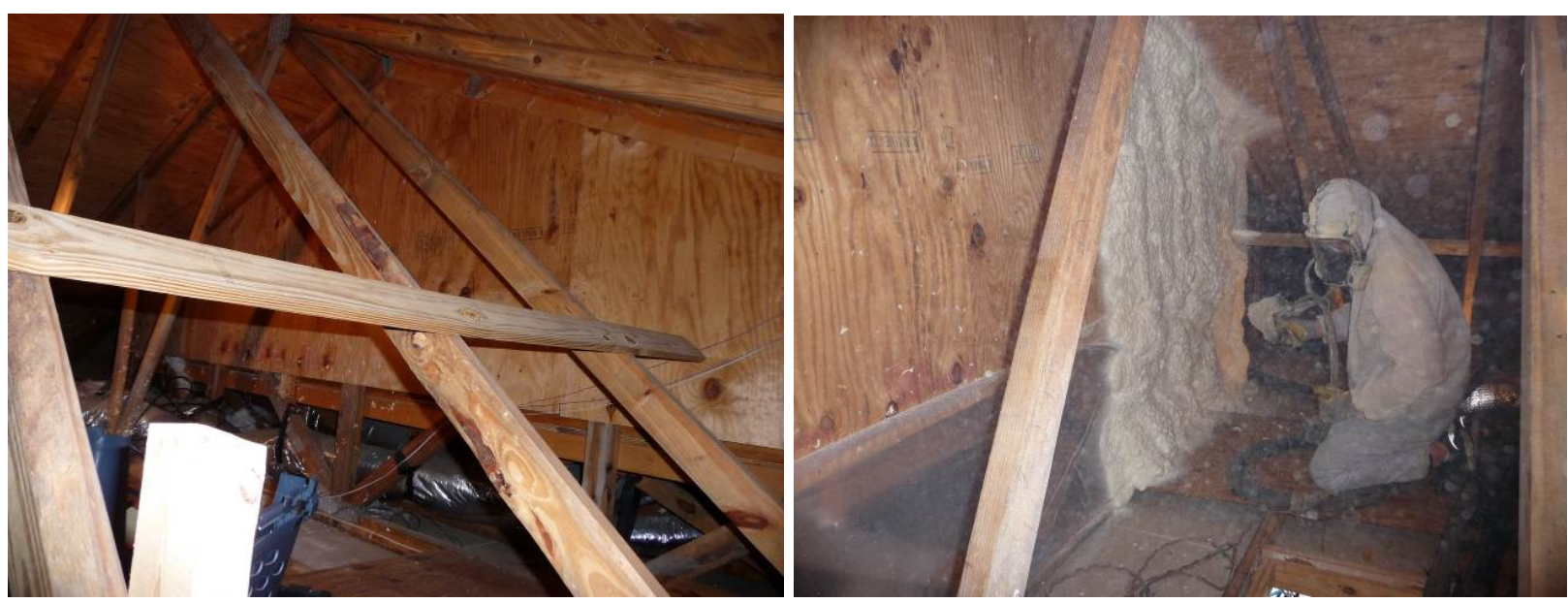

Figure A12. East side of floor cavity and knee wall before and during repair with spray LDF.

Air ducts are often run from the attic into the floor cavities. This creates a potential issue when considering adding insulation around a cold air supply duct. Adding insulation around the cold duct will cause the exterior surface of the duct to become colder wherever added insulation is in contact. The spray foam used in this project is open-cell LDF, which allows vapor diffusion to move through it. This means that vapor-laden attic air will migrate through the foam and can come in contact with the colder duct surface. Researchers were aware of this in Phase 1 and tested a measure that appeared to work.
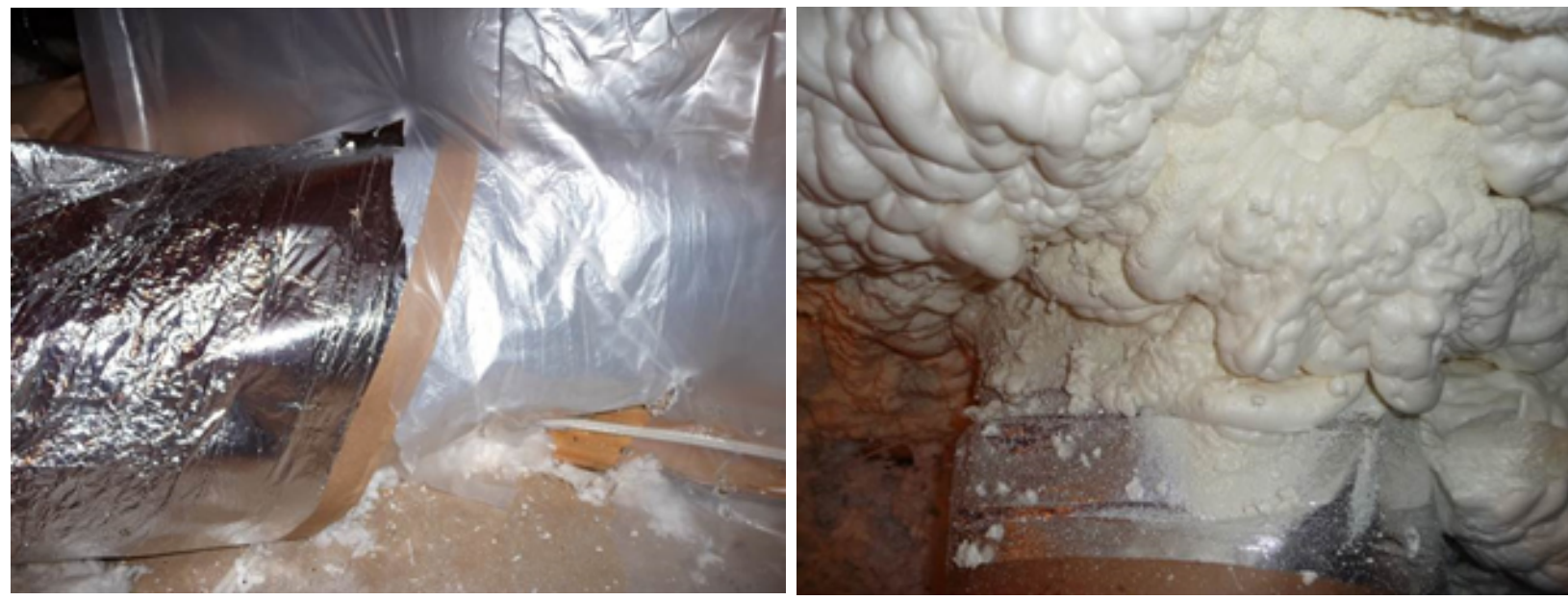

Figure A13. Photo on left was taken during the preparation to protect cold air supply duct with an insulating wrap having vapor barrier on outside. Photo on right is a view over top of duct after the wrap was carefully attached and foam was applied.

Supply ducts with R-6 were protected from condensation by not allowing the foam spray to come into direct contact with the duct. This was done by first wrapping an insulating vapor barrier around any cold supply duct where the foam will wrap around it. Figure A13 shows two photos of a wrapped supply duct. The photo on the left shows the wrap as it was applied but just before the final adjustments were made to create a tight fit around the duct. The photo on the right shows a close view after the floor cavity was sealed and foam was sprayed around the wrapped duct. 


\section{House H23K Test Results}

A house airtightness test (a blower door test) was performed according to ASTM E 779-87, "Standard Test Method for Determining Air Leakage Rate by Fan Pressurization," using a calibrated fan to draw air out of the house. When the house is tested at $50 \mathrm{~Pa}$ of pressure, the resulting measurement is called CFM50 (CFM = cubic feet per minute) (ASTM E779-03 2003). This CFM50 number is a measure of the absolute airtightness at a standard test pressure. Increased building leakage results in a higher CFM50 value. For comparison to other houses, CFM50 is often converted to ACH50 (ach at $50 \mathrm{~Pa}$ ), which is a measurement of relative airtightness. This house had an airtightness of 7.45 ACH50 before repair. This is about $22 \%$ leakier than typical homes built after 2004, which average 6.1 ACH50 (Swami et al. 2006).

Another assessment of house airtightness was completed through test standard ASTM 741 "Determining Air Change in a Single Zone by Means of a Tracer Gas Dilution" (ASTM E741-00 Reapproved 2006). This method makes a direct measurement of the rate of change of house air volume exchanged with outside air for the time period of the test. The air infiltration rate with the AHUs of both HVAC systems operating continuously was $0.45 \mathrm{ach}$. This means that a quantity of air equal to $45 \%$ of the house air volume was introduced into the house during a 1hour period when both AHUs were operating (with exhaust fans turned off and interior doors open). No tracer gas decay test was done to measure natural air infiltration (that generated by wind and dTs). Research has revealed, however, that a ballpark estimate of natural air infiltration in Florida homes can be predicted by dividing ACH50 by 40 (Cummings et al. 1990). In this case, the predicted natural air infiltration rate would be 0.19 ach. However, average natural air infiltration is likely higher than 0.19 because it is a two-story home and close to the ocean (in both instances yielding greater exposure to the wind).

Table A1 summarizes the house airtightness and infiltration rates before and after repair. House tightness testing by blower door indicates the house airtightness increased about $10.5 \%$ after the wind washing repair. The measured air infiltration rate with the AHU on does not indicate any difference. This was expected because the duct system had return dominant leakage outside the floor cavity.

Table A1. House Tightness Results Before and After Repair

\begin{tabular}{c|c|c|c|c}
\hline & CFM50 & ACH50 & Predicted Natural ach & ach With AHUs on \\
\hline Pre-Repair & 2854 & 7.45 & 0.19 & 0.45 \\
Post-Repair & 2556 & 6.67 & 0.17 & 0.45 \\
\hline
\end{tabular}

Table A2 shows results of duct-related leakage before and after repair. The leakage is shown from Ppan and RLF (tracer gas) test methods. Each of these methods was described in Section 3.3.2. System 1 is the central ducted system serving the first floor and system 2 serves the second floor. Recall that the Ppan method involves the use of a blower door. With the house depressurized to $-50 \mathrm{~Pa}$ wrt outdoors by a blower door, Ppan readings were taken at each supply and return grille location (with AHUs off) representative of various duct branches. Readings around $1 \mathrm{~Pa}$ generally indicate small cracks and seams. Relatively small Ppan values just above 1 Pa may still represent significant leakage, as can be seen in the RLF measurements in Table A2. Return Ppan measurements of 1.3 Pa for system 1 are associated with measured RLF that represents $9.5 \%$ of the system air. Most of the system 1 return leakage occurs where the AHU 
and return are connected, a location where the operational duct air pressures are greatest. So while the physical sizes of the return leak openings are relatively small (mostly cracks and seams), the actual return air leakage was found to be a relatively large $8.1 \%$ of total system flow or about $88 \mathrm{cfm}$. There was no notable difference in system 1 duct leakage before and after repair. This was expected because the supply leakage occurring within the floor cavity was small to begin with and the return leakage was primarily from the garage. The system 2 Ppan return measurements indicate a little less return leakage after the repair. The indicated decrease in return leakage may have been related to some hidden leakage through refrigerant line penetrations between the floor cavity and the system 2 return plenum. The remaining 5\% RLF after floor cavity repair came from return duct leakage in the second-story attic.

Table A2. Duct Tightness Measurements Before and After Repair

\begin{tabular}{c|c|c|c|c|c|c}
\hline & \multicolumn{4}{|c|}{ PPan Measurements } & System 1 & System 2 \\
\cline { 2 - 7 } & $\begin{array}{c}\text { System 1 } \\
\text { Supply }\end{array}$ & $\begin{array}{c}\text { System 1 } \\
\text { Return }\end{array}$ & $\begin{array}{c}\text { System 2 } \\
\text { Supply }\end{array}$ & $\begin{array}{c}\text { System 2 } \\
\text { Return }\end{array}$ & RLF \% & RLF \% \\
\hline Pre-Repair & 0.3 & 1.3 & 1.0 & 2.4 & $9.5 \%$ & 8.1 \\
Post-Repair & 0.3 & 1.3 & 1.1 & 1.5 & $9.2 \%$ & $5.0 \%$ \\
\hline
\end{tabular}

\section{House H36S}

This 2,094- $\mathrm{ft}^{2}$ wood-frame home is located in Jacksonville, Florida, and was built around 1942. The home is cooled and heated by a 4-ton nominal capacity heat pump. The second-floor area represents about $28 \%$ of the total floor area with $100 \%$ of the second floor directly over the conditioned first-floor area. The home has two vented attic sections on the east and west sides under a composite asphalt shingle roof. Figures A14 and A15 show the exterior sides of the home with no soffit overhang. The red dashed line in Figure A15 indicates approximately where the vertical plane of the floor cavity and knee wall is located within the east attic. The space was almost too small in the dormer areas to physically move through, making inspection and repairs much more difficult.

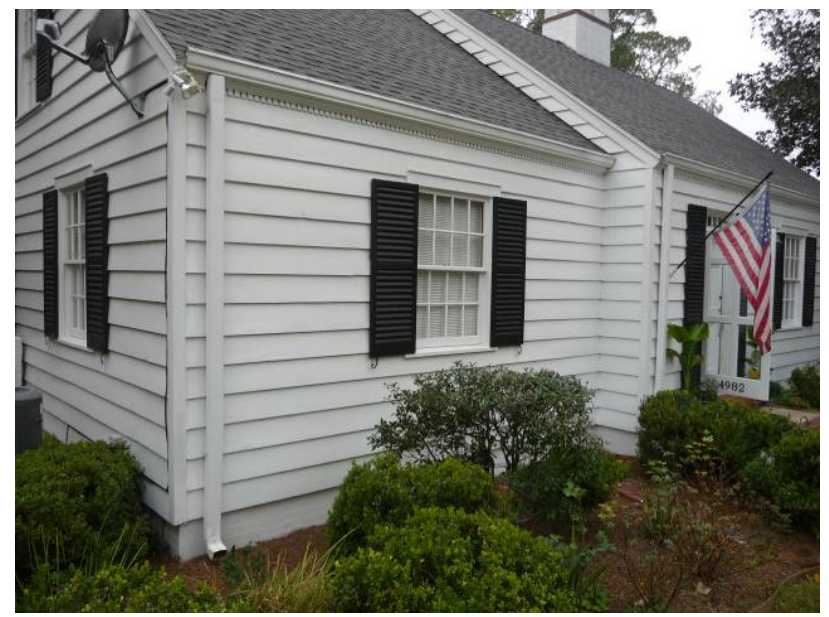

Figure A14. Front northwest corner of 1940s era House H36M. The west attic area is over the room on the northwest corner. 


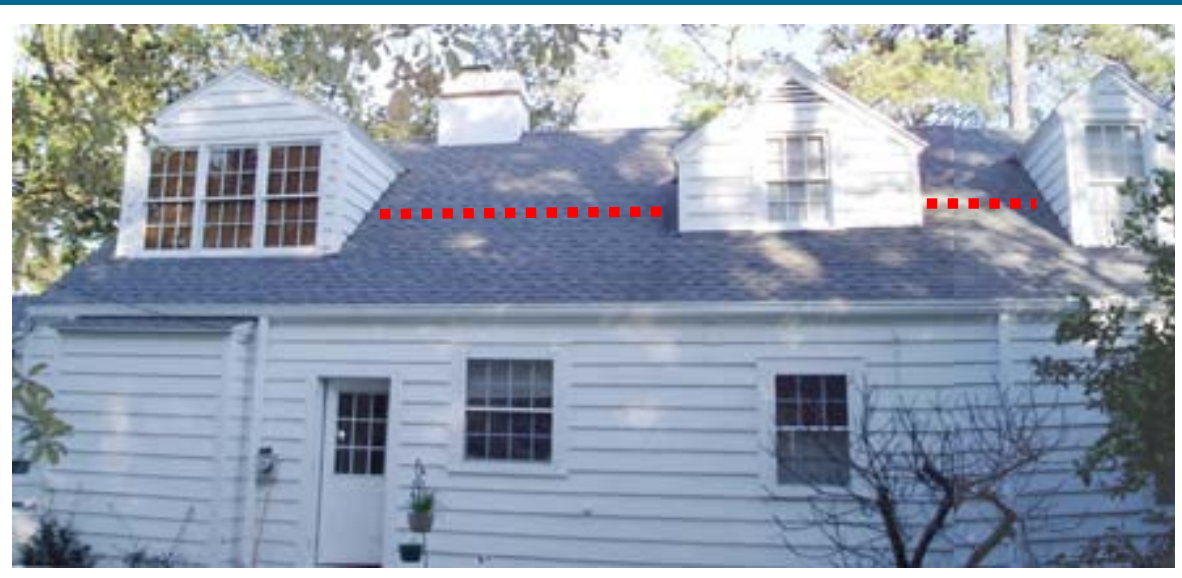

Figure A15. House H36M east back side where the shallow east attic is located. The vertical plane of the knee wall and floor cavity is approximately at the red dashed line.

Inspection of attic spaces revealed old, tattered, and filthy R-11 batts fastened to the wood roof deck. Pieces of batt insulation had broken down in some areas and fallen onto the attic floor below as seen in Figure A16. Attic vent openings seen in Figure A17 are more restrictive to wind-induced airflow into the attic space compared to a fully vented soffit. The total venting around the attic was just $1.9 \mathrm{ft}^{2}$ of net free area. If this home had a modern perforated vented soffit with a 1-ft overhang, the total free area of attic venting would be closer to $16 \mathrm{ft}^{2}$. Most of the second-story floor cavity had leak openings into both the east and west attic sections. The floor cavity is compartmentalized between solid wood joists $10 \mathrm{in}$. high and the pathways to attic varied from about $1-3 / 4$ in. to $10 \mathrm{in}$. high. The total accumulative open pathway areas to the west and east attics are $2.1 \mathrm{ft}^{2}$ and $10 \mathrm{ft}^{2}$, respectively. Photos of the nature of the air leak pathways in this home were shown earlier in Figures 5-9 of Section 3.2 of this report.

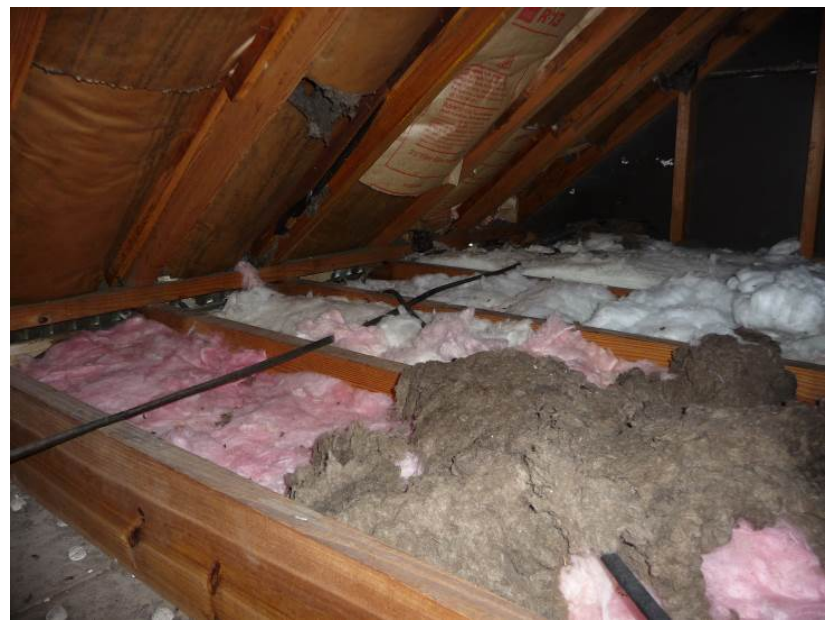

Figure A16. Pieces of old batt insulation, which have fallen from the roof deck above, can be seen in one area on the attic floor. 

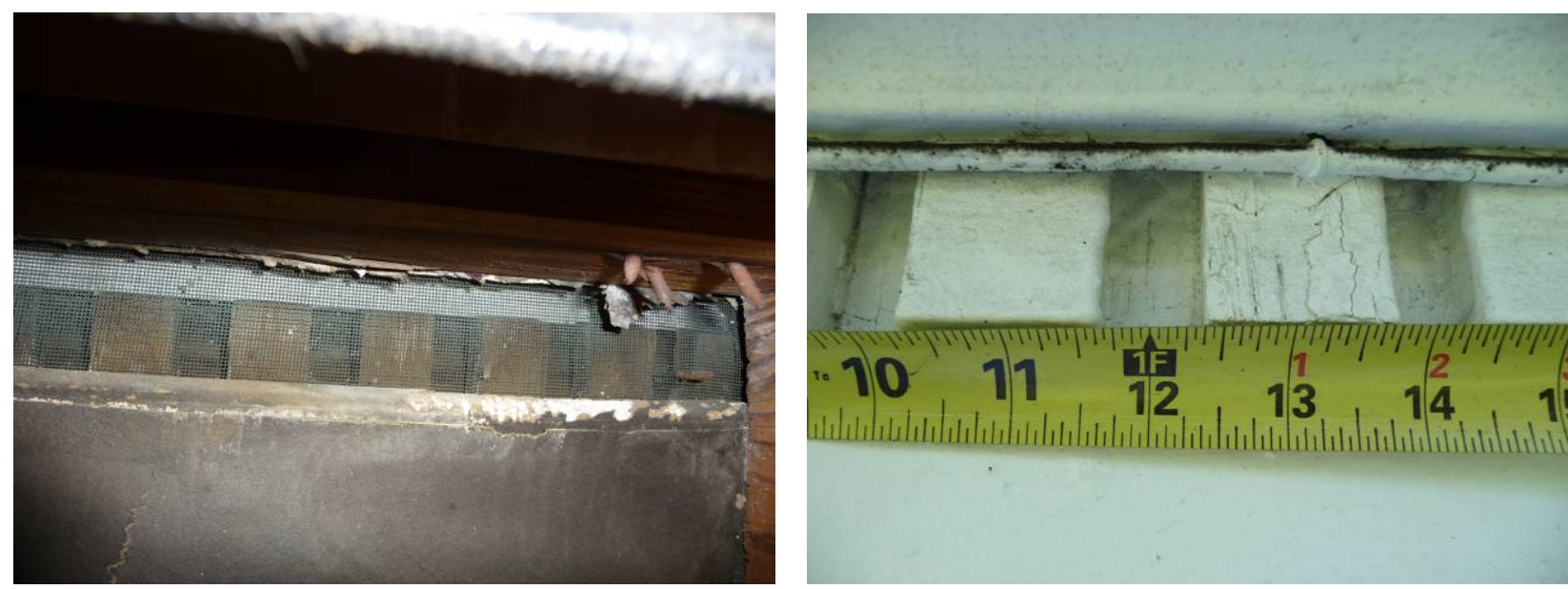

Figure A17. Dentil style attic venting viewed from inside attic and from outdoors. Venting is located along both east and west attic floor perimeters and has an insect screen on the attic side.

This home was repaired using R-30 kraft-faced batt insulation. Figure A18 shows a section of knee wall and floor cavity before and after insulation was added. The east attic area made this repair challenging with the very small attic area and numerous wire crossings and outlet boxes that had to be worked around. Without an inspection after work, this type of area is less likely to be completed well with batt insulation than if it were repaired with spray foam because extra effort is involved in manipulating and installing the batts.
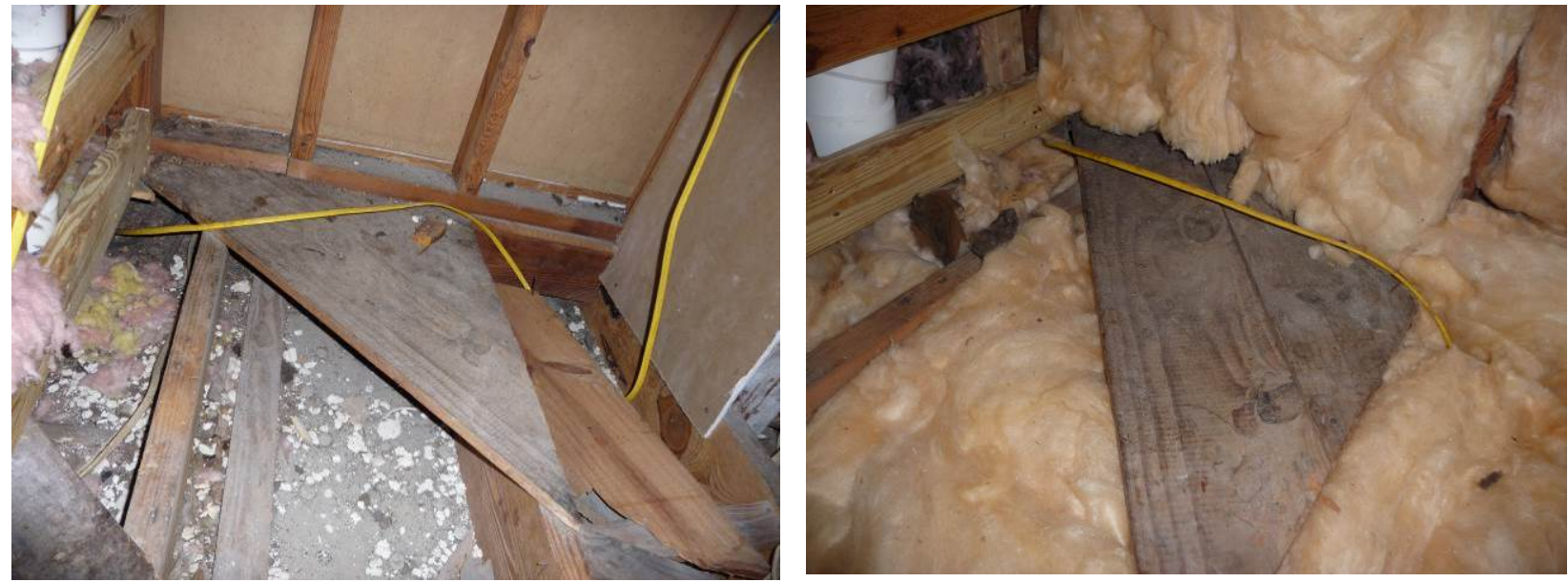

Figure A18. A section of unsealed and uninsulated floor cavity and knee wall in left photo and during repair with R-30 kraft-faced batt insulation installed in photo on the right.

Original construction plans were available for this home. During the original construction, the primary thermal barrier was the R-11 batt insulation located at the roof deck just under an asbestos shingle roof. The roof deck insulation remained over the years and significantly limited the heat transfer into the attic during the summertime. Figure A19 shows a composite plot of outdoor, attic and floor cavity temperatures $\left({ }^{\circ} \mathrm{F}\right)$ for all summer days from June 1 to September 1,2014 . This is during the post-repair period. Red is the attic space temperature, green is the attic roof deck temperature between the plywood and the deck insulation, blue is inside the floor cavity, and pink is the outdoors. These data show that the hottest temperatures in the lower attic 
area near the floor cavity averaged only about $87^{\circ} \mathrm{F}\left(3^{\circ} \mathrm{F}\right.$ cooler than the peak outdoor temperature), even though the roof deck temperature peaked at about $125^{\circ} \mathrm{F}$. This post-repair profile is very similar to the pre-repair profile (shown previously in Figure 43). Even the floor cavity temperature was about the same, indicating very little driving force of attic air into the cavity.

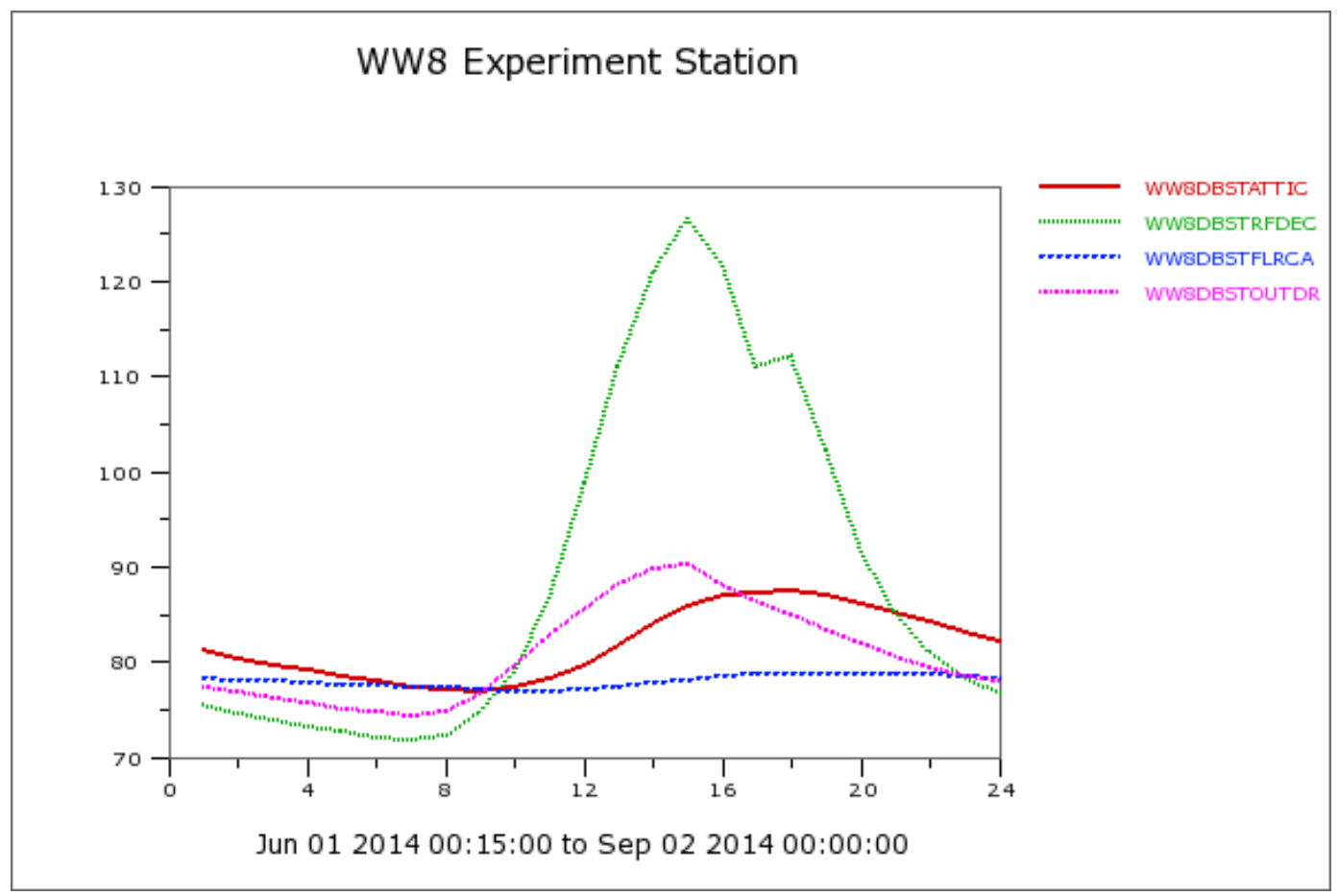

Figure A19. Daily composite profile of outdoor and attic temperatures during the summer period

Some insulation improvements apparently occurred through the years with batt insulation added to some knee wall and over flat ceiling areas under the attic. However, $430 \mathrm{ft}^{2}$ of knee wall area remained, needing insulation that could not be ignored. This was insulated along with the total $12 \mathrm{ft}^{2}$ of open floor cavity pathways.

\section{House H36S Testing Results}

Testing revealed that this was an extremely leaky home with an ACH50 of 22.1. The envelope leakage resulted from a combination of second-story-floor cavity leakage to the conditioned space and vented attic as well as leakage through the wood floor into the open crawlspace below. The home has a fireplace, which was sealed off during testing to prevent soot from entering the home. Moderate duct leakage is also present. Table A3 presents test results for airtightness and infiltration rates before and after repair. The house tightness test measurements show that the home became $14.4 \%$ tighter after wind washing repair.

able A3. House Tightness Results Before and After Repair

\begin{tabular}{c|c|c|c|c}
\hline & CFM50 & ACH50 & Predicted Natural ach & ach with AHUs on \\
\hline Pre-Repair & 6142 & 22.14 & 0.55 & 0.28 \\
Post-Repair & 5262 & 18.95 & 0.47 & 0.233 \\
\hline
\end{tabular}


In spite of the exceptionally leaky envelope, the house experienced a much lower air infiltration rate than expected of 0.28 ach (with the AHU operating, exhaust fans turned off, and interior doors open), which translates to air infiltration of about $80 \mathrm{cfm}$. No tracer gas decay test was conducted to measure natural air infiltration (that generated only by wind and dTs). Research revealed, however, that a ballpark estimate of natural air infiltration in Florida homes can be predicted by dividing ACH50 by 40 (Cummings et al. 1990). The estimated natural ach is higher than the measured ach with the AHU on. The ach with the AHU on is generally expected to be higher because of duct leakage that creates mechanically driven infiltration typically surpassing natural driving forces. A higher predicted natural ach can be explained by the fact that the predicted natural ach accounts for assumed greater natural driving forces than occurred during the tracer gas decay test. The measured ach during tracer gas decay occurred with very little driving force on the leaky house structure. There was less than $6^{\circ} \mathrm{F}$ difference between the indoor and outdoor temperatures and average wind speed was only $0-1$ mile per hour.

Table A4 shows results for the pressure pan and RLF tests. No change occurred in the duct tightness and none was expected because only one duct is located inside the floor cavity.

Table A4. Duct Tightness Measurements Before and After Repair

\begin{tabular}{c|c|c|c}
\hline \multirow{2}{*}{} & \multicolumn{2}{|c|}{ PPan Measurements (Pa) } & Tracer Gas \\
\cline { 2 - 4 } & $\begin{array}{c}\text { System 1 } \\
\text { Supply }\end{array}$ & $\begin{array}{c}\text { System 1 } \\
\text { Return }\end{array}$ & RLF \% \\
\hline Pre-Repair & 2.6 & 1.3 & $2.6 \%$ \\
\hline Post-Repair & 2.6 & 1.3 & $2.5 \%$ \\
\hline
\end{tabular}

\section{House H37M}

This 1,329- $\mathrm{ft}^{2}$ wood-frame home is located in Jacksonville, Florida, and was built about 1984. The home is the end unit of a triplex that faces east and has a vented attic space over a garage located on the north side of the house (Figure A20). The home is cooled and heated by a 2.5-ton heat pump. The second-floor area represents $50 \%$ of the total floor area with $100 \%$ of the second story directly above conditioned first-floor space.

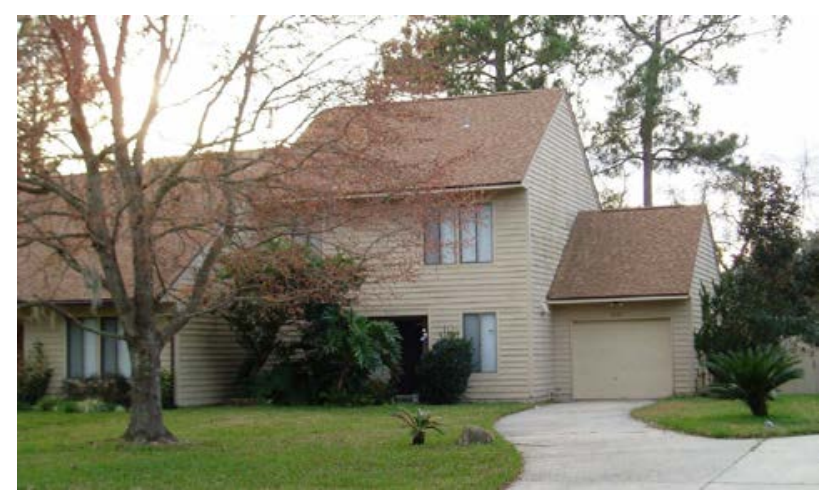

Figure A20. A front view of House H37M. The garage is on the north side.

The attic of the adjacent residence (to the south) was inspected and no connections were observed between the floor cavity of the study home and the neighboring attic. Inspection revealed $8.6 \mathrm{ft}^{2}$ of openings between the second-story floor cavity and the garage attic (Figure 
A21). It is more difficult to use batt insulation effectively in retrofit repairs in such locations where the attic truss sections abut the floor truss section.
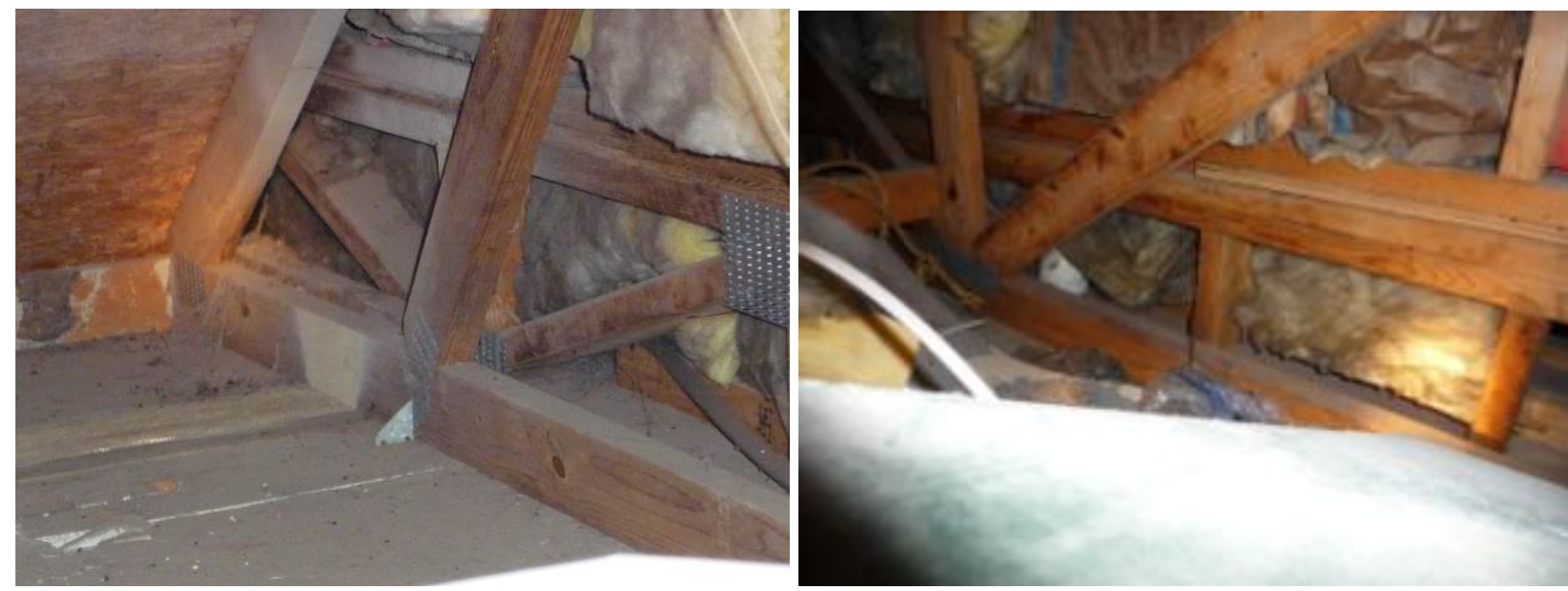

Figure A21. At left is a floor cavity section where existing batts do not seal the space. At right is another section with compressions and voids in the batt.

A significant return duct leak (10.4\% of total flow) provided a large mechanical driving force that pulls air from the garage attic into the floor cavity and then down into a leaky return plenum closet when the AHU is operating. The return plenum closet, located on the first floor, can be seen in Figure A22 with the door open. Figure A23 shows an upward-looking view of closet ceiling pathways to the floor cavity above. The clearance between the closet walls and the AHU was so small that this view was possible only by squeezing a camera into the space to take photos. Creating a good air barrier at the leaky floor cavity was especially important because there was large return duct leakage from the floor cavity that could not be sealed without tearing out the AHU or other ceiling areas around the closet. (Current Florida code requires adequate clearance around the AHU and adjacent walls.)

This home was repaired with foam because it was most likely to result in the tightest air seal and it provided an opportunity for the project to evaluate the costs and services of a different foam contracting company than in Phase 1 . Part of the knee wall and floor cavity can be seen in Figure A24 after the repair was completed. About $60 \mathrm{ft}^{2}$ of knee wall and $21 \mathrm{ft}^{2}$ of floor cavity area were insulated with the foam. 


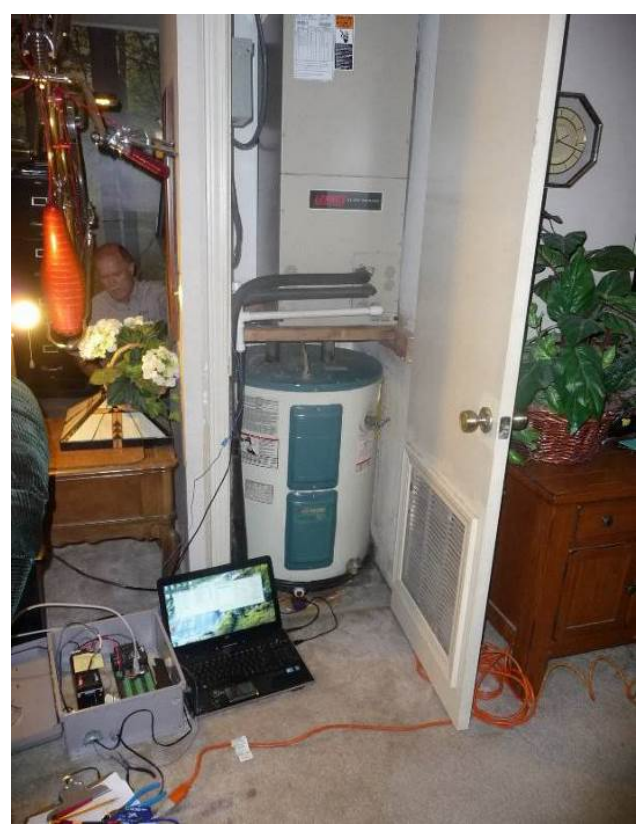

Figure A22. This closet operates as a return plenum (shown with door open during data acquisition system installation). A data logger can be seen on the floor next to the laptop.

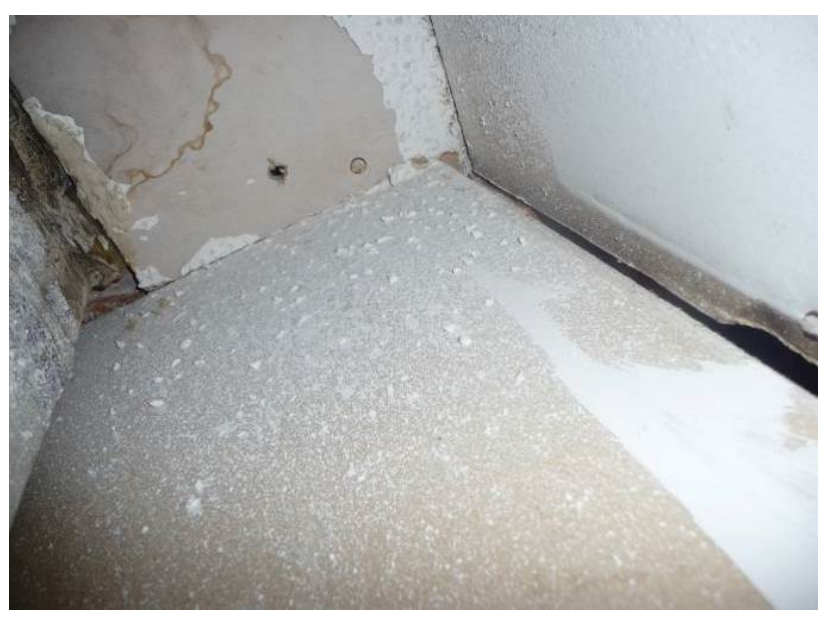

Figure A23. View of AHU closet ceiling. The closet, which operates at negative pressure because it is a return plenum, is very leaky to the second-story floor cavity as a result of unfinished drywall wall at the corner and large gaps in the ceiling. Some areas of air leakage were identified by squeezing a digital camera into tight areas between the AHU and the wall. 


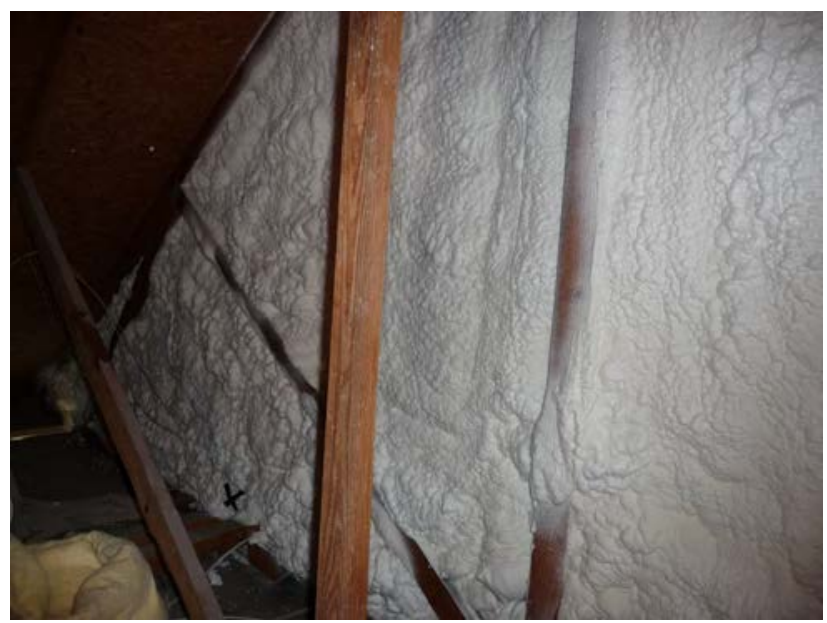

Figure A24. Finished view of foam sealed and insulated floor cavity and knee wall of House H37M

Because the large return leak could still pull air from the floor cavity, a small transfer grille was also placed into the first-floor ceiling near the return closet. This added some pressure relief to the floor cavity.

\section{House H37M Testing Results}

Testing revealed that this house had significant envelope leakage and duct leakage with results shown in Tables A5 and A6. The house leakage was reduced by $12.9 \%$ after repair. There was also a significant $66 \%$ drop in the ach AHU on infiltration rate after repair. This is due to the large return leakage in the central system. The duct leakage is due primarily to return leakage from an interior closet used as a plenum that has significant air pathways into the second-floor cavity above (Figures A22 and A23). To make the AHU closet airtight, the AHU would have to be removed. Sealing the floor cavity at the garage attic was an effective way to eliminate natural driven wind washing into the cavity and block attic air from being mechanically drawn into the house by large return duct leaks.

Table A5. House Tightness Results Before and After Repair

\begin{tabular}{c|c|c|c|c}
\hline & CFM50 & ACH50 & Predicted Natural ach & Ach With AHUs On \\
\hline Pre-Repair & 2,977 & 16.80 & 0.42 & 0.797 \\
Post-Repair & 2,593 & 14.64 & 0.37 & 0.267 \\
\hline
\end{tabular}

Table A6. Duct Tightness Measurements Before and After Repair

\begin{tabular}{c|c|c|c}
\hline \multirow{2}{*}{} & \multicolumn{2}{|c|}{ PPan Measurements (Pa) } & Tracer Gas \\
\cline { 2 - 4 } & System 1 Supply & System 1 Return & RLF \% \\
\hline Pre-Repair & 2.2 & 16.5 & $10.4 \%$ \\
\hline Post-Repair & 1.8 & 1.8 & $2.4 \%$ \\
\hline
\end{tabular}


Table A6 shows results for the Ppan and RLF tests. The return duct leakage was reduced about $77 \%$ from $10.4 \%$ RLF to $2.4 \%$ RLF as a result of the wind washing floor cavity repair. It is believed that the remaining $2.4 \%$ return leakage is coming down a vertical chase that rises from the floor cavity up into a second-floor vented attic. The supply Ppan values decreased by $18 \%$ after repair, whereas the return Ppan values decreased by $89 \%$.

\section{House H39L}

This 3,382- $\mathrm{ft}^{2}$ wood-frame home is located in Clermont, Florida, and was built in 1990. The second-floor area represents about $32 \%$ of the total floor area with $100 \%$ of the second-floor area directly over conditioned first-floor areas. The home sits on elevated land facing Lake Minnehaha, which is to the south (Figure A25). Vented attic spaces are adjacent to second-story floor cavity openings over the garage on the east side and over the master bedroom suite on the northwest side. The home is cooled and heated by two heat pumps. The first-floor system has nominal 3.5-ton capacity and the second floor system has 1.5 -ton nominal capacity.

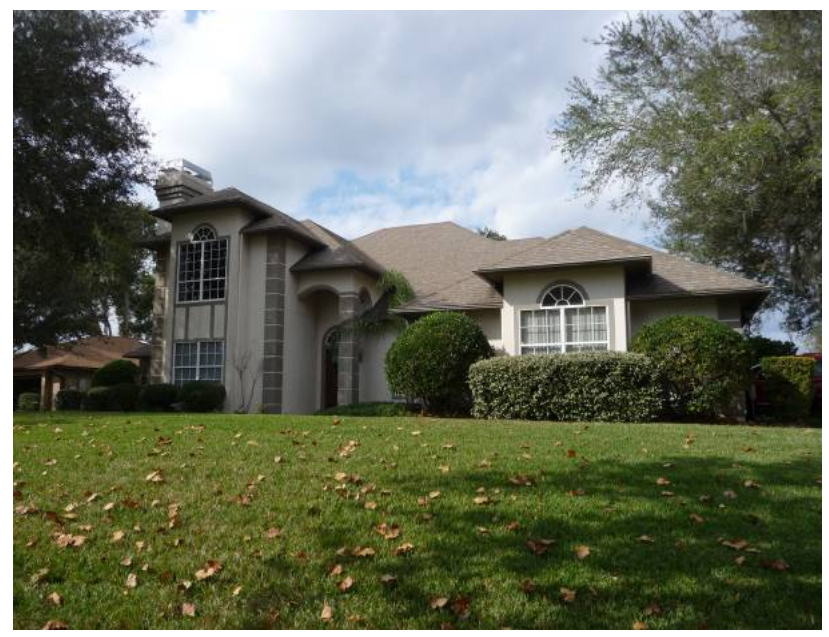

Figure A25. Front of House H39L faces southward. The garage attic is on the east side (right).

Because of its elevated location beside a nearby lake, this house has good exposure to winds from the south, east, and west. Inspection of attic space above the master bedroom on the west side of house revealed $0.3 \mathrm{ft}^{2}$ of openings between the second-story floor cavity and the attic. During inspection, strong northeasterly winds around $15 \mathrm{mph}$ resulted in noticeable airflow through the floor cavity. A short video and photo image were made showing a piece of paper readily blowing from the second-story floor cavity into the west attic as a result of a strong northeasterly wind blowing into the east attic. Figure A26 shows the paper at the west leakage area around a duct penetration. Inspection of the east attic space above the garage revealed $9.2 \mathrm{ft}^{2}$ of openings between second-story floor cavity and the attic (Figure A27 and A28). 


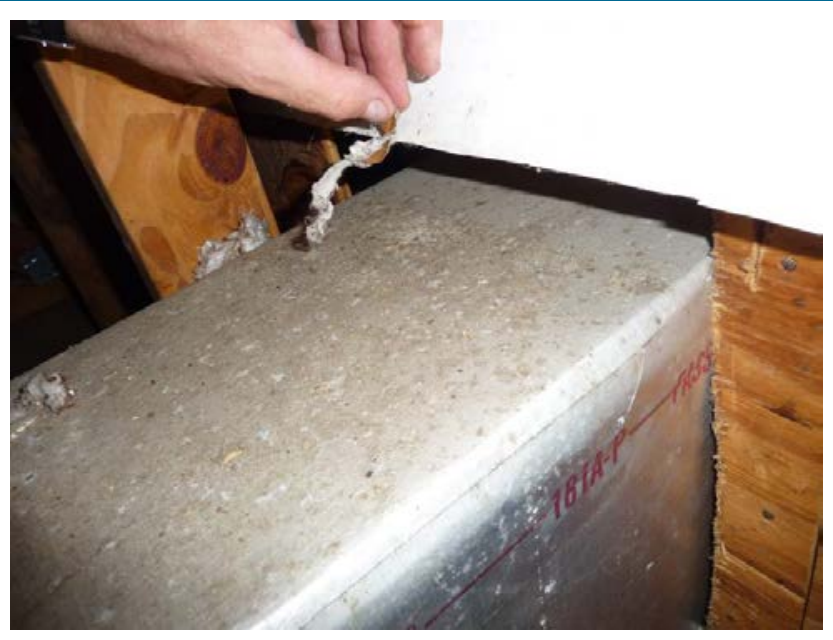

Figure A26. Air flows from floor cavity into west attic area pushing paper away from floor cavity leak toward the attic space. This leak is a complementary pathway to larger floor cavity leakage in the east attic.

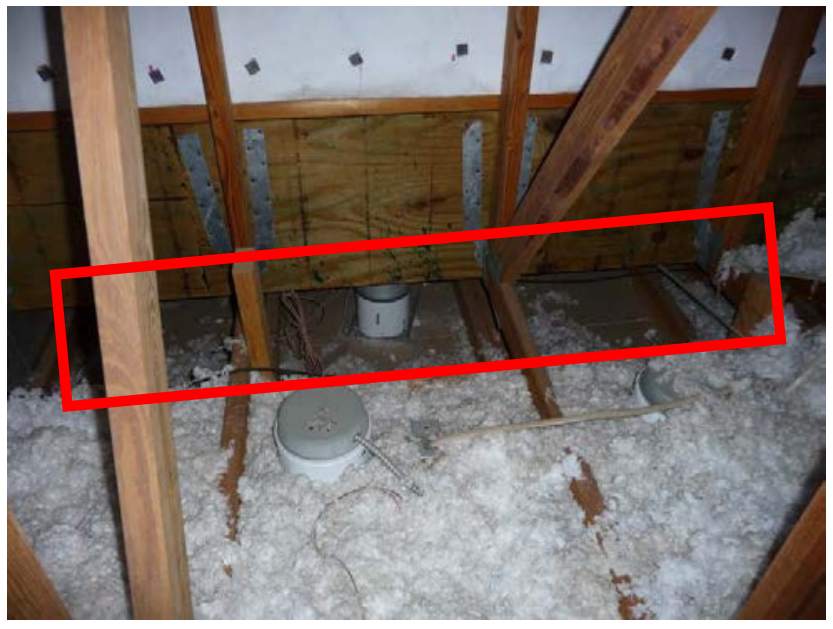

Figure A27. View of pathway from the garage (east) attic into a floor cavity, which results primarily from a dropped ceiling over the kitchen.

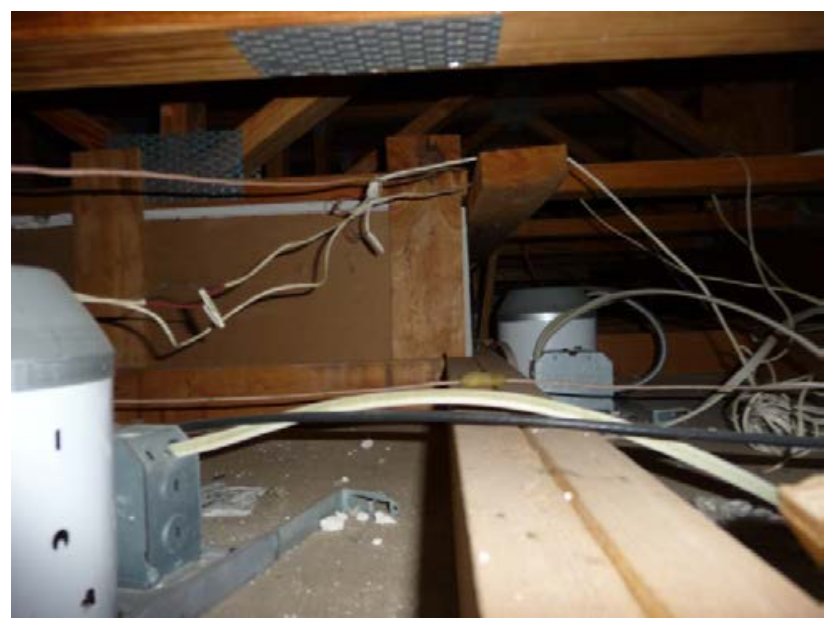

Figure A28. View from garage attic into the dropped kitchen ceiling with floor cavity above 


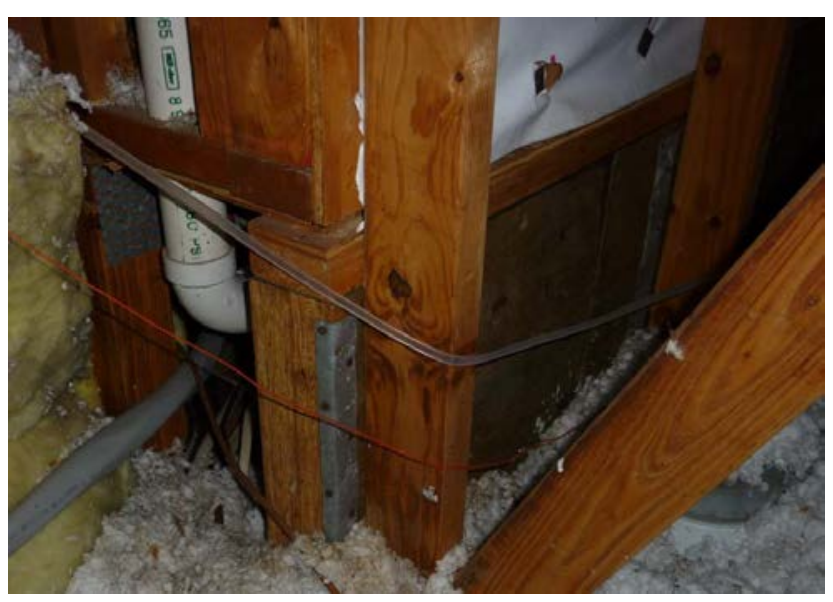

Figure A29. Corner of floor cavity with an air pathway around wire and plumbing penetration and a large area on the right side effectively blocked by plywood

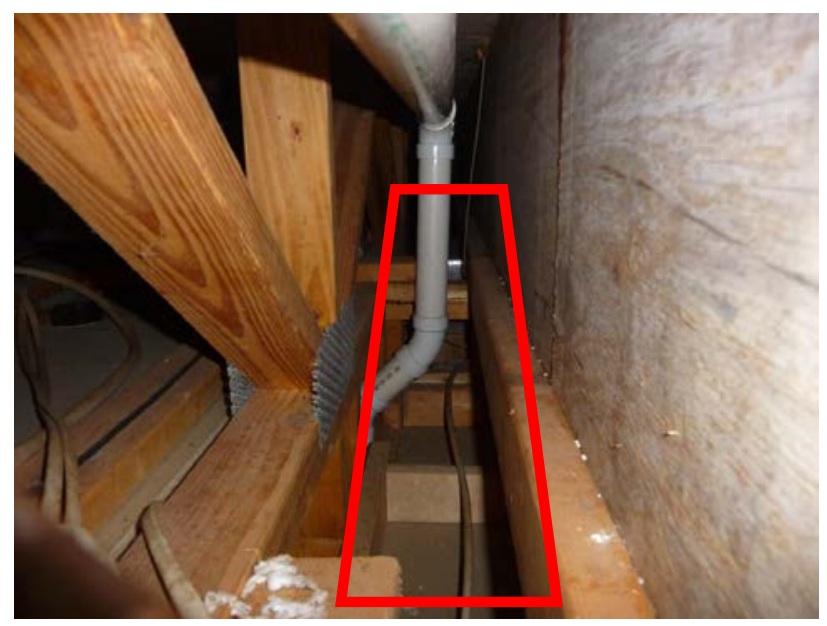

Figure A30. View of the inside floor cavity at corner leak in preceding figure. A large area of the floor cavity is effectively covered by well-placed plywood, but air circumvents this from under the dropped ceiling area at the red box.

Nearly all the floor cavity perimeter had plywood covering the perimeter in attic areas. This floor cavity would have been fairly tight if care had been taken to seal the dropped ceiling area and utility penetrations. While it would have been tight having an air barrier, it would still be missing a necessary thermal barrier.

Wind washing repair was completed using R-19 kraft-faced batts at the open floor cavity pathways at the dropped ceiling area in east attic. First, measured notches were cut into the batt wherever truss members intrude into it. Figure 31 shows a continuous batt section installed with the paper facing toward the attic. The installer considered it easier in this case to ensure a better seal by this orientation instead of the fiberglass outward. It was also easier, for demonstration purposes, to show how the paper needs to be in contact with all the construction materials at its perimeter. This should not be necessary if a generous amount of construction sealant is used around everything in contact with the paper perimeter. This means applying sealant along the top edge of floor cavity frame edge, the first-floor ceiling drywall at the bottom edge, and around each truss section or other materials that come into contact with the insulation facing. Duct tape 
can be seen at the top edge of the batt in Figure A31. This should not be used as a permanent fastening or sealing material. The tape was used to temporarily hold the batt in place during final adjustments by the solitary installer. A typical crew of two persons could avoid this. The paper perimeter could be sealed using caulk or other construction-grade glue or sealant.

Because the building code does not allow the paper face to be exposed to the attic without adequate fire ignition protection, another layer of R-19 insulation was placed in contact with the paper facing with fiberglass side facing the attic. Figure A32 shows the completed repair in the east attic. This step could be avoided if the initial seal can be done effectively by placing the paper facing against the solid construction material, leaving the fiberglass exposed to the attic.

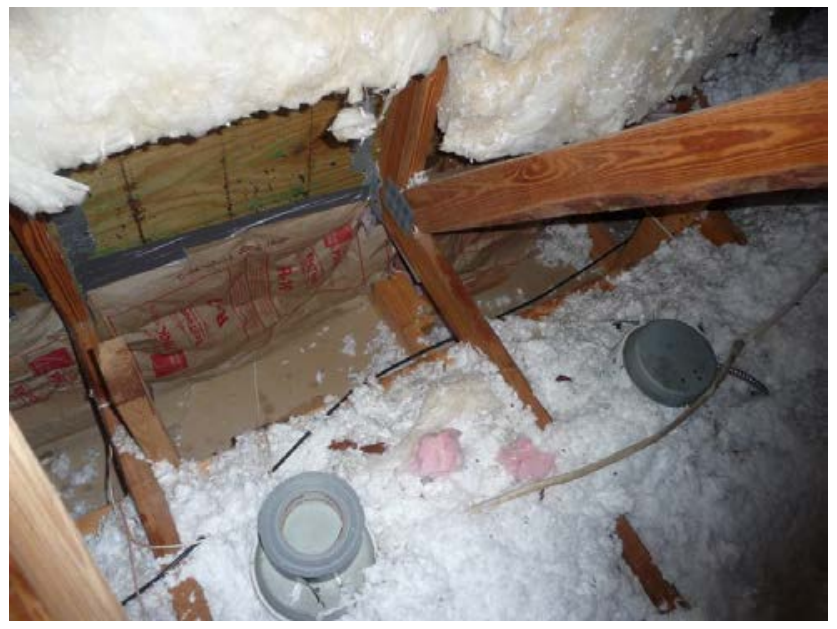

Figure A31. Sealing vertical plane of pathway with paper mechanically fastened and adhered to solid plywood above and adhered to the drywall ceiling below. Duct tape is not a lasting seal, but is used to reinforce the paper edge and provide temporary support during final placement.

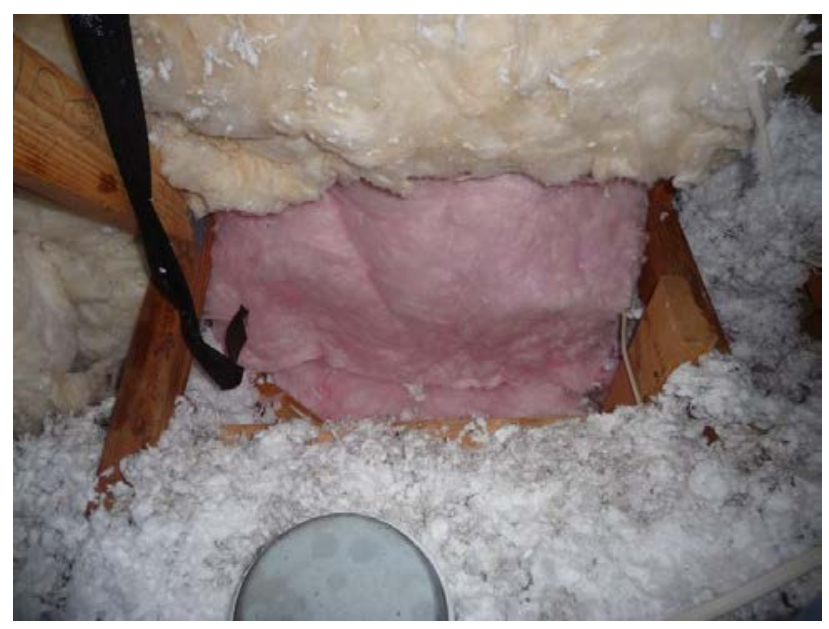

Figure A32. Section of completed repair with R-19 batt insulation fiberglass side out placed against the initial section of insulation in the previous figure. This is done to provide coderequired fire ignition protection of the paper facing.

As discussed earlier in the House H23K section of this appendix, it is important to provide condensation protection whenever placing vapor-permeable insulation against a cold supply air duct in vented attics, particularly in hot-humid climate zones. The image on the left of Figure 
A33 shows a vapor barrier against the duct surface before batt insulation is placed against it. The image on the right side of Figure A33 is after the batt insulation is placed against the duct.
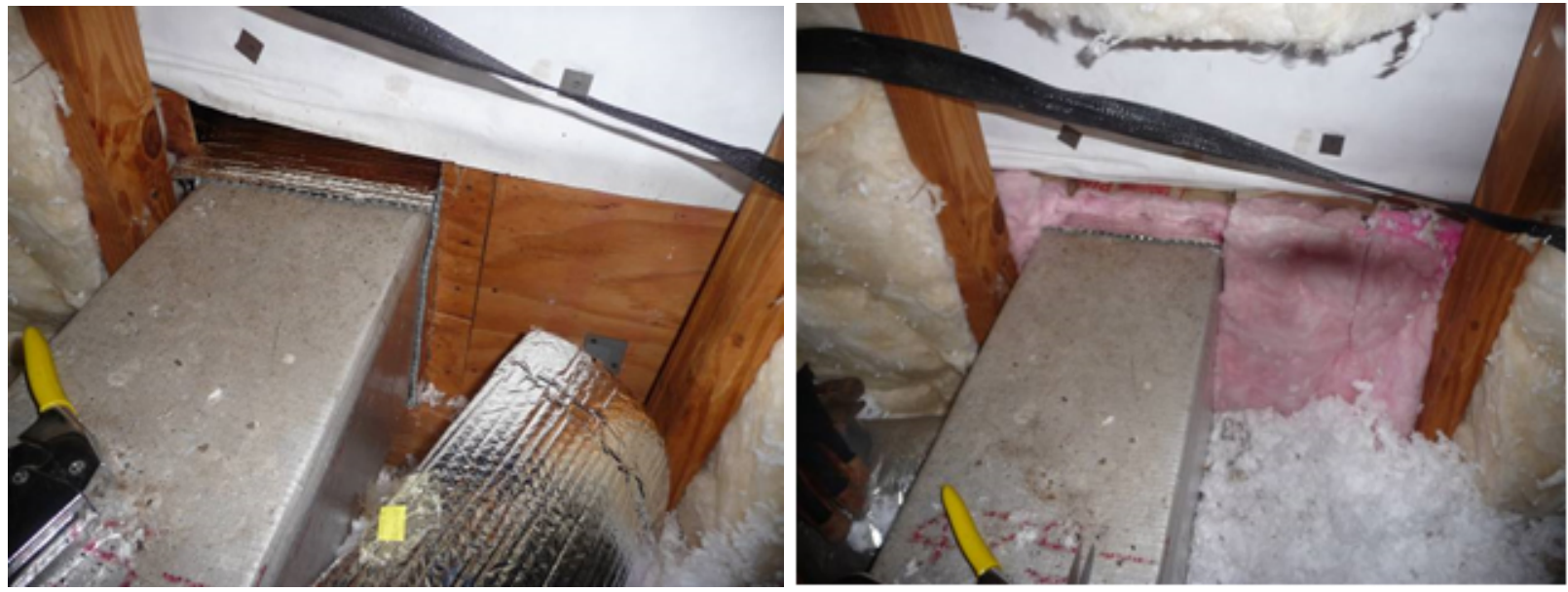

Figure A33. Repair in the west attic at duct penetration starts with application of a thin insulated vapor barrier placed against the cold supply duct. Then, batt insulation was placed against the vapor barrier.

\section{House H39L Testing Results}

The house envelope airtightness is about average for a 23-year-old two-story home. Table A7 shows results for the house tightness and air infiltration tests before and after wind washing repair. The house became about $22 \%$ tighter after the repairs. It is interesting to note that this home had the smallest open floor cavity pathway area sealed, but among the highest percent increase in tightness. This can be explained by the complementary pathways from the floor cavity into the home by way of old ventilated recessed can lights in the dropped-down kitchen ceiling area. These allow the floor cavity leakage to more readily flow into the home. There was also a significant $65 \%$ drop in the measured AHU on infiltration rate. It is believed that much of this is a result of much higher wind speed and a higher rate of infiltration during the pretest. Winds were about $12-15 \mathrm{mph}$ during pretesting and only about $0-5 \mathrm{mph}$ during the posttesting period.

Table A7. House Tightness Results Before and After Repair

\begin{tabular}{c|c|c|c|c}
\hline & CFM50 & ACH50 & Predicted Natural ach & ach AHU on \\
\hline Pre-Repair & 3226 & 6.94 & 0.17 & 0.455 \\
Post-Repair & 2500 & 5.38 & 0.13 & 0.157 \\
\hline
\end{tabular}

Table A8 shows results for the Ppan and RLF tests before and after repair. There is a small drop in system 1 supply Ppan values of $0.2 \mathrm{~Pa}$ after repair; however, this is within the error of measurement. However, a small drop is possible because about half of the system 1 supply ducts are located within the floor cavity. No significant change was expected for system 1 return duct or system 2 supply ducts, which are not located within the floor cavity. There was a 54.8\% drop in the measured RLF of system 2. This was due to leaks from the floor cavity to the return plenum from penetrations such as the refrigerant line. The second-floor central ducted system AHU is located inside a closet that is used as a return plenum. The remaining 3.7\% RLF is through air pathways from the attic into this second-story closet. Overall, there is the expected 
reduction in infiltration caused by the decreased infiltration from floor cavity repair as well as a reduction caused by the reduced return duct leakage on the second floor system. The amount of infiltration reduced as a result of decreased RLF is about $24 \mathrm{cfm}(8.2 \%-3.7 \%=4.5 \% \mathrm{RLF}$ eliminated by floor seal repair; $4.5 \%$ of $536 \mathrm{cfm}$ total system flow $=24 \mathrm{cfm}$ ).

Table A8. Duct Tightness Measurements Before and After Repair

\begin{tabular}{c|c|c|c|c|c|c}
\hline & \multicolumn{3}{|c|}{ PPan Measurements } & System 1 & System 2 \\
\cline { 2 - 7 } & $\begin{array}{c}\text { System 1 } \\
\text { Supply }\end{array}$ & $\begin{array}{c}\text { System 1 } \\
\text { Return }\end{array}$ & $\begin{array}{c}\text { System 2 } \\
\text { Supply }\end{array}$ & $\begin{array}{c}\text { System 2 } \\
\text { Return }\end{array}$ & RLF \% & RLF \% \\
\hline Pre-Repair & 0.6 & 0.0 & 0.6 & NA & $0.5 \%$ & $8.2 \%$ \\
Post-Repair & 0.4 & 0.0 & 0.6 & 1.5 & $0.0 \%$ & $3.7 \%$ \\
\hline
\end{tabular}

\section{House $\mathrm{H} 45 \mathrm{H}$}

This 3,360- $\mathrm{ft}^{2}$ wood-frame home is located in Jacksonville, Florida, and was built in 1993. The home faces west and has a vented attic space over a garage located on the west side of the house and another vented attic on the east side (Figure A34). The home is cooled and heated by a 2-ton heat pump on the second floor and by a 5-ton heat pump on the first floor. The second-floor area represents only $18 \%$ of the total floor area with $100 \%$ of the second story directly above conditioned first-floor space. This home has the smallest second-floor proportion of the monitored homes. It also has a relatively smaller soffit vent area that is about five times smaller than common perforated soffit panels. These two factors tend to diminish wind washing energy impacts. One factor that increases the wind washing potential was the complementary pathways in the floor cavity. There were open holes on opposing sides of the floor cavity open to two vented attic spaces. The complementary pathways consisted of substantial openings into the garage attic (west side) and large openings to the large east attic.

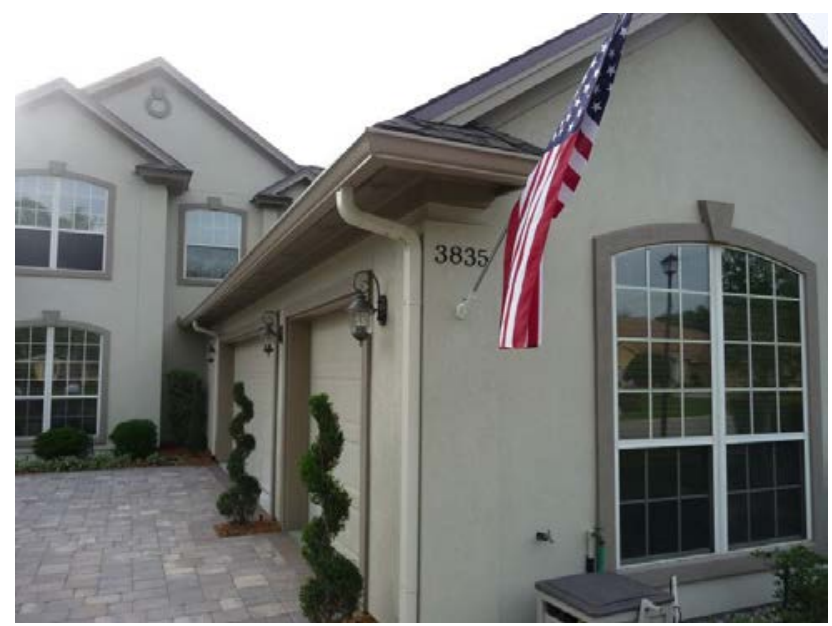

Figure A34. A partial front view of the west side of House $\mathrm{H} 45 \mathrm{H}$

Inspection revealed about $2.1 \mathrm{ft}^{2}$ of openings between the second-story floor cavity and the garage east attic and another $19.3 \mathrm{ft}^{2}$ of leakage to the east attic for a combined total of $21.4 \mathrm{ft}^{2}$. The open floor cavity pathways and some knee wall areas were repaired with foam. Figure A35 shows before and after images of the some of the open floor cavity on the east attic side that is just opposite of the west attic leakage. 

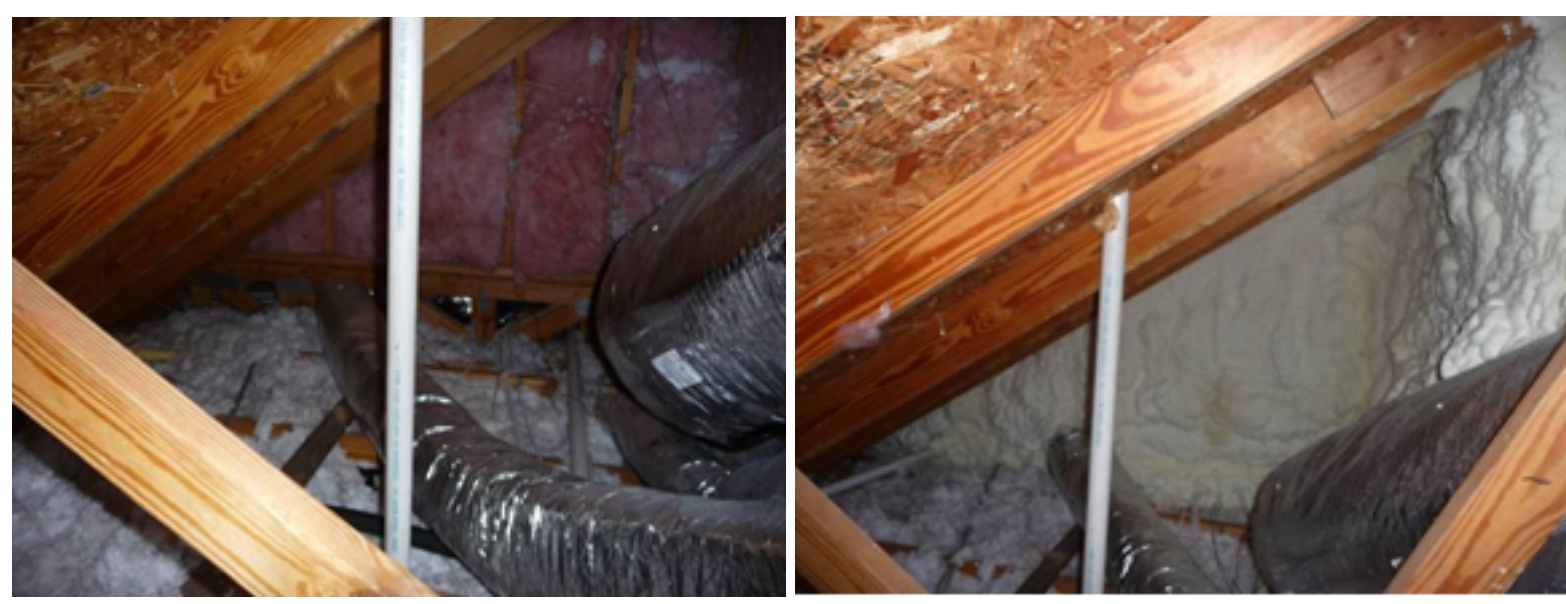

Figure A35. East side of floor cavity and knee wall before and after repair

\section{House H45H Testing Results}

Table A9 shows results for the house tightness and air infiltration tests before and after wind washing repair. The house became about $22.6 \%$ tighter after the repair and there was a $41 \%$ drop in the measured AHU on infiltration rate. Test conditions were similar during the pre- and posttesting periods.

Table A9. House Tightness Results Before and After Repair

\begin{tabular}{c|c|c|c|c}
\hline & CFM50 & ACH50 & Predicted Natural ach & ach AHU on \\
\hline Pre-Repair & 3932 & 6.82 & 0.17 & 0.347 \\
\hline Post-Repair & 3047 & 5.28 & 0.13 & 0.206 \\
\hline
\end{tabular}

Table A10 shows results for the Ppan and RLF tests before and after repair. This home had a small amount of duct leakage; therefore, little impact from floor cavity sealing was expected. There was no significant change in the overall supply leakage based upon the Ppan measurements; however, if only the supply ducts within the floor cavity are considered, the system $1 \mathrm{Ppan}$ average value drops by $0.2 \mathrm{~Pa}$ from $0.5 \mathrm{~Pa}$ to $0.3 \mathrm{~Pa}$. Each central system has an AHU located inside a mechanical closet within the second-floor conditioned space. Each system has a ducted return in which a small part of the return duct turns down into the floor cavity and then out into the east attic space. The reduction in the measured RLF is due to the tighter floor cavity, which helped encase a small amount of return leakage occurring within this space under the mechanical closet. 
Table A10. Duct Tightness Measurements Before and After Repair

\begin{tabular}{c|c|c|c|c|c|c}
\hline & \multicolumn{4}{|c|}{ PPan Measurements } & System 1 & System 2 \\
\cline { 2 - 7 } & $\begin{array}{c}\text { System 1 } \\
\text { Supply }\end{array}$ & $\begin{array}{c}\text { System 1 } \\
\text { Return }\end{array}$ & $\begin{array}{c}\text { System 2 } \\
\text { Supply }\end{array}$ & $\begin{array}{c}\text { System 2 } \\
\text { Return }\end{array}$ & RLF \% & RLF \% \\
\hline Pre-Repair & 0.3 & 0.2 & 0.2 & 1.8 & $2.5 \%$ & $2.6 \%$ \\
Post-Repair & 0.3 & 0.1 & 0.3 & 1.5 & $1.7 \%$ & $0.6 \%$ \\
\hline
\end{tabular}

\section{House H47W}

This 3,902- $\mathrm{ft}^{2}$ wood-frame home is located in Jacksonville, Florida, and was built in 1985. The home faces east and has floor cavity exposure to a vented attic space over a garage on the north (right side) of Figure A36. The home is cooled and heated by a 2-ton heat pump on the second floor and by a 3-ton heat pump primarily serving the first floor. The second-floor area represents $41 \%$ of the total floor area with $100 \%$ of the second story directly above conditioned first-floor space.

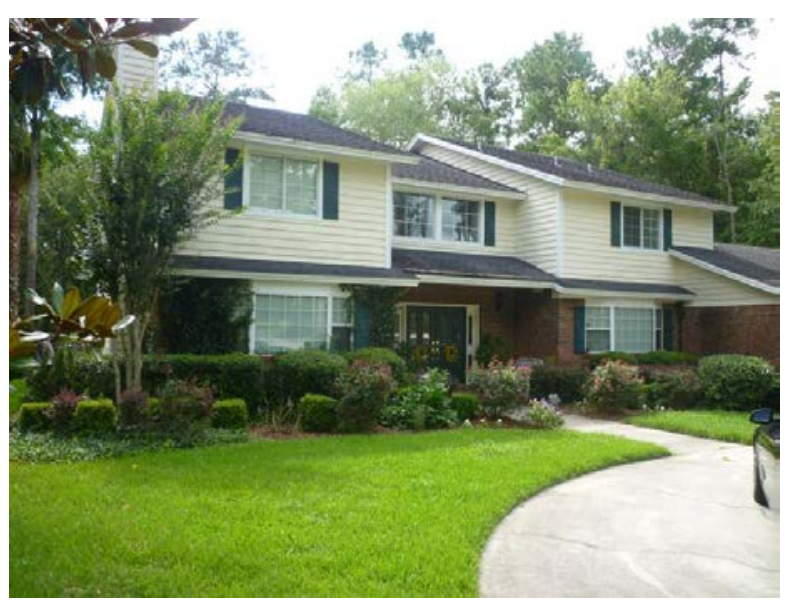

Figure A36. Front view of House H47W

The floor cavity leakage to attic was not as large as most homes in the monitoring study and consisted of a long narrow pathway about 3 in. wide and $18 \mathrm{ft}$ long $\left(4.5 \mathrm{ft}^{2}\right)$. The location can be found in Figure A37 at the red dashed line and in the photos of Figures A38 and A39. The blue outline of Figure A37 marks the second-floor perimeter. Inspection also revealed two vertical chases open to the second-story attic with at least one of them determined by smoke testing to have connectivity to the floor cavity. The total open vertical chase area was about $6 \mathrm{ft}^{2}$. 


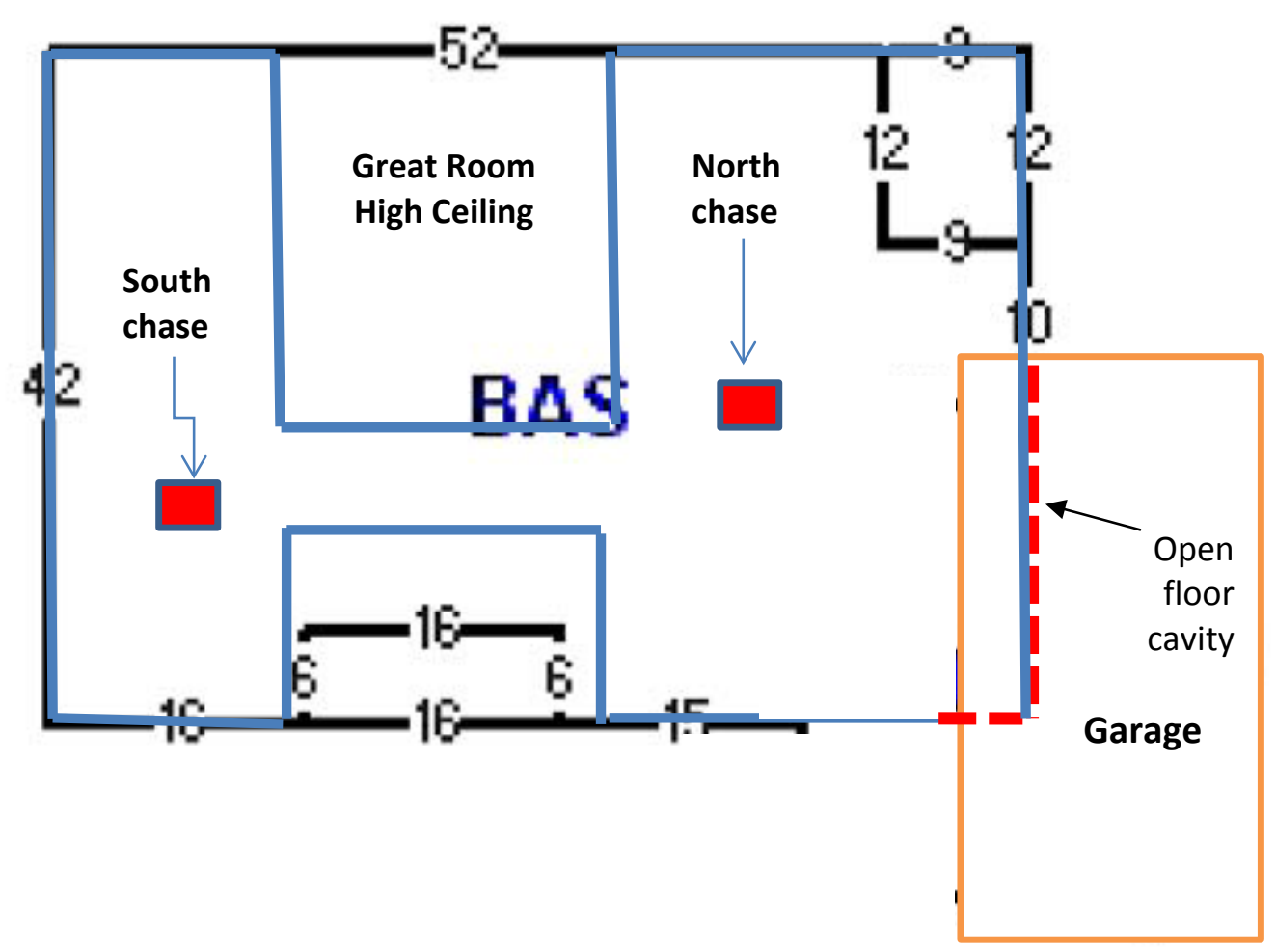

Figure A37. Floor plan layout of House H47W showing leakage areas at red dashed line and red boxes. The floor plan overlay of the second-floor area is outlined in blue lines.

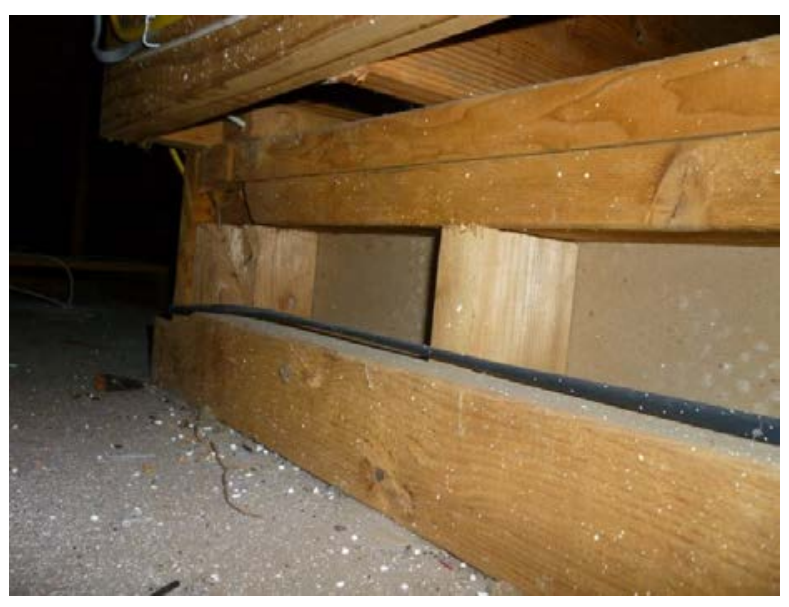

Figure A38. Second floor has a cantilever section inside the garage attic that resulted in a pathway about 3 in. wide by about $18 \mathrm{ft}$ long. 


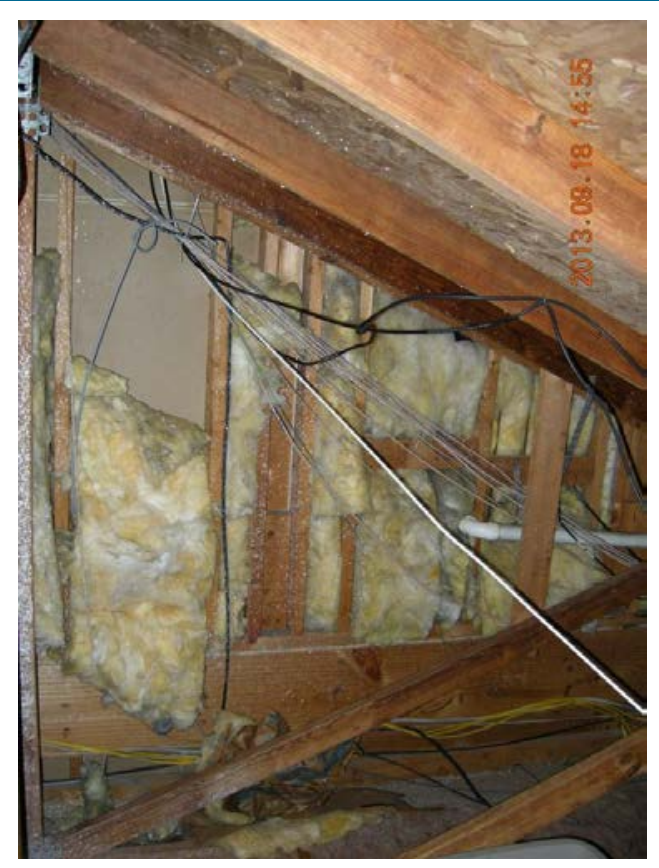

Figure A39. Garage knee wall with R-11 insulation in very poor condition. The irregular framing pattern and numerous wires make it more difficult to adequately insulate with fiberglass batts.

The open floor cavity pathway and garage knee wall areas were repaired with foam shown in Figure A40. The open vertical chases in the upper second-story attic were also sealed with foam shown in Figure A41. The vertical chases ran from the attic downward through the home to allow ducts to connect from the attic-located AHU down into the floor cavity where supply ducts and registers were located at the first-floor ceiling to provide first-floor space conditioning.

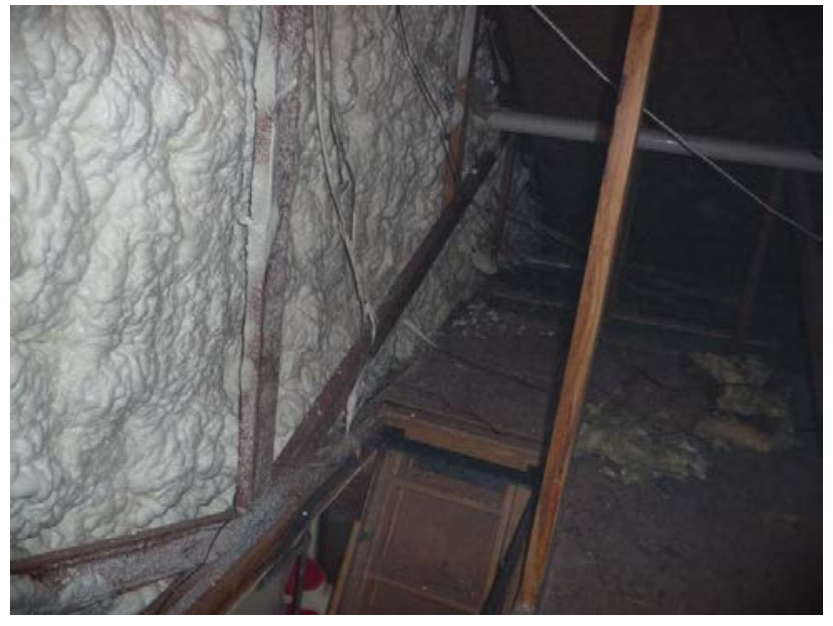

Figure A40. Floor cavity and knee wall after repair in garage attic 

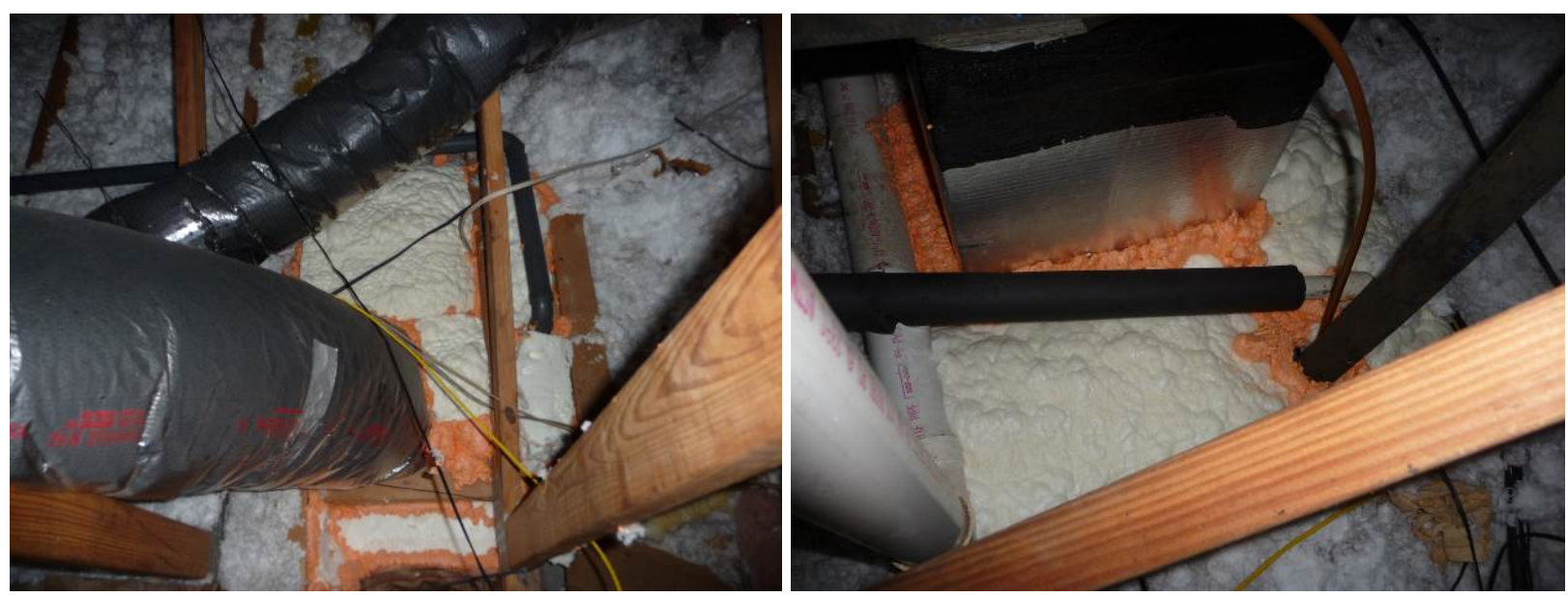

Figure A41. Vertical duct chase openings in second-story attic after sealing with foam

About 1 person-hour was avoided by being able to spray foam plug sections outdoors that could be carried into the attic, then placed into the open cavity sections. If the foam spray gun and long lines had to be taken up into the second-floor attic, protective plastic sheets would have to be placed over the floors from the first-floor front door all the way to the second floor. Figure A42 shows a crew member finishing up a foam plug spray outdoors onto a plastic sheet. The foam plugs are easily cut for a custom fit and sealed in place using a canned expansive foam.

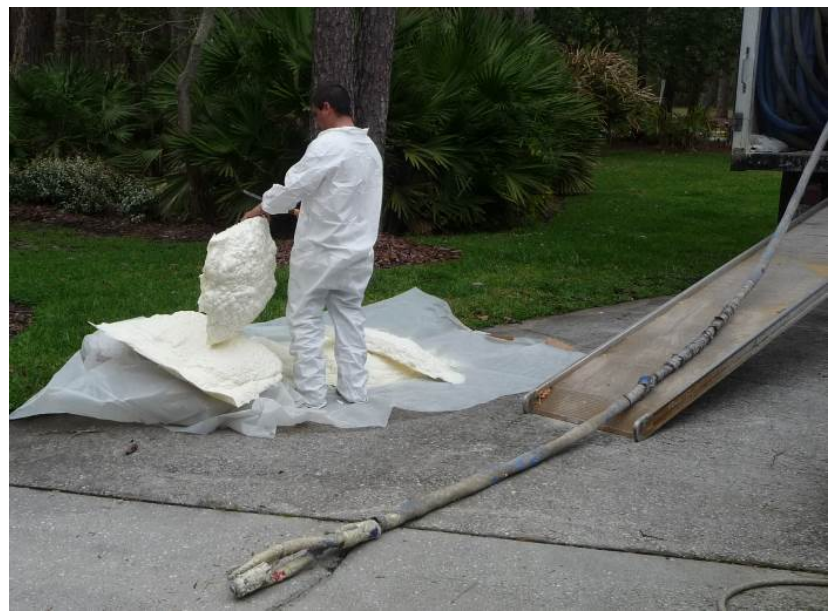

Figure A42. Foam plugs used to seal the second-story attic chase pathways were created outdoors, then easily carried up to the repair site.

\section{House H47W Testing Results}

Table A11 shows results for the house tightness and air infiltration tests before and after wind washing repair. Table A12 shows results for the Ppan and RLF tests before and after repair. The house became about $24.2 \%$ tighter after the floor cavity and vertical chase repairs. The postrepair measured AHU on infiltration actually rate increased about $10 \%$. The calculated flow rate of return leakage indicates that the overall net return duct leakage impact is about the same or slightly greater. Based upon the RLF and measured total system flow rate, the preinfiltration rate is about $106 \mathrm{cfm}$ from both systems and about $111 \mathrm{cfm}$ after floor cavity repair. It is believed that the RLF of system 1 dropped from $9 \%$ to $5.5 \%$ because some of the return duct leakage 
became isolated within the floor and vertical chase cavities. The entire return duct of system 2 is located within the upper-story attic; therefore, no decrease in RLF was expected after repair. The RLF of system 2 increased slightly from $3.9 \%$ to $5.7 \%$. This may be due to increased leakage at the AHU or possibly from dirty filters at the intake grille, resulting in greater depressurization of the return duct and increasing the driving force on the existing leakage. The remaining return duct leakage of each system is at the AHUs located inside the upper-story attic.

Table A11. House Tightness Results Before and After Repair

\begin{tabular}{c|c|c|c|c}
\hline & CFM50 & ACH50 & Predicted Natural ach & ach AHU on \\
\hline Pre-Repair & 7298 & 13.2 & 0.33 & 0.323 \\
\hline Post-Repair & 5544 & 10.0 & 0.25 & 0.356 \\
\hline
\end{tabular}

Table A12. Duct Tightness Measurements Before and After Repair

\begin{tabular}{c|c|c|c|c|c|c}
\hline & \multicolumn{4}{|c|}{ PPan Measurements } & System 1 & System 2 \\
\cline { 2 - 7 } & $\begin{array}{c}\text { System 1 } \\
\text { Supply }\end{array}$ & $\begin{array}{c}\text { System 1 } \\
\text { Return }\end{array}$ & $\begin{array}{c}\text { System 2 } \\
\text { Supply }\end{array}$ & $\begin{array}{c}\text { System 2 } \\
\text { Return }\end{array}$ & RLF \% & RLF \% \\
\hline Pre-Repair & 3.1 & 3.6 & 0.8 & 0.6 & $9.0 \%$ & $3.9 \%$ \\
Post-Repair & 0.8 & 3.0 & 0.8 & 1.0 & $5.5 \%$ & $5.7 \%$ \\
\hline
\end{tabular}

The drops in average Ppan values were expected for system 1 because most of its supply ducts and many of its return ducts are located within the floor cavity and vertical chases that were sealed. No change was expected in the system 2 Ppan values because all of its ducts are located within the second-story attic unaffected by the repair. The supply values stayed the same as expected, but the return value increased some. It should be noted that before the repair, the house was too leaky to reach $50 \mathrm{~Pa}$ and each pretest Ppan value had to have a factor of 1.5 applied to adjust it to as if it were tested at $50 \mathrm{~Pa}$. There is more error associated with this adjustment; therefore, the pretest has more uncertainty. An increase in the post-test Ppan value and an increase in RLF indicate the hole size of the return leakage increased slightly. Return Ppan values around 1 are common in Florida return ducts and are usually associated with a normal amount of AHU panel leakage. Simply not replacing a taped seam or not tightening a service panel at the same torque as before is enough to account for a difference from $0.6 \mathrm{~Pa}$ to $1.0 \mathrm{~Pa}$. 
